\title{
Modeling and flight testing of differential thrust and thrust vectoring on a small UAV
}

\author{
Zachary J. Merceruio \\ West Virginia University
}

Follow this and additional works at: https://researchrepository.wvu.edu/etd

\section{Recommended Citation}

Merceruio, Zachary J., "Modeling and flight testing of differential thrust and thrust vectoring on a small UAV" (2011). Graduate Theses, Dissertations, and Problem Reports. 291.

https://researchrepository.wvu.edu/etd/291

This Thesis is protected by copyright and/or related rights. It has been brought to you by the The Research Repository @ WVU with permission from the rights-holder(s). You are free to use this Thesis in any way that is permitted by the copyright and related rights legislation that applies to your use. For other uses you must obtain permission from the rights-holder(s) directly, unless additional rights are indicated by a Creative Commons license in the record and/ or on the work itself. This Thesis has been accepted for inclusion in WVU Graduate Theses, Dissertations, and Problem Reports collection by an authorized administrator of The Research Repository @ WVU. For more information, please contact researchrepository@mail.wvu.edu. 
MODELING AND FLIGHT TESTING OF DIFFERENTIAL THRUST AND THRUST VECTORING ON A SMALL UAV

\author{
by \\ Zachary J. Merceruio \\ Thesis submitted to the \\ College of Engineering and Mineral Resources \\ at West Virginia University \\ in partial fulfillment of the requirements \\ for the degree of \\ Master of Science \\ in
}

Aerospace Engineering

Approved by

Dr. Yu Gu, Committee Chairperson

Dr. Gary Morris

Dr. Marcello Napolitano

Dr. Srikanth Gururajan

Department of Mechanical and Aerospace Engineering

Morgantown, West Virginia

2011

Keywords: Propulsion Assisted Control, Thrust Vectoring, Differential Thrust, Aircraft, UAV

Copyright 2011, Zachary J. Merceruio 


\section{Abstract \\ MODELING AND FLIGHT TESTING OF DIFFERENTIAL THRUST AND THRUST VECTORING ON A SMALL UAV}

\section{by Zachary J. Merceruio}

The primary objectives of this research are to mathematically model the propulsion forces applied to the aircraft during nominal, differential thrust, and thrust vectored flight configurations, and verify this modeling through simulation and flight testing experiments. This thesis outlines the modeling process, simulator development, design, and implementation of a propulsion assisted control system for the WVU Flight Control Systems Lab (FCSL) research aircraft. Differential thrust and thrust vectoring introduce additional propulsive terms in the aircraft force equations that are not present when the thrust line passes through the center of gravity. These additional forces were modeled and incorporated into a simulator of the research aircraft. The effects from differential thrust were small and difficult to quantify. The thrust vectoring effects were also found to be small with the elevator having significantly more pitch control over the vectored motors at the simulated flight conditions.

Differential thrust was implemented using the on-board computer to command a different thrust level to each motor. The desired thrust differential was programed into a flight scheme based on simulation data, and activated during flight via a control switch on the transmitter. The

thrust vectoring mechanism was designed using SolidWorks ${ }^{\circledR}$, built and tested outside of the aircraft, and finally incorporated into the aircraft. A high torque servo was used to rotate the motor mounting bar and vector the motors to a desired deflection. Utilizing this mechanism, the thrust vectoring was flight tested, mimicking scenarios tested in simulation. The signal to noise ratio was very low, making it difficult to identify the small changes in the aircraft parameters caused by the vectored thrust. 


\section{Acknowledgments}

I would firstly like to thank my family for the love and support they have given me throughout this journey. Without their support this would have been a much more difficult undertaking.

I would like to thank my committee chairman, $\mathrm{Dr}$. $\mathrm{Yu} \mathrm{Gu}$, for offering me a direction, and then guiding me along that path. Also I would like to thank my research advisor and committee member, Dr. Marcello Napolitano, for giving me the opportunity to work in the Flight Controls Research Lab.

I would like to thank my remaining committee members, Dr. Gary Morris and Dr. Srikanth Gururajan, for giving me advice and guidance, better preparing me for life after graduate school.

I would like to extend a thank you to the flight testing crew who helped me to achieve my research goals. Thank you to the pilots who flew the research platforms beautifully: Mike Eden, Mike Spencer, and Dave Ellis. Thank you to the students who facilitated this research through constant efforts: Kerri Phillips, Jason Gross, Frank Barchesky, Matt Rhudy, Daniele Tancredi, Marc Gramlich, Amanda McGrail, Giovanni DeNunzio, Matteo Dariol, and Matteo Guerra. I would also like to thank Dr. Brad Seanor and Dr. Haiyang Chao for their assistance in this research.

I would like to thank the West Virginia Space Grant for giving me a tremendous amount of support and allowing me to have some great experiences. Thank you Dr. Majid Jeraiedi, Ms. Candy Cordwell, and Ms. Amy Diznoff for all you have done for me.

I would finally like to thank West Virginia University, the College of Engineering and Mineral resources, and the Mechanical and Aerospace Engineering Department for not only giving me a great education, but also life changing experiences and a place that felt like home. 


\section{Table of Contents}

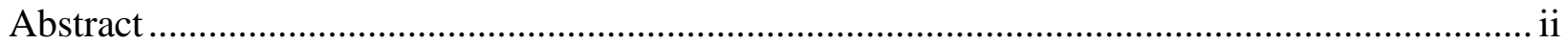

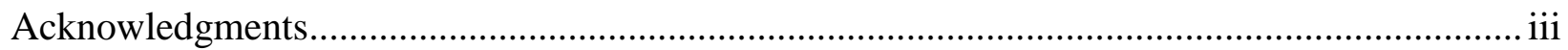

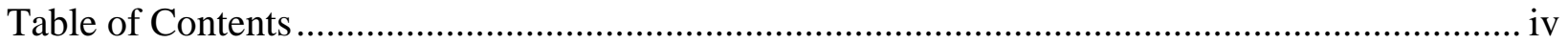

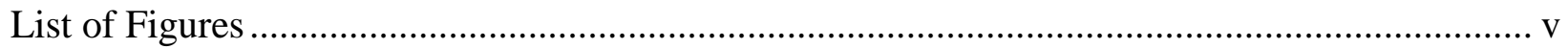

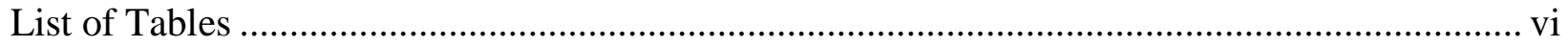

Nomenclature .......................................................................................................... vii

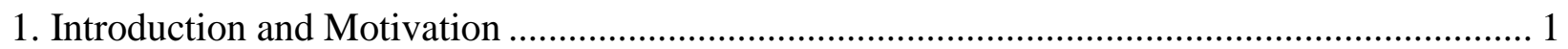

1.1 Research Background ……………………………………………………………………1

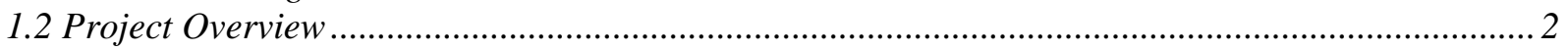

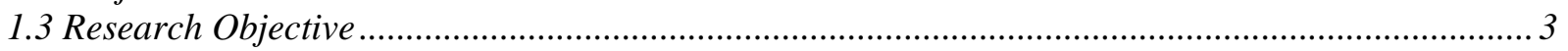

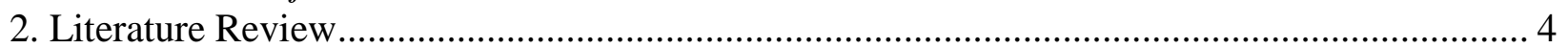

2.1 Ducted Fans and Wind Tunnel Testing ...................................................................................

2.2 Full-Scale Aircraft Use of Differential Thrust............................................................................ 8

2.3 Full-Scale Aircraft Use of Thrust Vectoring as Augmented Control............................................... 13

2.4 UAV Use of Differential Thrust and Thrust Vectoring ............................................................ 19

3. WVU Propulsion Assisted Control Test Bed.......................................................................... 25

3.1 Propulsion Assisted Control Aircraft System ………………………………………………...2 25

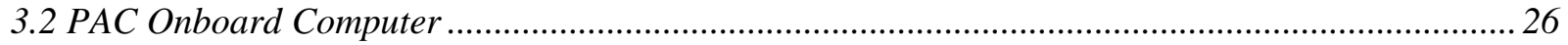

3.3 PAC Sensors and Communication Hardware …………………………………………............2.

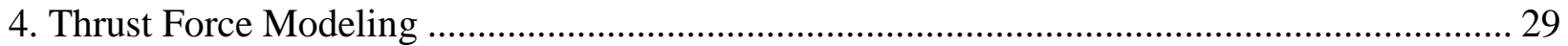

4.1 Static Thrust Force Modeling.............................................................................................. 29

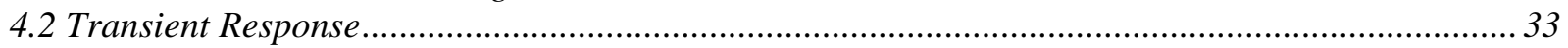

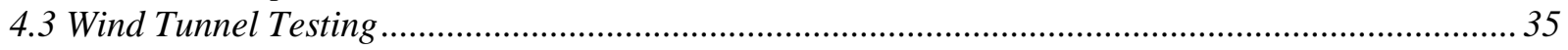

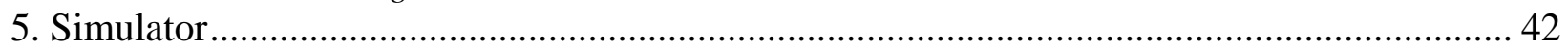

5.1 Overview of the Simulator ………………………………………………………………....4 42

5.2 Differential Thrust and Thrust Vectoring Simulator ………………………………………….... 44

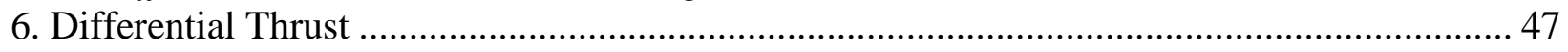

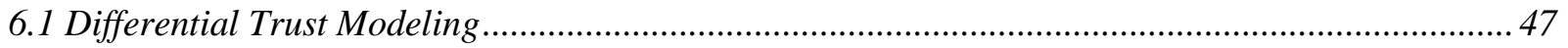

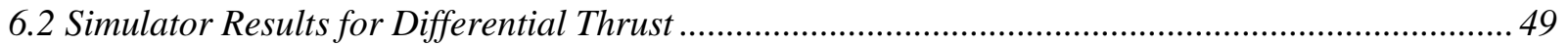

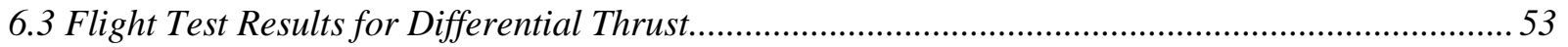

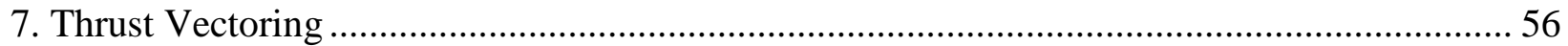

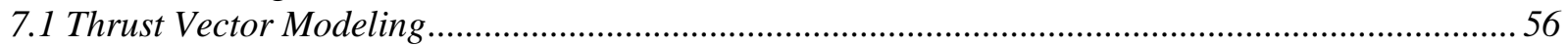

7.2 Simulator Results for Thrust Vectoring ………………………………………………….... 57

7.3 Thrust Vectoring Test Stand ................................................................................................... 63

7.4 Implementation of Thrust Vectoring on the Aircraft …………………………………………........66

7.5 Flight Test Results for Thrust Vectoring …………………....................................................... 67

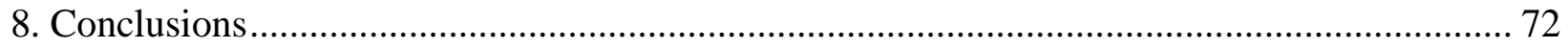

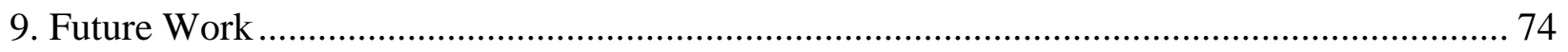

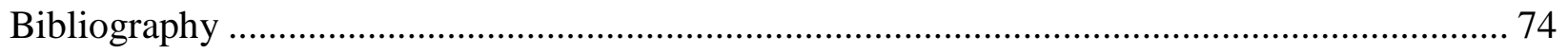




\section{List of Figures}

Figure 1: Caproni-Stipa Aircraft (Reproduced from Reference 5) ............................................. 4

Figure 2: Slipstream Profile for an Open Propeller (Left) and a Ducted Fan (Right) (Reproduced

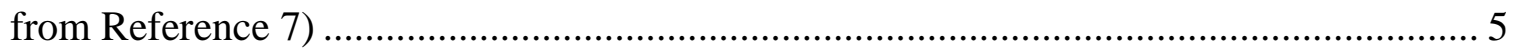

Figure 3: Caltech Ducted Fan (Reproduced from Reference 8) ………………......................... 6

Figure 4: Ducted Fan Test in the NASA Ames 7- by 10-Foot Wind Tunnel (Reproduced from

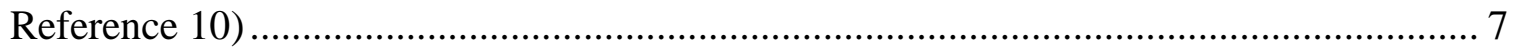

Figure 5: Comparison of Stall Performance of Isolated Duct and Rotor/Duct Combination $V_{0}=35$ kts, 9000 RPM (Reproduced from Reference 11) ...................................................... 8

Figure 6: The GE Axis-Symmetric Vectoring Nozzle (AVEN) ................................................... 14

Figure 7: Mach Contours along Nozzle Centerline with NPR of 5.2 (Reproduced from Reference 42) 19

Figure 8: Quadrotor Schematic (Reproduced from Reference 47) ……………………............ 20

Figure 9: The GTSpy Small Ducted Fan Aircraft (Reproduced from Reference 54)................... 22

Figure 10: WVU Propulsion Assisted Control Test Bed .............................................................. 25

Figure 11: ARIA System (Reproduced from References 58, 59) …………………………...... 27

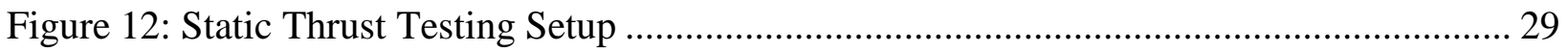

Figure 13: Relationship between PWM and Thrust Established from Static Thrust Testing ....... 33

Figure 14: Normalized Throttle Command and RPM Response Time.......................................... 34

Figure 15: Transient Response of the Motor to a Throttle Command .......................................... 35

Figure 16: Ducted Fan and Wake Rake in Wind Tunnel.......................................................... 38

Figure 17: Incremental Areas Corresponding to Respective Stagnation Ports .............................. 39

Figure 18: Change in Thrust for Constant RPM and Varying Wind Speed ................................. 40

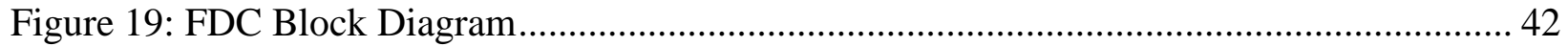

Figure 20: Aircraft Modeling Block ……………………................................................... 43

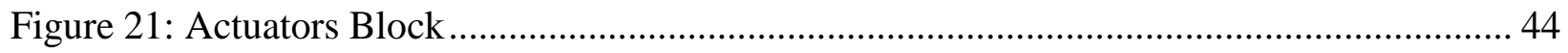

Figure 22: Engine Model for Differential Thrust and Thrust Vectoring ...................................... 44

Figure 23: Differential Thrust Definition .......................................................................... 47 
Figure 24: Simulated Aircraft Roll Response to a Thrust Differential 50

Figure 25: Simulated Aircraft Roll Response to a Thrust Differential with Aileron Compensation 51

Figure 26: Rudder Compensation for a Differential Thrust of $12 \mathrm{~N}$.................................... 52

Figure 27: Simulated Aircraft Response to a Thrust Differential........................................... 53

Figure 28: Rudder Deflection Required to Compensate for Engine Failure ............................ 55

Figure 29: Thrust Vectoring Doublet Maneuver Performed on the Motors .............................. 58

Figure 30: Aircraft Response to a 5 Degree Thrust Vector Doublet ......................................... 59

Figure 31: Aircraft Response to a 10 Degree Thrust Vector Doublet ...................................... 60

Figure 32: Simulated Aircraft Response to a Compensated Thrust Vector Doublet .................. 61

Figure 33: Thrust Vector Step Maneuver Performed on the Motors ....................................... 62

Figure 34: Aircraft Response to a Thrust Vector Step of 15 Degrees ..................................... 62

Figure 35: Simulated Aircraft Response to a Compensated Thrust Vector 15 degree Step ........ 63

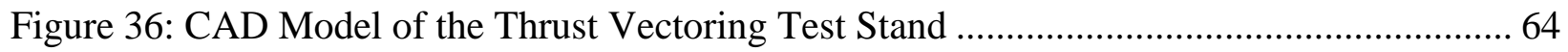

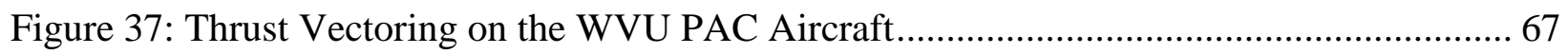

Figure 38: Thrust Vector Doublet Maneuver Performed In-Flight ...................................... 68

Figure 39: Angle of Attack during a Doublet Maneuver on the Motors ................................... 69

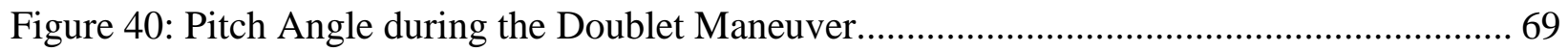

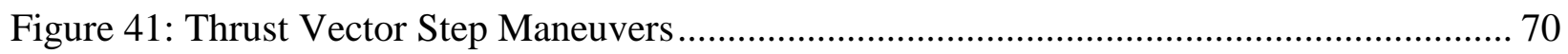

Figure 42: Elevator Deflection during Thrust Vector Step Manuever ................................... 71

\section{List of Tables}

Table 1: Geometric Parameters of the PAC Aircraft ................................................................ 26

Table 2: Static Thrust Measurements for Test One ............................................................... 31

Table 3: Static Thrust Measurements for Test Two............................................................... 31

Table 4: Static Thrust Measurements for Test Three........................................................... 32

Table 5: Wind Tunnel Testing Scheme with Recorded Motor RPM Values ............................. 38

Table 6: Wind Tunnel Measurements and Static Thrust Comparison ........................................ 39 


\section{Nomenclature}

$\begin{array}{ll}a & =\text { linear acceleration }\left(\mathrm{m} / \mathrm{s}^{2}\right) \\ A & =\text { state matrix, area } \\ b & =\text { wing span }(\mathrm{m}) \\ B & =\text { input matrix } \\ C & =\text { aerodynamic coefficient } \\ \bar{c} & =\text { mean aerodynamic chord }(\mathrm{m}) \\ e & =\text { error } \\ h & =\text { altitude }(\mathrm{m}) \\ I & =\text { moment of inertia }\left(\mathrm{kg} \mathrm{m}^{2}\right) \\ J & =\text { product of inertia }\left(\mathrm{kg} \mathrm{m}^{2}\right) \\ m & =\text { aircraft mass }(\mathrm{kg}) \\ p & =\text { roll rate }(\mathrm{deg} / \mathrm{s}) \\ q & =\text { pitch rate }(\mathrm{deg} / \mathrm{s}) \\ \bar{q} & =\text { dynamic pressure }\left(\mathrm{psi}^{2}\right) \\ \dot{Q} & =\text { volumetric flow rate }\left(\mathrm{m}^{3} / \mathrm{s}\right) \\ r & =\text { yaw rate }(\text { deg/s }) \\ S & =\text { wing surface area }\left(\mathrm{m}^{2}\right) \\ T & =\text { thrust }(\mathrm{N}) \\ V & =\text { velocity }(\mathrm{m} / \mathrm{s})\end{array}$

Greek Letters

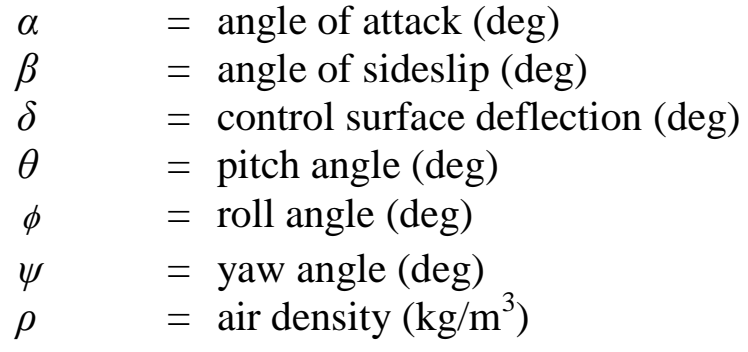

\section{Subscripts}

$\begin{array}{ll}D & =\text { drag } \\ l & =\text { rolling moment } \\ L & =\text { lift } \\ m & =\text { pitching moment } \\ n & =\text { yawing moment } \\ T & =\text { thrust } \\ x x & =\text { about the x-axis (body) }\end{array}$


$x z=$ about the $\mathrm{x}$ and $\mathrm{z}$ axes (body)

$Y=$ side force

yy $\quad=$ about the $y$-axis (body)

$z z=$ about the $\mathrm{z}$-axis (body)

\section{Acronyms}

$\mathrm{AFB}=$ air force base

$\mathrm{CFD}=$ computational fluid dynamics

$\mathrm{CG} \quad=$ center of gravity

DOF $=$ degree of freedom

FCSL = Flight Control System Laboratory

HARV $=$ High Angle of Attack Research Vehicle

PAC $=$ propulsion assisted control

PCA = propulsion controlled aircraft

$\mathrm{PCB}=$ printed circuit board

RANS = Reynolds Averaged Navier-Stokes

RPM = revolutions per minute

UAV = unmanned aerial vehicle

UCAV = uninhabited combat aerial vehicle

WVU = West Virginia University 


\section{Introduction and Motivation}

\subsection{Research Background}

The use of differential thrust and/or thrust vectoring presents an appealing option to maneuver an aircraft in the event of control surface failures or loss of control surface effectiveness. It may also prove useful in laterally trimming an aircraft in lieu of rudderdeflections, possibly reducing drag. The potential advantages of differential thrust have led to research efforts in which the engine thrust is manipulated to provide an extra channel of flight control authority in unmanned aircraft. For example, commercial jetliner pilots have utilized asymmetric thrust to assist in yaw and roll control in the event of primary control surface failures ${ }^{1}$, and remote-controlled aircraft hobbyists have used differential thrust to assist in some aerobatic flight maneuvers. Thrust vectoring has been implemented in several fighter aircraft configurations, such as the McDonnell Douglas AV-8B Harrier II and the Lockheed Martin F35B Lightning, to assist in short take-offs and vertical landings in difficult environments like an aircraft carrier ${ }^{2}$.

For manned aircraft, the use of differential thrust to accommodate for adverse flight conditions is often determined at the discretion of the pilots and is mainly used as a last resort. Because the failure of primary control surfaces has been recognized as one of the main causes of accidents in military and civilian aviation, contributing to $25 \%$ of commercial aircraft accidents in the past 60 years ${ }^{3}$, the use of differential thrust accommodation in the event of these incidents has become common practice in pilot training. A prime example of pilots utilizing propulsion assisted flight control is the case of United Airlines Flight 232, where an uncontained failure of the vertical tail-mounted engine caused debris to rupture the hydraulic lines to the control surfaces ${ }^{1}$. These failures left the McDonnell Douglas DC-10 aircraft without three of its flight control systems and with no redundant power sources to operate them. However, using asymmetric thrust in the wing-mounted engines the aircraft was brought to a "marginally flyable" condition. 
Additionally, the use of unmanned aerial vehicles (UAVs) has become an increasingly appealing option in research and military applications and the need for fault-tolerant flight controls in these applications is evident. Propulsion assisted control provides another degree of freedom for the flight control systems to apply in the event of adverse conditions such as primary control surface failures. In providing this additional degree of freedom, an accurate model of the engine or power source is required to implement within the flight computer. This includes accurately modeling the static and dynamic thrust of an engine as well as understanding the geometry of the aircraft which has a significant effect on the degree of control authority gained by differential thrust and thrust vectoring for that aircraft. With UAVs being used for a wide array of missions - reconnaissance, environmental research, and military attacks - it becomes increasingly necessary to have system robustness, and the ability to survive the elements and complete the given tasks. The research applied to UAV flight controls may also be directly applicable to assisting pilots in the event of failures in controlling their aircraft with differential thrust, allowing them to focus on other pressing tasks such as communicating with air traffic control to establish emergency landing plans.

\subsection{Project Overview}

The Flight Control Systems Lab (FCSL) at West Virginia University (WVU) is developing and testing a fault-tolerant flight control system to handle both sensor and actuator failures. Within this effort, actuator and sensor failure detection, identification, and accommodation (AFDIA/SFDIA) schemes are being developed to maintain stable flight for a UAV under specific failure scenarios. A portion of this effort focuses on implementing and flight testing differential thrust and thrust vectoring on board the WVU Propulsion Assisted Control (PAC) research platform. The objective of this research is to accurately model the propulsive forces associated with differential thrust and thrust vectoring, and verify the modeling process through simulation and flight testing experiments.

To implement differential thrust and thrust vectoring capabilities on the WVU PAC research aircraft, an accurate model of the thrust produced by the engines was required. For this research, 
both the static and dynamic thrust were modeled, as well as the transient response of the motors. For the static thrust modeling, one of the motors was mounted to an engine test stand where the static thrust could be measured for different engine throttle settings. To measure the dynamic thrust, the ducted fan engine was mounted within the WVU subsonic wind tunnel to estimate the thrust produced at different flight speeds for given engine revolutions per minute (RPMs). The transient response was determined by observing the delay between the input signal and the response of the motor. Additionally, a modeling effort was completed on how the thrust vectoring and differential thrust would perform on the PAC research aircraft, specifically the forces and moments that would be generated on the aircraft for a given thrust output. Following this detailed modeling effort, simulation studies were conducted to validate the identified parameters before incorporating them on the actual aircraft for flight tests.

A thrust vectoring test stand was developed to observe the performance of the engines under vectoring motion before implementing them onto the aircraft. The design of the mechanism for vectoring on the test stand was also incorporated in the final design of the actual thrust vectoring platform within the aircraft. This design was flight tested by performing thrust vector doublets as would traditionally be done using the conventional control surfaces, as well as step inputs on the thrust vectoring channel.

\subsection{Research Objective}

The objective of this research was to model the propulsive forces associated with differential thrust and thrust vectoring, in order to provide the FCSL with a propulsion assisted controlled aircraft with which an additional degree of freedom could be exploited within a fault tolerant flight control system. Specifically, a complete model of the motor including static thrust, dynamic thrust, and transient response was necessary, along with an understanding of the response of the aircraft to the forces and moments produced by differential thrust and the thrust vectoring system. 


\section{Literature Review}

The following sections review prior work relevant to the proposed research effort on propulsion assisted control. Specifically, topics that are summarized include the aerodynamics of ducted fans and wind tunnel testing of engines, the use of differential thrust for emergencies and as augmented controls in full-scale aircraft, the use of thrust vectoring in full-scale aircraft, and the use of differential thrust and thrust vectoring in UAVs.

\subsection{Ducted Fans and Wind Tunnel Testing}

The ducted fan dates back to as early as 1932 when an Italian engineer named Luigi Stipa invented the "intubed propeller" for the Caproni Stipa aircraft. Luigi Stipa was an aeronautical, hydraulic and civil engineer who applied his study of hydraulic engineering to aircraft in an attempt to increase the aircraft efficiency. Based on Bernoulli's principle in fluid dynamics, Stipa believed that directing the air behind the propeller through a Venturi tube of decreasing diameter would increase its velocity and improve the efficiency of the engine. After spending years mathematically studying this idea, Stipa published his work and convinced the Air Ministry to build a prototype aircraft to test the theory in order to prove his concept. This resulted in the Caproni Stipa experimental airplane which is credited as the first use of a "ducted fan" in an aircraft. On October 7, 1932, the prototype was flown proving Stipa's concept that the intubed propeller increases engine efficiency; however, his design also increased the drag on the aircraft to the point that it negated the gains made by the increased engine efficiency. Since his design did not offer an improvement in the overall performance over conventional aircraft, no further development took place ${ }^{4}$.

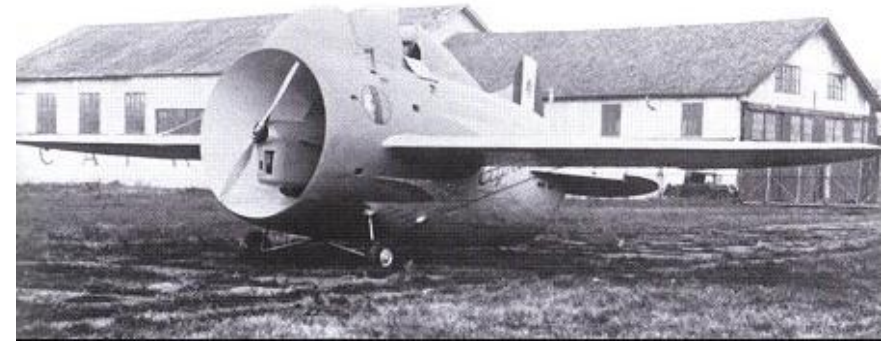

Figure 1: Caproni-Stipa Aircraft (Reproduced from Reference 5) 
More recently, research has been performed on ducted fans because of their potential for higher static thrust when compared to an isolated propeller of the same diameter. Additionally, they offer several advantages over isolated propellers including reducing blade tip losses which increases the efficiency of the blades especially at higher rotational speeds. Ducted fans also offer a supplementary safety feature by enclosing the rotating propeller, allowing for safer indoor flight or flights in congested areas making ducted fans an attractive option for unmanned aircraft. Ducted fans produce less noise than isolated propellers due to the reduction of the tip vortices and the smaller diameter reducing the tip speed of the blades ${ }^{6}$.

Applying the principle of conservation of mass, conservation of momentum, and the Bernoulli principle to both an open propeller and a ducted fan in a free stream helps to model the aerodynamic differences between the two. For an open propeller, the velocity of the slipstream behind the propeller is higher than the free stream velocity and therefore forces the slipstream to contract. However the velocity of the slipstream exiting the duct is essentially equal to the free stream velocity and therefore does not contract ${ }^{7}$.
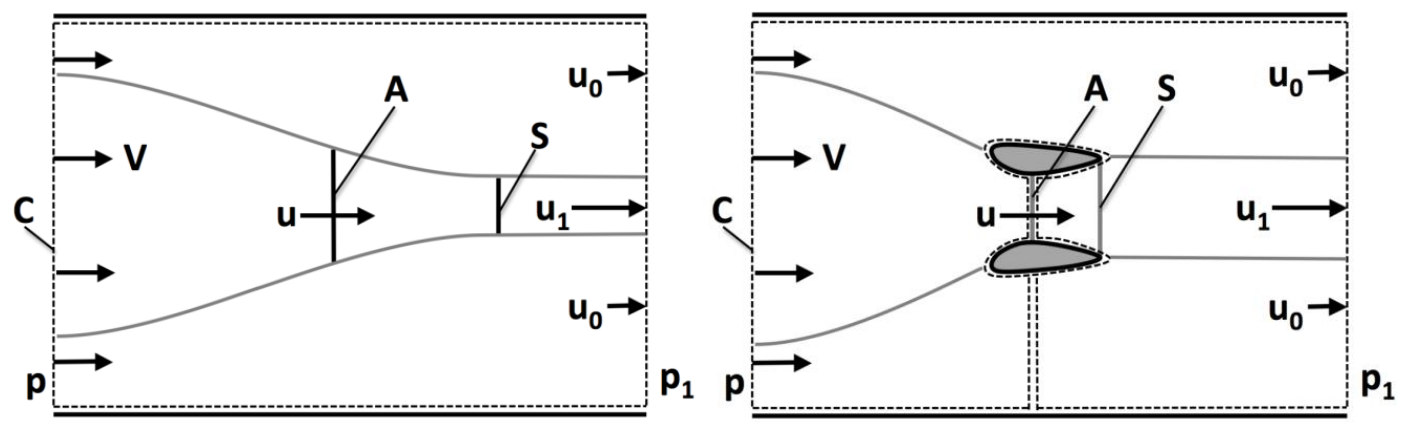

\section{Figure 2: Slipstream Profile for an Open Propeller (Left) and a Ducted Fan (Right) (Reproduced from Reference 7)}

Researchers at California Institute of Technology in Pasadena, California developed a testbed for nonlinear flight control techniques using a platform centered on a ducted fan ${ }^{8}$. The Caltech ducted fan is a scaled model of the longitudinal axis of a flight vehicle that allows for research and development of nonlinear flight guidance and control laws. Figure 3 shows the experimental setup of the Caltech ducted fan. 


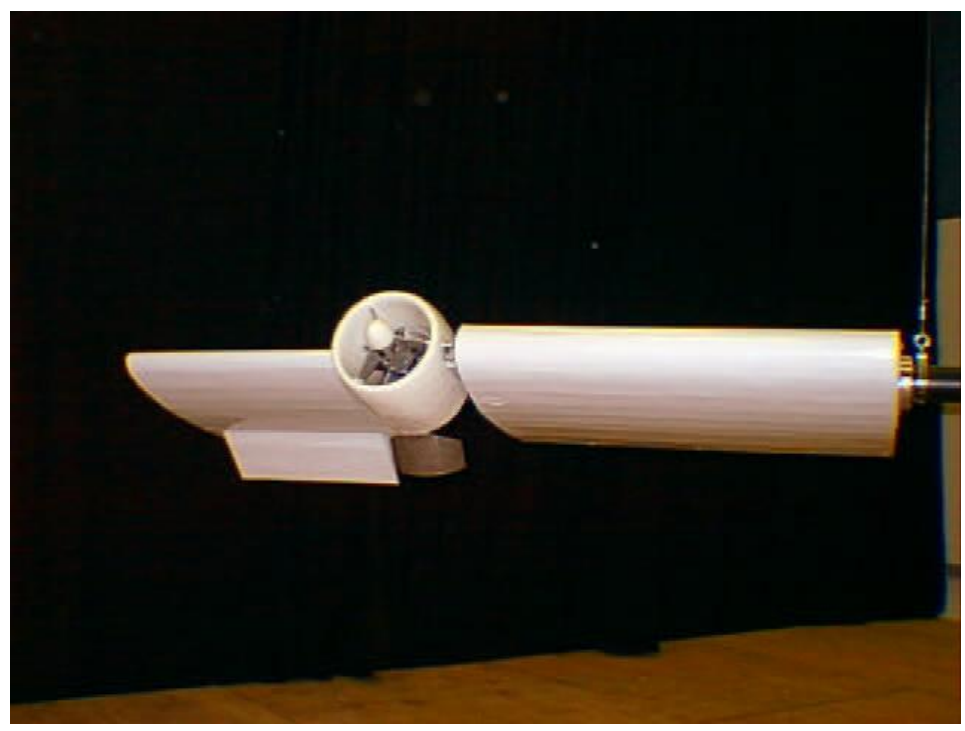

Figure 3: Caltech Ducted Fan (Reproduced from Reference 8)

The Caltech ducted fan is a tethered representation of the longitudinal dynamics of a flight vehicle, with flight tests conducted indoors. Thrust vectoring of the ducted fan allows for a larger flight envelope, as well as a range of stability and modeling options which are available due to the ease with which it is reconfigured ${ }^{8}$. The purpose of the scaled model was to apply the guidance, surface allocation, and flight control algorithms to advance the technology for uninhabited combat air vehicles (UCAVs). The test bed objectives included: assessment of future direction of UCAV guidance and control, and the safety risks and cost of such a research platform. Initial flight tests were conducted in an open-loop configuration where the wings were positioned so the ducted fan was statically stable. As the ducted fan was operating, elevator pulses were performed at defined trim conditions to provide a visualization of the short period dynamics. Additionally, setting up the thrust vectoring paddles and operating the trimmed system at a constant velocity of $6.5 \mathrm{~m} / \mathrm{s}$ allowed for additional identification of the short period dynamics. Following these initial experiments, researchers were able to show that the Caltech ducted fan test bed "qualitatively exhibits the natural longitudinal dynamics of a flight vehicle"

Researchers at the University of California also performed a study on the design and construction a ducted fan for use in non-linear control experiments. The ducted fan was designed 
to include a high efficiency electric motor driving a 6-inch blade, with the ability to produce $9 \mathrm{~N}$ of thrust. The ducted fan used flaps to direct the exhaust and produce thrust vectoring capability. This vectored thrust motor provided a challenging platform for non-linear robust control theory. The research concluded that the system "contained a large uncertainty since detailed modeling of the flow of air through the unit is not easily obtained in a form useful for control"'.

Performance studies have been conducted on ducted fan systems to identify how changes to the system parameters affect the performance of the ducted fans. One such performance study was conducted at NASA Ames Research Center in the 7- by 10-foot wind tunnel. The tested ducted fan had a 38-in diameter, 10-in duct chord, and a 5-bladed fixed-pitch fan. The variable experimental parameters included the angle of attack, exit vane flap length, flap deflection angle, and duct chord length. The tests were performed for axial and forward flight conditions, and the axial tests yielded a decrease in the figure of merit with an increasing advance ratio. The forward flight tests yielded an increasing propulsive force with a decreasing duct angle of attack. This study also showed that extending the duct chord did not affect the duct performance. The exit vane flap deflection angle and the flap chord length were found to be effective methods of producing duct side forces. Figure 4 shows the ducted fan experimental setup in the NASA Ames 7 - by 10 -foot wind tunnel ${ }^{10}$.

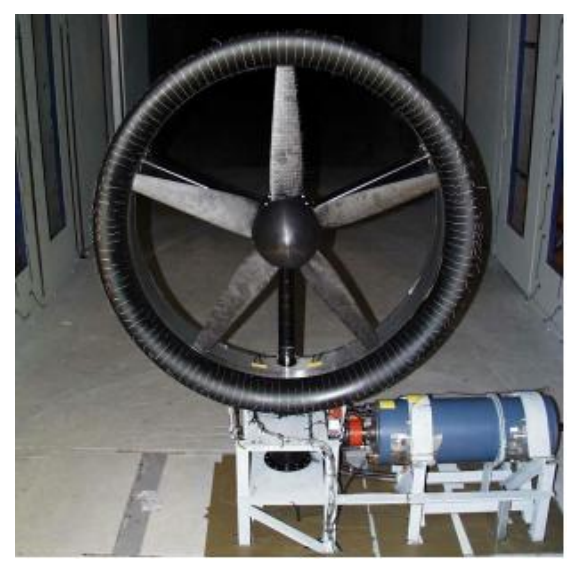

Figure 4: Ducted Fan Test in the NASA Ames 7- by 10-Foot Wind Tunnel (Reproduced from Reference 10) 
A 10-inch ducted rotor VTOL UAV was tested in the US Army 7 x 10 foot wind tunnel for performance and flow field measurements. The tests ranged from $0^{\circ}$ to $110^{\circ}$ angle of attack and 0 to $128 \mathrm{ft} / \mathrm{s}$ wind speeds. Tests were performed with and without a rotor present in the duct to determine the difference in stall. Figure 5 shows the results from this test with the stall of the rotor and duct not occurring until $40^{\circ}$ while the duct without the rotor stalled at 15 degrees ${ }^{11}$.

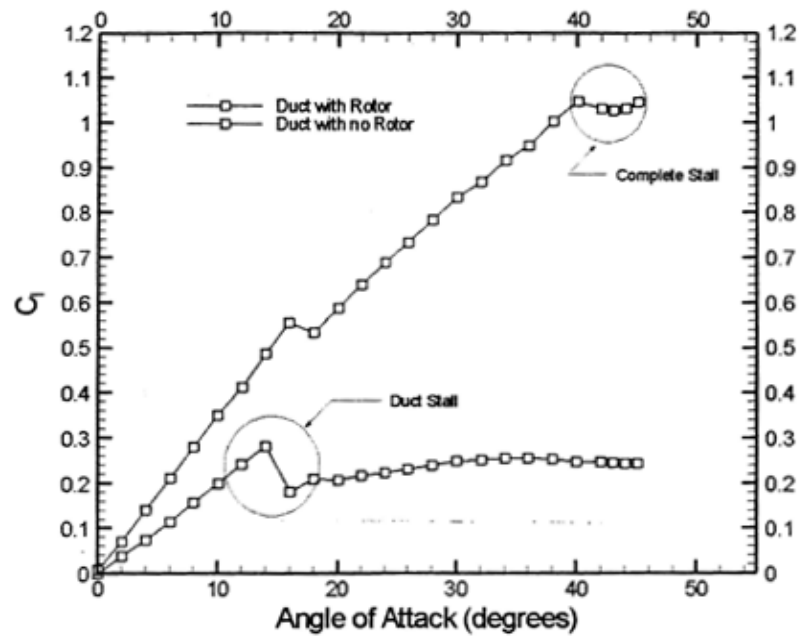

Figure 5: Comparison of Stall Performance of Isolated Duct and Rotor/Duct Combination $V_{0}=35$ kts, 9000 RPM (Reproduced from Reference 11)

\subsection{Full-Scale Aircraft Use of Differential Thrust}

Differential thrust has been used by pilots in emergency situations when individual control of the engines has been necessary to maintain control of the aircraft. Japanese Airlines Flight 123, a Boeing 747-100, was an aircraft that experienced a catastrophic failure leaving the pilots with only the asymmetric thrust of the engines for control ${ }^{12}$. During the climb phase of the flight, the rear pressure bulkhead was torn open, removing a significant portion of the vertical stabilizer. The four hydraulic lines used for controlling the surfaces on the aircraft were also ruptured, leaving the elevators, ailerons, and rudders unusable. Although the pilots were ultimately unable to control the aircraft to a safe landing, the use of differential thrust proved successful in maintaining more stable flight. Once the pilots began to implement the use of asymmetric flaps in conjunction with the differential thrust, they began to once again lose stability in the aircraft. 
The crew of Flight 123 was able to utilize asymmetric thrust to keep the aircraft aloft for 32 minutes, longer than any crews trying to recreate the incident in a simulator during the investigation $^{12}$.

Several studies ${ }^{13,14}$ have been conducted to implement propulsion assisted control and thrust vectoring in flight controls for commercial aircraft. These studies have been fueled by aircraft accidents and incidents where the pilots have needed to utilize differential thrust to maintain safe flight. There, however, has been difficulty in trying to control both the lateral and longitudinal modes with differential thrust alone ${ }^{15}$, specifically on commercial transport aircraft configurations such as the Boeing 747. Inspired by this challenge, a team at the University of Leicester in conjunction with the Volvo Aero Corporation Military Engines conducted a study on the design of integrated flight and propulsion control systems for large civil transport aircraft. They utilized a detailed model of the Boeing 747-100 aircraft within a Matlab/Simulink software environment to study the ability to use differential thrust and thrust vectoring for the purposes of emergency flight control ${ }^{15,16}$.

The project implements the capability to combine aerodynamic control surfaces, thrust vectoring, and differential thrust capabilities within the flight controller. The dynamic response of the engine was modeled for the simulation study because of the need for an accurate thrust representation. The engine dynamics were modeled as a second-order filter in conjunction with operating-point-dependent eigenvalues to represent the "spool dynamics of a typical turbofan engine" ${ }^{\prime 15}$. Additionally, the engine model was extended to incorporate thrust vectoring, with the assumption that it can be considered "perfect" meaning that the effective thrust vector angles are equal to the measured mechanical vector angles. It was also assumed that there existed no losses in engine efficiency when the engines are vectored ${ }^{15}$.

Within the flight control laws, thrust vectoring and differential thrust were used to simultaneously control the lateral and longitudinal modes. Functions were implemented to distribute the thrust and vectoring commands between the four wing-mounted engines on the Boeing 747 aircraft. Additionally, the commands could be blended between the lateral and 
longitudinal controls using a fixed-distribution method dependent on flight condition and flight mode. It was designed in this manner so it could potentially be used in conjunction with a failure detection system to accommodate for failures by optimally redistributing the controls ${ }^{15}$. Simulations from this study indicated that stable flight in large civil transport aircraft could be achieved using differential thrust to provide lateral control and collective thrust to provide longitudinal control. This study also showed that propulsion only control could be a viable means of maintaining stable flight in emergency situations, such as the case of control surface failures. The use of thrust vectoring about the yawing body axis showed significant improvement in lateral control, and when thrust vectoring was combined with differential thrust within the control scheme, the flying qualities were greatly improved during failure scenarios ${ }^{15}$.

According to a NASA study ${ }^{17}$, in the 20-year period between 1976 and 1996 the Boeing 747, B-52, L-1011, C-5A, and DC-10 aircraft have experienced "major" flight control system failures during which the pilot was required to use asymmetric throttles for emergency flight control. The Boeing 747, DC-10, and C-5A accidents claimed over 1200 lives. NASA Researchers at Dryden Flight Research Center began conducting flight test studies to evaluate the amount of control available from asymmetric thrust on several different aircraft platforms including both military and civilian aircraft. The study proved that sufficient control was available using both symmetric and asymmetric thrust to control the flight path and generate sideslip, respectively ${ }^{17}$. Dryden researchers also developed a propulsion controlled aircraft and tested it during landing scenarios. From this research, they began to develop and test a propulsion controlled aircraft which uses only engine thrust for control. This type of emergency flight control system was implemented on a MD-11 aircraft ${ }^{17,18,19,20,21}$ which "augments pilot flightpath and track commands with aircraft feedback parameters to control engine thrust ${ }^{18}$." Control in the lateral-directional plane was produced from differential thrust generating sideslip which, through the dihedral effect, resulted in the aircraft rolling, causing a turn and heading change. Control in the longitudinal plane was more complex with the pitch of the aircraft being driven by an offset of the thrust line from the vertical center of gravity $(\mathrm{CG})^{17}$. Research was also extended to use thrust modulation to control flight path during the tests on the MD-11 aircraft. The goal of this project was to develop a 
Propulsion-Controlled Aircraft Emergency Backup System to assist a pilot in safely landing an aircraft in the event of having engines as the only control effectors or an inoperative flight control system ${ }^{22}$. Similar work was also conducted using a modified F-15 aircraft for both simulation and flight test studies using throttles for flight control $^{23}$. NASA has also conducted simulations to show the applicability of propulsion control for the total loss of the rudder for a manned transport aircraft. The simulations showed that although the necessary thrust differential generation was slower than the typical moment generated by the rudder for yaw control, it provided a sufficient means to control the aircraft ${ }^{24}$.

NASA Dryden Flight Research Facility conducted a study in 1991 to determine the emergency flight control capability of multiengine airplanes using throttle-only control ${ }^{25}$. Both simulations and flight tests were performed to determine the level of control available for various types of aircraft including piston-powered light twin-engine aircraft, high performance fighter aircraft, and commercial transport aircraft. It was found through simulations that most aircraft had significant control power with manual throttle-only control but were difficult to control due to lags in the system response. The aircraft tested in the piloted simulators in which throttle-only control was implemented included the F-15, B-720, B-727, MD-11, C-402, and the B-747. In order to improve the aircraft performance using differential thrust, an augmented control system was developed and tested on the B-720 25 .

Prior to the augmented control system, the available control power from manual throttle-only control could be used to maintain gross control including holding heading and altitude and making a controlled decent. However, landing on a runway proved extremely difficult for the pilot because of a one second lag in pitch and roll before the aircraft began to respond to the throttles ${ }^{25}$. The augmented control provided feedback for phugoid damping, flight path angle control, and bank angle control, while allowing the pilot to fly using normal flight control effectors (control wheel, stick, or autopilot trim wheels). It was found that with the augmented control system it was possible to make repeatable landings on a runway. Cooper-Harper pilot ratings for the augmented control system were approximately four times higher than they were for manual control, indicating a substantial control improvement ${ }^{25}$. 
The National Defense Academy performed a study to determine the feasibility of an automatic approach and landing for a Boeing 747 propulsion controlled aircraft ${ }^{26}$. A flight control system was designed for the propulsion controlled aircraft in which available control authority was provided only by thrust. This study focused on the approach and landing phases of flight, since they are often viewed as the most critical phases. The designed control system was able to achieve satisfactory approach and landing using the amount of thrust available. The landing speed was slightly higher than that of an aircraft landing with nominal conditions, but the sink rate at touchdown was small enough to make a safe landing. The wing mounted engines helped to provide lateral-directional control with adequate control power in yaw control, without unfavorable oscillations such as Dutch-roll ${ }^{26}$.

Researchers at the University of Virginia in Charlottesville along with the NASA Langley Research Center developed an aircraft model that incorporated independently adjustable engine throttles and ailerons within an adaptive control scheme for use in the presence of actuator failures $^{27}$. Rudder and aileron failures were considered in this study with a large transport aircraft platform. Simulation results showed that the adaptive scheme was able to provide "satisfactory performance" in the presence of the failure scenarios observed ${ }^{27}$. Researchers at the University of California, Davis and the NASA Ames Research Center conducted a study to investigate adaptive control methods on a generic transport aircraft model under adverse flight scenarios such as damage or failures ${ }^{28}$. Within this research, differential thrust was applied under the assumption that the engine thrust vector was aligned with the aircraft body $x$-axis and that the left and right engines produced equal thrust when given the same input. Differential thrust throttle position would be utilized when the rudder control power was insufficient due to damages. Due to the lag between applying the differential engine thrust and it actually ramping up to perform the desired yaw trimming, the engine actuator dynamics had to be accounted for within the simulation to accurately portray the control authority on a real system ${ }^{28}$. Similar work was conducted on the development of an integrated neural flight and propulsion control system, which utilized a neural network-based approach to apply asymmetric control power in the presence of damage or failures ${ }^{29}$. Under these adverse flight conditions, integrated propulsion 
control was used in conjunction with unconventional flight control surface maneuvers to achieve the desired performance. Again piloted simulation studies were performed on a commercial transport aircraft simulator, with the control laws demonstrating the potential for improving the aircraft handling qualities and increasing the likelihood of survivability rates for certain failures $^{29}$. A study utilizing $\mathrm{H}_{\infty}$ model matching for propulsion control of a "crippled" aircraft noted that the Dutch roll mode of an aircraft is excited with the use of differential thrust ${ }^{30}$. The engine signal produced by the controller to suppress the Dutch roll mode had significant oscillatory motion. This complicated throttle signal is difficult for a pilot attempting to fly a damaged aircraft by manual throttle-only control to achieve by intuition ${ }^{30}$. Because these complicated engine thrust signals have been common amongst many of the differential thrust studies, it has provided the community with further incentive to develop propulsion assisted control laws to assist pilots maintain the aircraft in adverse flight conditions.

\subsection{Full-Scale Aircraft Use of Thrust Vectoring as Augmented Control}

Thrust vectoring techniques have been successfully demonstrated to implement short take-off and landing, increased maneuverability during air combat engagements against conventional fighter aircraft, and high angle of attack flights. The majority of the early thrust vectoring research was performed at low speeds in a high angle of attack flight regime. The F-15 ACTIVE Flight Research Program sought to expand the flight envelope in which thrust vectoring would be useful for increased performance, maneuverability, and controllability with production-representative nozzles. This was achieved through extensive simulations and flight testing procedures in which thrust vectoring was flown open loop first to establish the response of the aircraft. During the initial thrust vectoring flights, the response of the aircraft to thrust vectoring was significantly lower than predicted. With a greater understanding of the aircraft response, the program managed several important milestones including the highest speed (Mach 1.6) yaw vectoring at that time. This study also found that Pratt \& Whitney could provide a successful design for modern fighter aircraft with effective thrust vectoring capabilities. Additionally, thrust vectoring nozzles used as primary flight control effectors appeared to be realizable with this design approach ${ }^{31}$. 
The multi-axis thrust vectoring (MATV) program proved the effectiveness of thrust vectoring in the F-16, stating that it was not aircraft, engine or technology limited, but budget limited. This study showed that thrust vectoring could be considered "a reliable and highly effective means of control for tactical jet aircraft and significantly enhanced the combat capability of the F-16," and could be integrated economically. The vectoring technique implemented on the F-16 MATV system is the GE Axis-symmetric Vectoring Exhaust Nozzle (AVEN), which uses three actuators located 120 degrees apart to drive a vectoring ring. Figure 6 shows the AVEN, whose configuration allows for control in pitch, yaw, and any combination thereof.

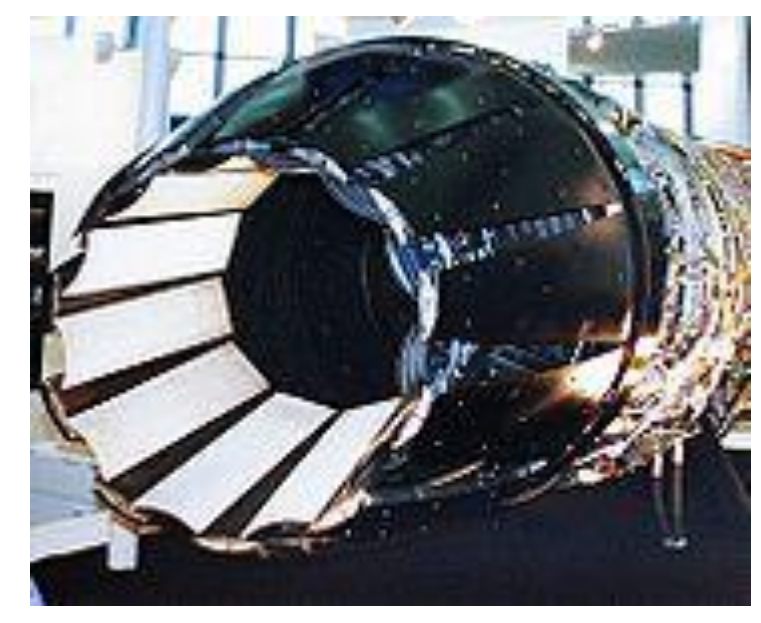

\section{Figure 6: The GE Axis-Symmetric Vectoring Nozzle (AVEN)}

The F-16 is one of the most maneuverable fighters in the world, but at angles of attack between 30 and 50 degrees, directional stability is lost due to the blockage of the vertical tail by the fuselage. The aircraft achieves maximum lift at an angle of attack of 32 degrees but flight control limiters are required to restrict command of angle of attack to 25.5 degrees. With the implementation of MATV, the F-16 was able to perform maneuvers like the "cobra" and the "Jturn" 32 .

Researchers at the Wright Laboratory at Wright-Patterson AFB conducted a simulation study utilizing the modified F-16 with full-envelope control laws ${ }^{33}$. The research morphed from 
simulations being conducted utilizing the Variable Stability In-Flight Simulator Test Aircraft (VISTA) and the MATV nozzle where they could assess performance during high angle of attack flight. The control system evaluated for this project incorporated thrust vectoring for both low and high angle of attack maneuvers. The thrust vectoring was employed during the simulated maneuvers to provide additional control power in pitch and $\mathrm{yaw}^{33}$.

Aircraft spin is one of the most complex and dangerous phenomena encountered in flight. A significant portion of aircraft accidents, both military and general aviation, are stall/spin related incidents ${ }^{34}$. A study was performed by the Indian Institute of Technology Bombay, exploring the use of nonlinear dynamic inversion with and without thrust vectoring as a method for aircraft spin recovery. Thrust vectoring was utilized to add two additional control effectors; pitch thrust vector deflection and yaw thrust vector deflection. This allowed the dynamic inversion algorithm to compute five control commands as opposed to only three without the use of thrust vectoring. The additional control effectors improved the spin recovery performance and through simulations proved to decrease recovery time by nearly $60 \%$ by removing the need for the twostep recovery procedure necessary without thrust vectoring capabilities ${ }^{35}$.

Researchers at NASA Langley Research Center developed a method for integrating thrust vectoring with convention aerodynamic control within a high performance fighter aircraft ${ }^{36}$. The method of pseudo controls, where several aircraft controls are integrated to achieve a desired operation, was implemented within the lateral/directional controls of the aircraft. The experimental set of lateral/directional controls as applied to the thrust vectoring was utilized to enhance stability and maneuvering capabilities over an expanded flight envelope and high angles of attack. For this study, the NASA High-Alpha Research Vehicle (HARV) was used as it is a high performance twin-engine jet fighter aircraft modified to house a thrust-vectoring apparatus. The thrust vectoring integrated within the pseudo controls allowed for the development of moments about the aircraft body axes to satisfy requirements of the stability augmentation feedback loops, pilot commands, and inertial decoupling observed in flight. The thrust vectoring apparatus generated pitch, roll, and yaw control moments by exhaust plume deflection. Symmetric vertical deflections of the two engines produced a pitching moment, while 
differential vertical deflections caused a rolling moment. Horizontal deflection of the engines provided the necessary yawing moments for the desired maneuvers. The roll and yaw thrustvector angles were commanded to be proportional to the roll and yaw pseudo control variables as follows ${ }^{36}$ :

$$
\begin{aligned}
& \delta_{T V r}=+\delta_{T V r m} v_{\text {roll }} \\
& \delta_{T V y}=-\delta_{T V y m} v_{\text {yaw }}
\end{aligned}
$$

where $v_{\text {roll }}$ and $v_{\text {yaw }}$ are the pseudo roll and yaw controls, respectively, and $\delta$ represents the roll and yaw thrust vectoring deflection angles.

The thrust vectoring control moments were then proportional to the deflection angles and engine thrust. The following equations describe the roll and yaw moments produced by the thrust vectoring controls with respect to the body axes ${ }^{36}$ :

$$
\begin{gathered}
L=L_{T V} v_{\text {roll }}-\frac{l_{z}}{l_{T V}} N_{T V} v_{\text {yaw }} \\
N=N_{T V} v_{\text {yaw }}
\end{gathered}
$$

where $L$ and $N$ are the roll and yaw control moments, $l_{z}$ is he distance of the thrust vectored nozzles below the aircraft $\mathrm{CG}$, and $l_{T V}$ is the distance from the $\mathrm{CG}$ to the thrust vectored nozzles.

The rolling and yawing moment capabilities of the thrust vectoring controls were a function of the maximum rolling and yawing thrust vector angle, respectively, the total engine thrust, the lateral position of the engines and the longitudinal distance between the vectoring nozzles and the airplane $\mathrm{CG}$, respectively ${ }^{36}$.

$$
\begin{gathered}
L_{T V}=l_{y} T\left(\frac{\pi}{180}\right) \delta_{T V r m} \\
N_{T V}=l_{T V} T\left(\frac{\pi}{180}\right) \delta_{T V y m}
\end{gathered}
$$


where $l_{y}$ is the lateral distance from the aircraft centerline to the nozzles.

Within the simulation studies, NASA researchers were able to schedule the thrust vectoring usage based on the relative effectiveness to that of aerodynamic controls. Additionally, a calculation of the interference in the lateral accelerometer output caused by the thrust vectoring was incorporated to correct the acceleration feedback signals in the pseudo controls ${ }^{36}$. Similar work was done using the same HARV platform at NASA Dryden Flight Research Center in the development of a research flight control system (RFCS) that incorporated a thrust-vectoring mixer $^{37}$. The thrust-vectoring vanes on the HARV were incorporated within the flight control laws through a mixer which translated the pitch and yaw thrust vectoring commands from the RFCS into vane commands. The mixer was utilized to "compute the proper thrust-vane deflections required to achieve the desired moments" 37 .

Another thrust vectoring technique was explored at the University of Manchester, where fluidic thrust vectoring of low observable unmanned air vehicles was utilized ${ }^{38}$. A summary of fluidic thrust vectoring concepts is found in a paper by Gridley and Walker ${ }^{39}$. The method explored in this study used a coflow of fluid along a Coanda surface to vector the exhaust. The Coanda effect is the tendency of a moving fluid to adhere to a solid curved surface ${ }^{40}$. A secondary jet is blown along the Coanda surface which causes the exhaust to bend towards this curved surface, resulting in thrust vectoring. This study found that at low secondary jet mass flow rates, a "dead zone" appeared. This "dead zone" was dependent on the diameter of the Coanda surface, and the mass flow rate of the secondary flow. This method was found to successfully vector the thrust by a small amount, but proved to only provide small forces in the vectored directions ${ }^{38}$.

Additional control capabilities result from thrust vectoring techniques, but often the implementation of thrust vectoring using exhaust flaps and nozzle deflections lead to increased weight and decreased efficiency. Lockheed Martin Aeronautics Company demonstrated the use of fluidic throat skewing for thrust vectoring in structurally fixed nozzles. It was found through experimentation data, that "fluidic throat skewing is an effective and efficient means of 
providing multi-axis thrust vectoring control in a fixed-geometry nozzle." The quantification of the result was that 2 degrees yaw or 1.7 degrees pitch were achieved for every 1 percent of injected mass flow. This study also found that this method of thrust vectoring achieved multiaxis control without significant impacts on thrust efficiency ${ }^{41}$.

A computational study was conducted at NASA Langley Research Center on fluidic thrust vectoring where three-dimensional simulations of a two-dimensional convergent-divergent nozzle with fluidic injection for pitch vector control was implemented. The computational fluid dynamics (CFD) code PAB was used with turbulence closure and linear Reynolds stress modeling, and simulations were conducted with static freestream conditions $(M=0.05)$ at range of Mach numbers from 0.3 to 1.2. The goal of the research was to show possible advantages of fluidic thrust vectoring since moving mechanical hardware is not involved, improving aircraft weight and drag compared to mechanical thrust vectoring ${ }^{42}$.

Fluidic injection for thrust vectoring has been studied since the 1990's, and concepts such as throat skewing and shock vector control have begun to mature $e^{42,51,52,53}$. The study conducted at NASA Langley focused on initiating external flow effects on the fluidic thrust vectoring. A secondary air stream was injected through an opening on the lower divergent wall of the nozzle, and the CFD code was utilize to simulate the nozzle at specified pressure ratios. The implemented code solved the three-dimensional Reynolds-averaged Navier-Stokes (RANS) equations and implemented turbulence modeling to predict the solutions across many flow fields. Runs were conducted at static conditions with no fluidic injection to establish a baseline. A scenario matrix was run for different freestream conditions and nozzle pressure ratio combinations to achieve an overview of the performance. This study showed that the freestream flow decreased the vectoring performance and thrust efficiency when compared to static conditions. Specifically, the aerodynamic penalty to thrust vector angles was found to be between 1.5 degrees to 2.9 degrees based on the nozzle pressure ratio and Mach conditions ${ }^{42}$. Figure 7 shows one of the runs for a static $(M=0.05)$ free stream condition with a nozzle pressure ratio of 5.2. 


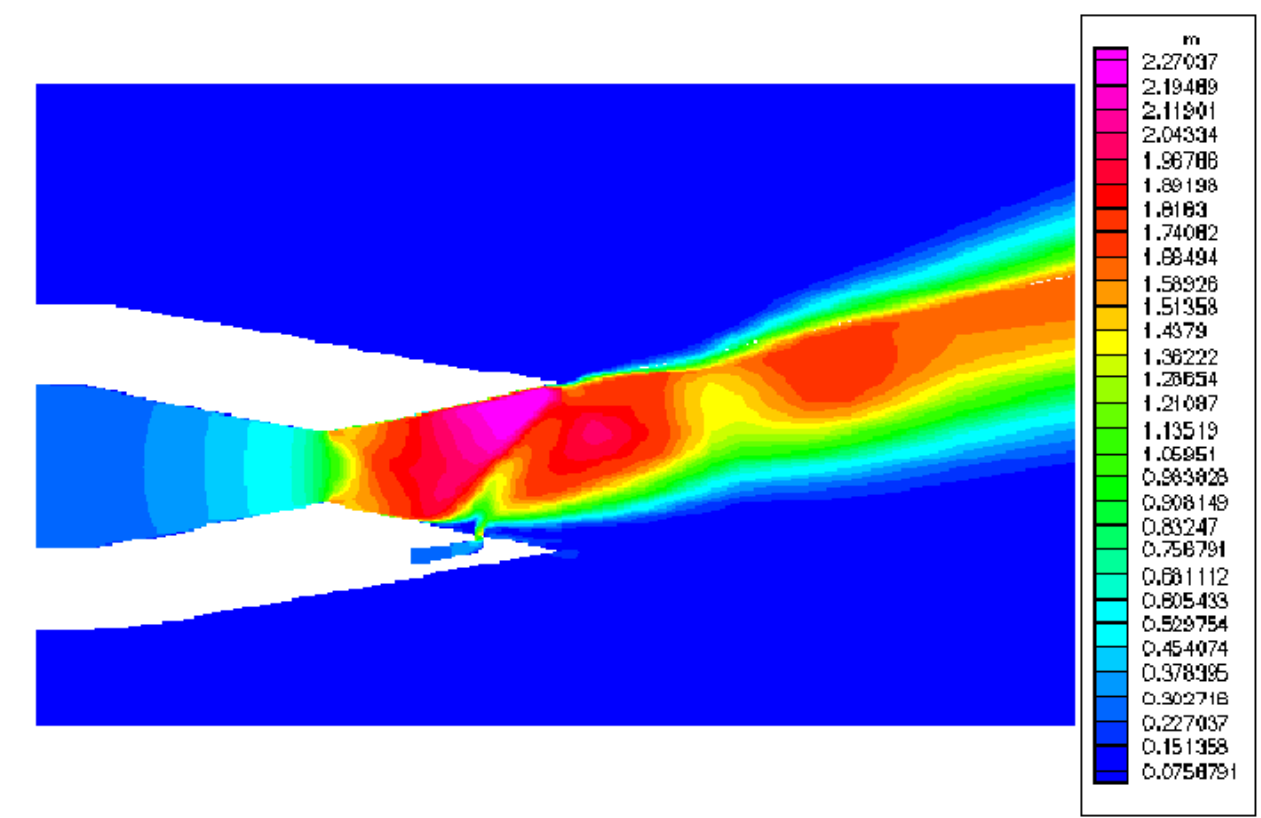

Figure 7: Mach Contours along Nozzle Centerline with NPR of 5.2 (Reproduced from

\section{Reference 42)}

\subsection{UAV Use of Differential Thrust and Thrust Vectoring}

With the increased use of UAVs for research and military applications, there has been a growing need for advanced control design. As technology advances and drives the progression of UAV design, there is a push to reduce the size, noise, power usage, and cost of these platforms. Additionally, the use of differential thrust and thrust vectoring has become an appealing option to assist in the control and maneuvering of these aircraft.

Researchers at the California Institute of Technology developed the Caltech ducted fan (described in Section 2.1), a research platform utilizing a ducted fan to develop control laws applicable to $\mathrm{UAVs}^{8}$. One study ${ }^{43,44}$ focused on controlling the ducted fan in forward flight and modeled it as a thrust vectored flying wing within a simulator for application within UAV flight control laws. The Boeing Company is developing a solar-powered, long-duration aircraft, the Solar Eagle ${ }^{45}$, which may employ differential thrust for lateral-directional control. With computer-controlled asymmetric thrust capabilities on unmanned aircraft, the control system has an additional degree of freedom. Other research has considered using propulsion-only control for 
small UAVs, such as the quad-rotor design ${ }^{46}$. In the quad-rotor UAV, the vehicle consists of four electric-motor-driven propellers that provide both attitude control and propulsion. Figure 8 shows a schematic of a typical quadrotor design.

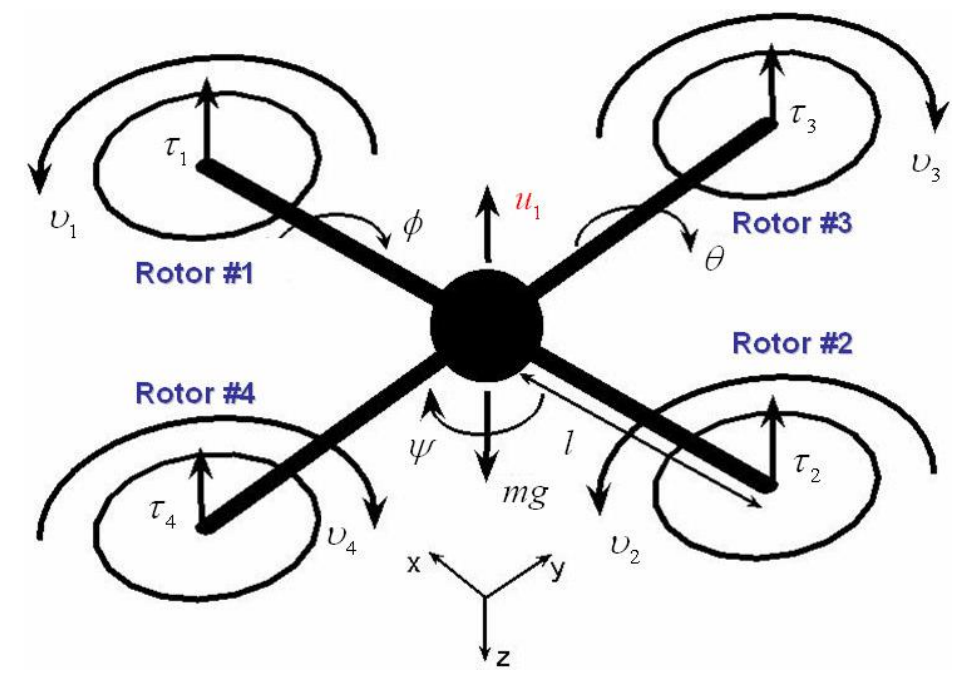

Figure 8: Quadrotor Schematic (Reproduced from Reference 47)

Researchers at Auckland University of Technology in New Zealand developed a quad-rotor UAV that is capable of vertical takeoff and landing (VTOL), hover, and transitioning between vertical and horizontal flight. The zero-angular-momentum (ZAM) UAV was designed as a research platform to test control algorithms to assist a pilot in the transition between vertical and horizontal flight when remotely operating the aircraft. Attitude adjustments are made through the complimentary pairing of rotors to maintain zero angular momentum while adjusting the orientation $^{46}$. These types of VTOL UAVs are becoming increasingly appealing due to their ability to perform in urban, mountainous, and maritime environments, i.e. low altitude operating environments. Typically these aircraft will be smaller in size and lower in weight, and they can operate below controlled airspace free from cloud coverage. With the smaller size and lower cost of these platforms, they are also a strong candidate to perform in UAV swarms ${ }^{48}$.

Following the September 11, 2001 attacks on the United States of America, research of the application of small VTOL UAVs for spying and defense has seen a substantial increase. VTOL 
Technologies, a British company, has been developing a VTOL UAV that combines a flying wing with four thrust vectored motors. In 2009, the company completed a proof-of-concept study to showcase their ability to decrease weight by reducing the number of redundant mechanical systems. Additionally, VTOL Technologies described some of the advanced features that allow the UAV to maintain flight in adverse conditions utilizing thrust vectoring capabilities. The thrust vectoring capability allows the aircraft to have "almost instantaneous stall recovery, gust insensitivity, reverse thrust to enable the platform to be 'sucked down' onto the deck of a ship pitching in heavy seas, and minimum power to rotate the thrust vectoring propulsion units" ${ }^{, 49,50}$.

The modeling, control, and flight testing of a ducted fan aircraft known as the GTSpy was performed at Georgia Institute of Technology. The objective of the study was to use dynamic inversion and neural network adaptation to develop an adaptive controller for the aircraft. The modeling process focused on the major forces and moments acting on the vehicle. The exact values of these parameters were of secondary importance behind the proper functional dependence, correct sense, and order of magnitude.

"The basic dynamic equations are given as:

$$
\begin{gathered}
\dot{p}=v \\
\dot{v}=\frac{F}{m} \\
\dot{q}=\frac{1}{2}\left[\begin{array}{ccc}
-q_{2} & -q_{3} & -q_{4} \\
q_{1} & -q_{4} & q_{3} \\
q_{4} & q_{1} & -q_{2} \\
-q_{3} & q_{2} & q_{1}
\end{array}\right] \omega \\
\dot{\omega}=I^{-1}(M-\omega \times I \omega)
\end{gathered}
$$

in which $\mathbf{p} \in R^{3}$ represents the position vector, $\mathbf{v} \in R^{3}$ is the velocity vector, $\mathbf{q} \in R^{4}$ is the quaternion vector, and $\omega \epsilon \mathrm{R}^{3}$ represents the angular velocity vector. The vehicle mass is represented by $m, i q$ represents the four components of the quaternion vector3, I is the vehicle inertia matrix, and the 
$\mathbf{F}$ and $\mathbf{M}$ terms represent the sum of external forces and moment vectors acting on the vehicle ${ }^{54}$." The force and moment vectors can be expressed as:

$$
\begin{gathered}
F=F_{\text {gear }}+F_{\text {aero }}+F_{\text {rotor }}+F_{\text {duct }}+F_{c s}+F_{\text {grav }} \\
M=M_{\text {gear }}+M_{\text {aero }}+M_{\text {rotor }}+M_{\text {duct }}+M_{c s}+M_{\text {gyro }}
\end{gathered}
$$

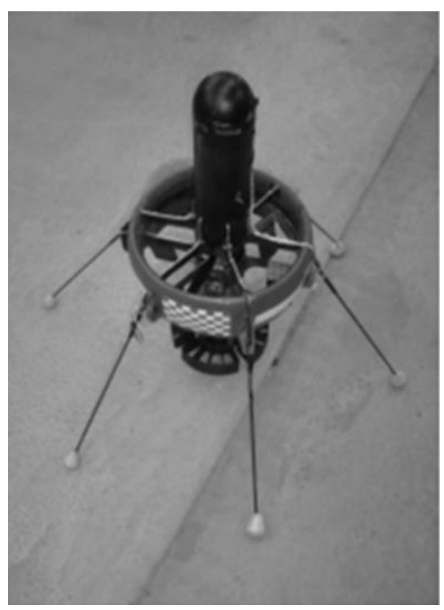

Figure 9: The GTSpy Small Ducted Fan Aircraft (Reproduced from Reference 54)

Errors in the model were successfully corrected for using the neural network adaptive controller. This model was successfully implemented in the feedback linearization through dynamic inversion. This approach has been proven to work on other vehicles and was found to be well suited to the small ducted fan GTSpy ${ }^{54}$. The force and moment parameters used in this study are applicable to the ducted fan aircraft configuration shown in Figure 9, but many of these terms will be negligible when applied to a conventional style aircraft with ducted fan propulsion.

The Damselfly tactical UAV, built by SELEX Sensors and Airborne Systems, combines VTOL with a smooth transition to horizontal flight with thrust vectoring capabilities. The Damselfly operates in a quadrotor setup that allows the aircraft to take off and land within a constrained space and reach top speeds of $280 \mathrm{~km} / \mathrm{h}$. In April 2007 a subscale $1 \mathrm{~m}$ version of the aircraft powered only by electricity, completed successful hover trials and in November 
demonstrated transition between vertical and horizontal flight once fitted with an internal combustion engine ${ }^{55}$.

Researchers at the Department of Aerospace Sciences at Cranfield University in partnership with BAE Systems completed a computational investigation of the DEMON unmanned air vehicle thrust vectoring system ${ }^{56}$. The investigation studied the interaction of the thrust vectoring from the main engine with the subsonic flow around the DEMON UAV. The unmanned aircraft platform consisted of a cropped diamond wing planform and lacked a tail. Several simulations sets were run to evaluate the thrust vectoring jet entrainment effects caused by the aerodynamic forces and moments at varying angles of attack and flight speeds. Noting that a primary advantage of thrust vectoring is an increase in control moments unaffected by angle of attack, the study sought to show thrust vectoring as a feasible method to control the unmanned aircraft under high angle of attack conditions ${ }^{56}$.

Although static thrust measurements provide an ideal estimate of the normal force component developed from thrust vectoring, additional contributions occur in nature from jetinduced interference. This is due to the external flow of air altering the jet angle through a change in the pressure distribution. These induced forces must be added to the reaction forces to estimate the deflection angle of the jet through thrust vectoring. The computation study assessed these forces caused by fluidic thrust vectoring on the DEMON UAV to demonstrate longitudinal control without relying on aerodynamic surfaces. Results from the study showed that the pitching moment generated by the thrust vectoring was the primary component responsible for the jet-lift portion of the nozzle resultant thrust. The jet-interference contributions were found to not be negligible, and in some cases, proved beneficial in improving thrust vectoring performance. Additionally, the forces and moments caused by thrust vectoring were found to be independent of angle of attack, reaffirming its potential use at high angle of attack flight for UAVs. It was concluded that "reaction forces induced by the modified pressure on the integrated boundary of the body results in an enhancement of the thrust vectoring effectiveness in producing the forces and moments required for the flight vehicle trim and maneuvering" 
Due to the nature of this research project, there is a limited amounted of directly related information. This literature review serves to explore the research topics that are closely related to the topic of this thesis but does not guarantee that the methods described were implemented in this research. Control systems utilizing differential thrust in the feedback were explored to better understand future applications of this work. Several thrust vectoring techniques were examined to gain a global understanding of research efforts in this field. This research is unique in that it utilizes ducted fan propulsion on a conventional configuration aircraft, while implementing thrust vectoring through rotational deflections of the entire duct. The aircraft response to differential thrust and thrust vectoring is very configuration dependent, changing with motor mounting location, inertial properties of the aircraft, and propulsive forces. 


\section{WVU Propulsion Assisted Control Test Bed}

The following sections describe the WVU PAC research aircraft platform and its capabilities for flight testing.

\subsection{Propulsion Assisted Control Aircraft System}

The WVU PAC research aircraft is an unmanned radio-controlled aircraft designed, constructed, and instrumented at West Virginia University and is continuously adapted for various research projects ${ }^{57}$. The fuselage is a carbon fiber and fiberglass composite body with plywood bulkheads within the aircraft body for structural integrity. The propulsion system consists of two $90 \mathrm{~mm}$ ducted fans, each powered by a brushless in-runner motor. These motors provide approximately $28.9 \mathrm{~N}(6.5 \mathrm{lbs})$ of thrust each for a total thrust of approximately $57.83 \mathrm{~N}$ (13 lbs). The aircraft is a T-tail configuration and has winglets mounted on the tips of the wings. The primary control surfaces - ailerons, elevators, and a rudder - are all commanded using digital servos. The takeoff weight is approximately $10.43 \mathrm{~kg}$ including an electronic payload consisting of an on-board computer utilizing a MOD-5213 microcontroller, several printed circuit boards for signal routing and hardware interfacing, a 6 DOF inertial measurement unit (IMU) and a Novatel 50Hz OEM-V GPS receiver. Figure 10 shows the PAC aircraft in flight.

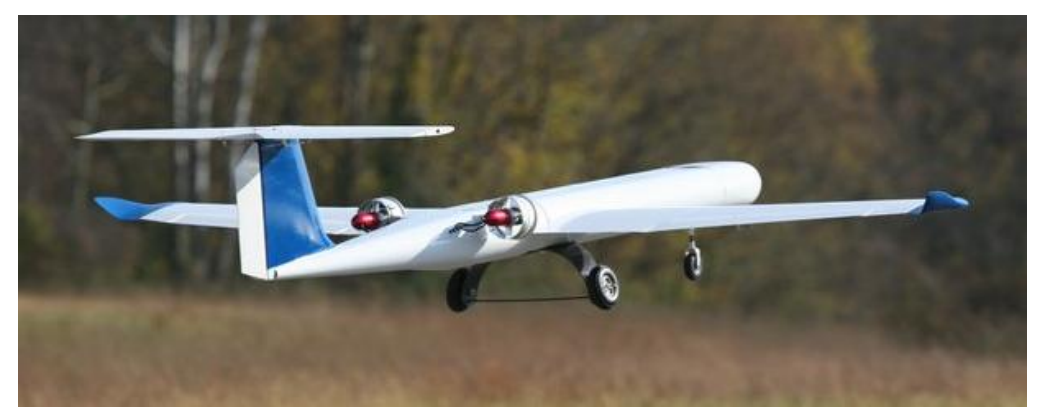

Figure 10: WVU Propulsion Assisted Control Test Bed

Table 1 shows some of the geometric parameters of the PAC Aircraft, for the wing, horizontal tail, and vertical tail. 
Table 1: Geometric Parameters of the PAC Aircraft

\begin{tabular}{|c|c|c|c|c|c|c|c|c|}
\hline \multicolumn{2}{|c|}{ Total Wing Estimation } & $\begin{array}{c}\text { HORIZONTAL TAIL } \\
\text { (including elevators) }\end{array}$ & \multicolumn{2}{|c|}{$\begin{array}{c}\text { VERTICAL TAIL } \\
\text { including rudder) }\end{array}$} \\
\hline Dimension & Value Units & Dimension & Value & Units & Dimension & Value & Units \\
\hline $\mathrm{AR}$ & 6.758 & - & $\mathrm{AR}_{\mathrm{H}}$ & 4 & - & $\mathrm{AR}_{\mathrm{V}}$ & 1.92 & - \\
\hline$\Lambda_{\mathrm{LE}}$ & 0 & $(\mathrm{deg})$ & $\Lambda_{\mathrm{LE}}$ & 5.04 & $(\mathrm{deg})$ & $\Lambda_{\mathrm{LE}}$ & 21.09 & $(\mathrm{deg})$ \\
\hline$\Lambda_{0.25}$ & -1.77 & $(\mathrm{deg})$ & $\Lambda_{0.5}$ & 0.84 & $(\mathrm{deg})$ & $\Lambda_{0.5}$ & 10.3 & $(\mathrm{deg})$ \\
\hline$\Lambda_{0.5}$ & -3.58 & $(\mathrm{deg})$ & $\Lambda_{0.25}$ & 2.95 & $(\mathrm{deg})$ & $\Lambda_{0.25}$ & 15.24 & $(\mathrm{deg})$ \\
\hline $\bar{c}$ & 12 & $(\mathrm{in})$ & $\bar{c}$ & 8.38 & $(\mathrm{in})$ & $\bar{c}$ & 11.44 & $(\mathrm{in})$ \\
\hline $\mathrm{b}$ & 80.25 & $(\mathrm{in})$ & $\mathrm{b}_{\mathrm{H}}$ & 34 & $(\mathrm{in})$ & $\mathrm{b}_{\mathrm{V}}$ & 11 & $(\mathrm{in})$ \\
\hline $\mathrm{S}$ & 952.97 & $\left(\mathrm{in}^{2}\right)$ & $\mathrm{S}_{\mathrm{H}}$ & 288.94 & $\left(\mathrm{in}^{2}\right)$ & $\mathrm{S}_{\mathrm{V}}$ & 251.56 & $\left(\mathrm{in}^{2}\right)$ \\
\hline
\end{tabular}

\subsection{PAC Onboard Computer}

The Advanced Research Integrated Avionic (ARIA) System was specifically developed for the PAC aircraft to test fault-tolerant flight control laws. This computer was developed by researchers at WVU, and was designed to have four Printed Circuit Boards (PCBs) with each providing a specific function to the system. The top most board is a custom designed printed circuit board which includes a compact flash card reader, a GPS receiver, indicator LEDs, and microSD data recorders. The second board is a Single Board Computer (SBC) with four serial ports. The third board is a PC-104 power supply with extra RS-232 serial ports. The bottom-most board is a custom board that was designed to act as a signal distribution system and an interface to onboard sensors. ARIA was also integrated with a MEMS IMU on the bottom board, and the need for a vertical gyroscope was eliminated by the use of a GPS/INS sensor fusion algorithm, thus reducing the platform weight ${ }^{58,59}$. Figure 11 shows the ARIA System developed for the PAC research aircraft. 


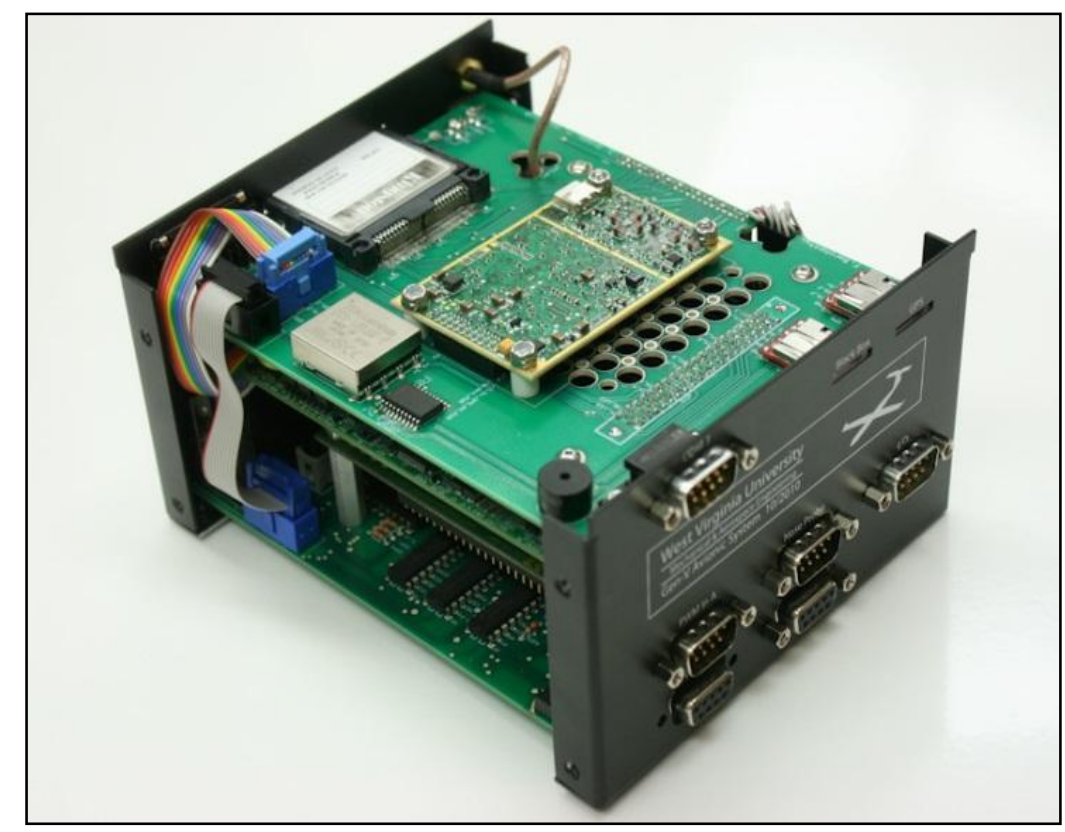

Figure 11: ARIA System (Reproduced from References 58, 59)

ARIA consists of a 32-bit $66 \mathrm{MHz}$ Freescale ColdFire MOD 5213® microprocessor integrated with a real-time operating system. The MOD 5213 enables the prioritization of tasks, such as interfacing with the MEMS IMU and reading control command signals from a ground pilot, with seven interrupt levels. The microprocessor also may receive inertial information through a serial peripheral interface (SPI) from a high precision tri-axis IMU made by Analog Devices. This allows for the recording of inertial information such as three-axis acceleration and angular rates. The primary flight computer within the ARIA system is the Diamond Systems' $800 \mathrm{MHz}$ Athena II general purpose SBC. The ARIA System provides six RS-232 ports for communication with devices such as the embedded microprocessor, GPS unit interface, and an RF modem ${ }^{59}$.

\subsection{PAC Sensors and Communication Hardware}

The WVU PAC aircraft is instrumented with a complete sensor suite for measuring flight data parameters. A MEMS IMU integrated on the PCB provides measurements of the linear accelerations and angular rates, while a GPS receiver provides position and velocity information 
in three dimensions with respect to the earth centered earth fixed (ECEF) reference frame. A GPS/INS sensor fusion algorithm provides pitch and roll information for the aircraft, and allows for the elimination of the vertical gyroscope. Vanes designed and manufactured in-house are attached to frictionless potentiometers to provide measurements of the angle of attack and sideslip angle. The control surface deflections are determined through the measurement of the pilot inputs onboard the aircraft. A relationship between the commanded input and the actuator model was established to determine the control surface deflections. The following lists some of the sensor specifications for the suite onboard the PAC research aircraft ${ }^{60}$ :

- Inertial Measurement Unit (ADIS 16355® IMU), providing 14-bit measurements for the accelerations $a x, a y, a z$ (range $\pm 10 \mathrm{~g}$ ), and the angular rates $p, q$, and $r$ (range $\pm 150^{\circ} / \mathrm{sec}$ ).

- $\quad$ GPS Receiver (Novatel-OEM1), providing measurements for $x, y, z, V x, V y, V z$ with respect to an earth reference frame.

- Vanes (designed/constructed at WVU), providing measurements of flow angles $\alpha$ and $\beta$, with ranges of $\pm 30^{\circ}$.

- Laser Range Finder with an accuracy of $+/-1 \mathrm{~m}$.

- Temperature/Humidity Sensor with an accuracy of $+/-3 \%$ RH

- Castle Creations Electronic Speed Controller capable of recording motor RPM, battery voltage, current draw, speed controller temperature, power usage, and throttle setting.

- Pitot Tube and Pressure Sensors for obtaining air speed. 


\section{Thrust Force Modeling}

\subsection{Static Thrust Force Modeling}

In order to properly implement differential thrust and thrust vectoring on the aircraft, a complete understanding of the forces generated by the motors must exist. This equates to identifying how the thrust forces change as a function of changes in the throttle setting, wind speed, and the angle of attack of the motor. Identifying the effects of these parameters on the total thrust of the motor was accomplished by dividing the testing into two categories: static thrust testing and dynamic thrust testing. The static thrust testing allowed for the establishment of the relationship between commanded pulse width modulation (PWM), RPM, and thrust. The dynamic thrust established the relationship between PWM, airspeed, angle of attack, and thrust. Understanding the results of these two tests allowed for the modeling of the forces generated by the motor in various flight conditions.

The static thrust is the thrust produced by the engine when it is stationary or not moving through the air. This basic test serves as a good starting point for modeling the capabilities of the motor. Figure 12 shows the test setup used to obtain the static thrust mapping.

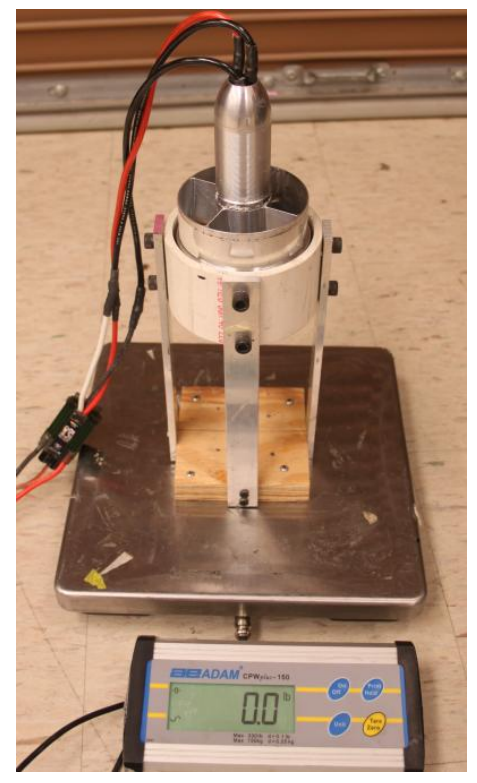

Figure 12: Static Thrust Testing Setup 
The test setup consisted of a mount to stabilize the motor in a vertical position, a scale for measuring thrust, and a data recorder board for recording the throttle command (PWM). The motor was placed in the mount so that the force produced by the motor would point directly downward. This mount was placed on the scale so that an increase in thrust would correspond to an increased "weight" read by the scale. The motor was connected to a Phoenix Ice 100 speed controller which converts the PWM signal into a voltage to drive the motor. This speed controller was selected because of its logging capability, which was utilized to record the RPM of the motor as well as the power driving the system. The speed controller was connected to a $2.4 \mathrm{GHz}$ receiver through a "Y" harness, so that the command going to the speed controller could also be sent to the data recorder board.

The test consisted of setting the throttle on the transmitter to a user defined value, and reading the corresponding force applied to the scale. This was repeated as the throttle was stepped down from full to zero throttle, so that the thrust level would not be affected by a decreased voltage in the battery as the test was performed. Once the entire range of throttle settings had been explored, the recorded data was downloaded from the recorder board and the speed controller. The PWM and RPM values were recorded and matched to the corresponding forces. From this a mapping could be produced between any of these three parameters. This experimental process was repeated three times, each time with a fresh battery and covering the entire operational range of the motor, to obtain a more accurate relationship which helped to mitigate errors due to varying battery voltage, imperfections in motor mounting, and other unforeseen errors.

Table 2 shows the results from the first static thrust test performed. 
Table 2: Static Thrust Measurements for Test One

\begin{tabular}{|c|c|c|c|c|}
\hline Data Number & RPM (Rounded) & PWM & Thrust (lbs) & Thrust (Newtons) \\
\hline 1 & 32100 & 207 & 6.5 & 28.9 \\
\hline 2 & 28500 & 188 & 5.2 & 23.1 \\
\hline 3 & 27000 & 178 & 4.6 & 20.5 \\
\hline 4 & 25000 & 166 & 3.9 & 17.3 \\
\hline 5 & 23500 & 160 & 3.5 & 15.6 \\
\hline 6 & 19800 & 142 & 2.4 & 10.7 \\
\hline 7 & 17000 & 129 & 1.7 & 7.6 \\
\hline 8 & 15800 & 122 & 1.5 & 6.7 \\
\hline 9 & 14500 & 117 & 1.3 & 5.8 \\
\hline 10 & 12000 & 103 & 0.8 & 3.6 \\
\hline 11 & 9000 & 92 & 0.4 & 1.8 \\
\hline 12 & 5400 & 81 & 0.1 & 0.4 \\
\hline
\end{tabular}

Table 3 shows the second set of data collected from the static thrust testing. Comparing

Table 2 and Table 3, it should be noted that the same throttle settings were not used for both tests. This was in an attempt to validate several points and gain additional points along the curve to establish the relationship between the parameters.

Table 3: Static Thrust Measurements for Test Two

\begin{tabular}{|c|c|c|c|c|}
\hline Data Number & RPM (Rounded) & PWM & Thrust (lbs) & Thrust (Newtons) \\
\hline 13 & 32300 & 207 & 6.6 & 29.4 \\
\hline 14 & 29000 & 188 & 5.3 & 23.6 \\
\hline 15 & 27000 & 177 & 4.6 & 20.5 \\
\hline 16 & 25000 & 166 & 3.9 & 17.3 \\
\hline 17 & 22500 & 153 & 3 & 13.3 \\
\hline 18 & 21000 & 147 & 2.7 & 12.0 \\
\hline 19 & 19700 & 141 & 2.4 & 10.7 \\
\hline 20 & 18100 & 134 & 2.1 & 9.3 \\
\hline 21 & 17000 & 128 & 1.7 & 7.6 \\
\hline 22 & 15500 & 122 & 1.5 & 6.7 \\
\hline 23 & 13250 & 110 & 1 & 4.4 \\
\hline 24 & 10300 & 97 & 0.6 & 2.7 \\
\hline 25 & 7350 & 86 & 0.3 & 1.3 \\
\hline 26 & 0 & 67 & 0 & 0.0 \\
\hline
\end{tabular}


Table 4 shows the third set of data collected from the static thrust testing. Again the throttle settings were determined at the discretion of the experimenter at the time of testing.

Table 4: Static Thrust Measurements for Test Three

\begin{tabular}{|c|c|c|c|c|}
\hline Data Number & RPM (Rounded) & PWM & Thrust (lbs) & Thrust (Newtons) \\
\hline 27 & 32000 & 207 & 6.5 & 28.9 \\
\hline 28 & 29750 & 193 & 5.5 & 24.5 \\
\hline 29 & 27800 & 182 & 4.8 & 21.4 \\
\hline 30 & 25900 & 172 & 4.1 & 18.2 \\
\hline 31 & 24700 & 166 & 3.8 & 16.9 \\
\hline 32 & 23300 & 159 & 3.4 & 15.1 \\
\hline 33 & 22200 & 153 & 3 & 13.3 \\
\hline 34 & 19700 & 141 & 2.4 & 10.7 \\
\hline 35 & 18300 & 135 & 2 & 8.9 \\
\hline 36 & 17000 & 128 & 1.7 & 7.6 \\
\hline 37 & 14600 & 116 & 1.3 & 5.8 \\
\hline 38 & 12000 & 104 & 0.8 & 3.6 \\
\hline 39 & 9000 & 92 & 0.5 & 2.2 \\
\hline 40 & 7300 & 86 & 0.3 & 1.3 \\
\hline 41 & 5100 & 80 & 0.1 & 0.4 \\
\hline 42 & 0 & 67 & 0 & 0.0 \\
\hline
\end{tabular}

These data sets were plotted together to produce a second order polynomial curve fit. An expression for determining the thrust given a PWM was desired since the PWM is the signal which is commanded through the onboard computer. For this reason, the PWM data points were plotted on the $\mathrm{x}$-axis while the thrust data points were plotted on the y-axis. Figure 13 shows the plotted data points along with the second order polynomial trend line. Eq. (4.1) shows the relationship defined by the second order polynomial curve fit where $y$ is the thrust produced by the motor in Newtons, and $x$ is the commanded PWM signal. 


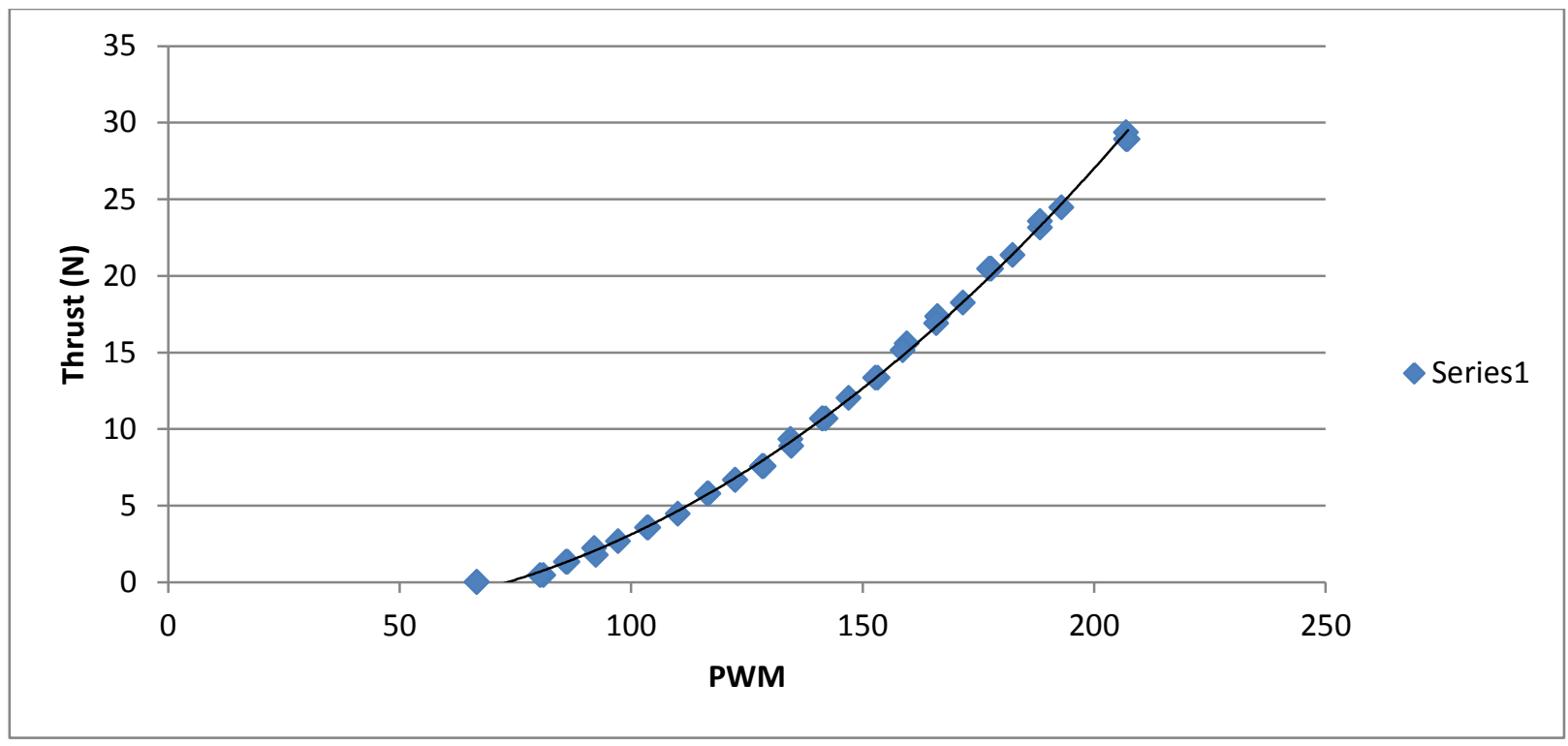

Figure 13: Relationship between PWM and Thrust Established from Static Thrust Testing

$$
\mathrm{y}=0.0010 \mathrm{x}^{2}-0.0504 \mathrm{x}-1.4819
$$

\subsection{Transient Response}

The transient response of the motor was found by comparing the timing between the input signal and the motor response. These signals were recorded using the Castle Creations electronic speed controller logging capability. Figure 14 shows the throttle command and the RPM response to that input. 


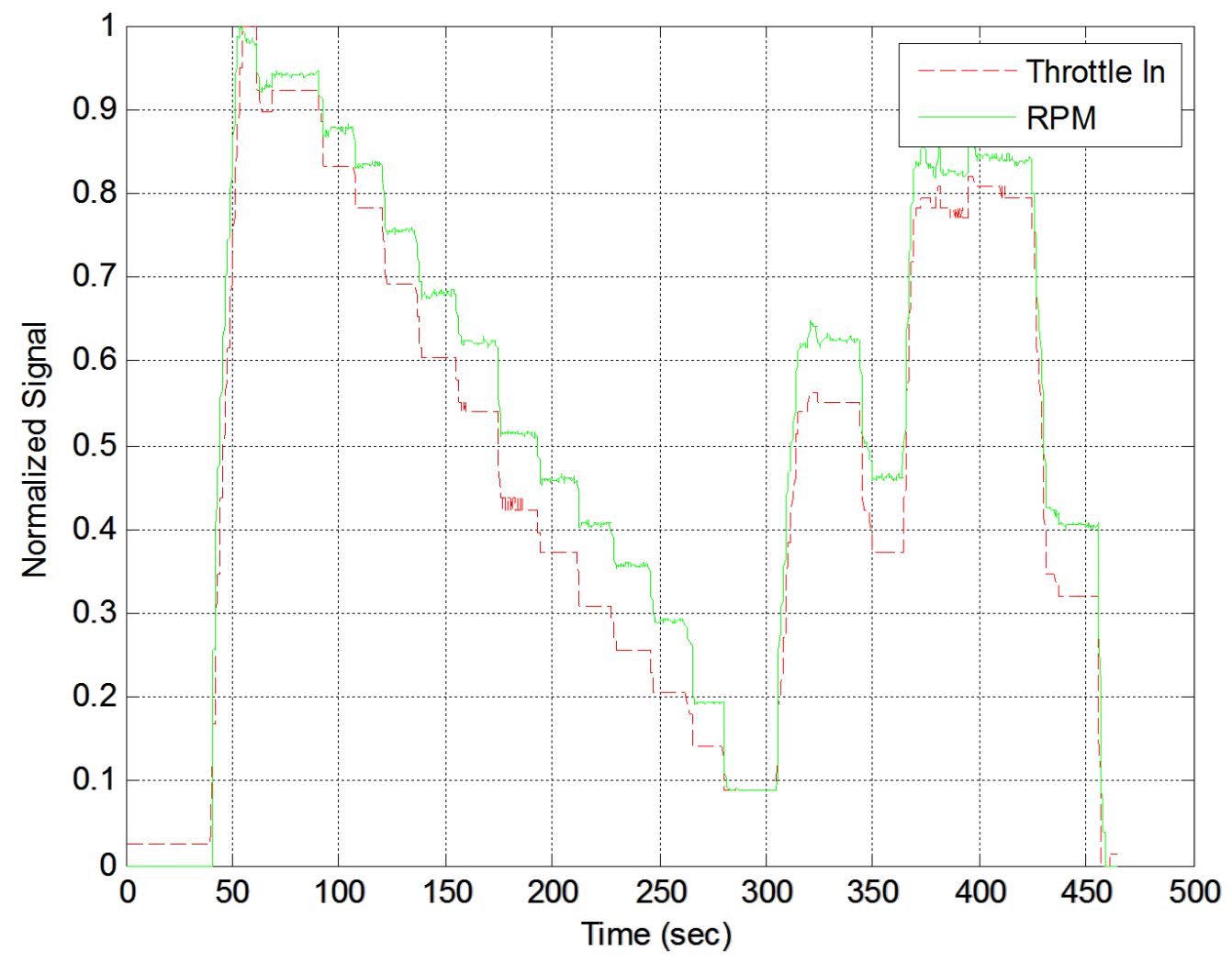

Figure 14: Normalized Throttle Command and RPM Response Time

The magnitudes of the input and response have been normalized to more easily observe the difference between the two signals. The test was performed by repeatedly stepping the throttle down from full throttle until zero RPM was achieved. The delay was determined by measuring the lag between the input signal and the commanded output. Figure 15 shows the delay throughout the test to be approximately .02 seconds. This value can be considered negligible when modeling the motor dynamics. The large spikes seen in the plot are from imperfections in the data caused by drop outs and noise. 


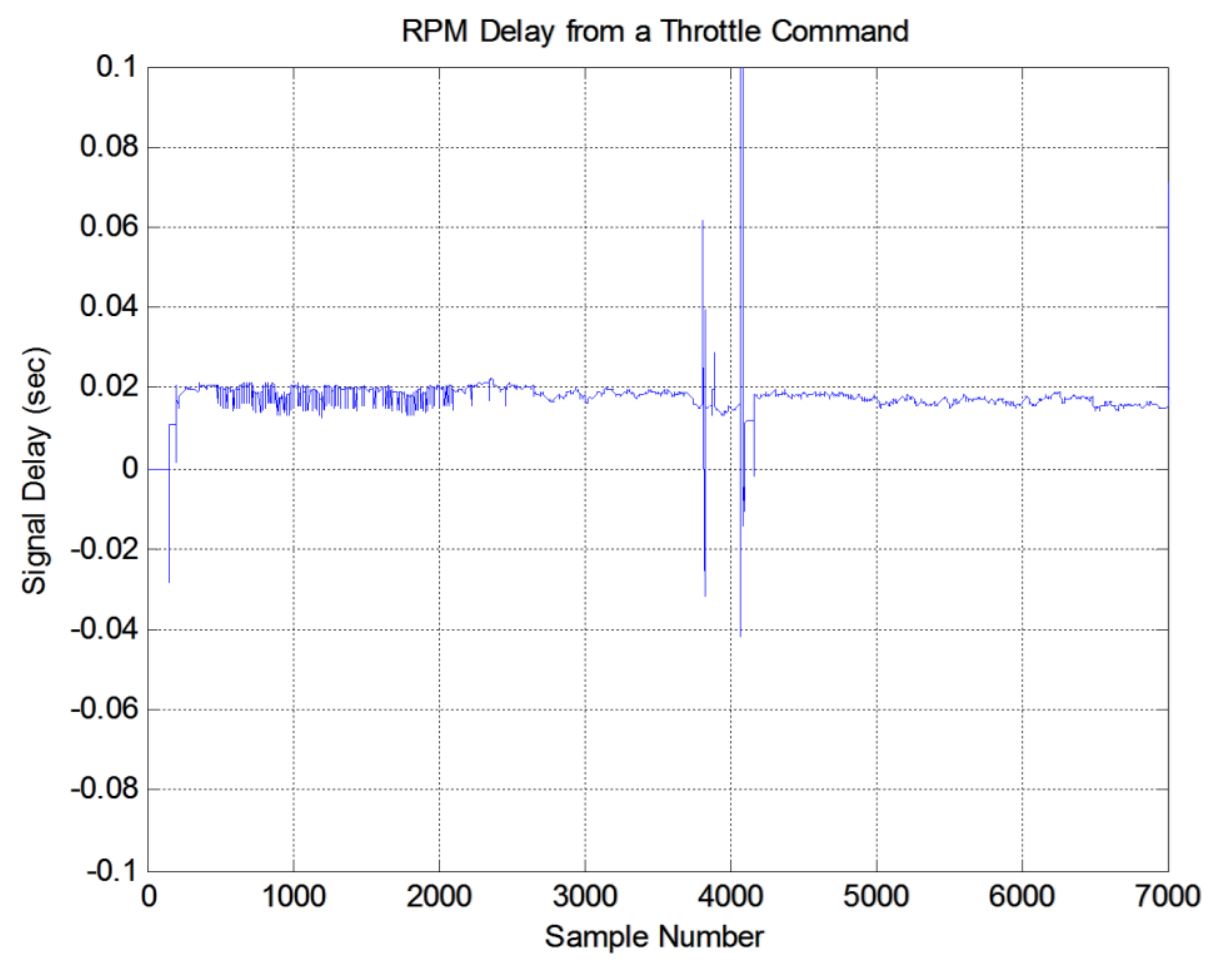

Figure 15: Transient Response of the Motor to a Throttle Command

\subsection{Wind Tunnel Testing}

One way to analyze the dynamic thrust is to use the momentum formulation of Reynolds Transport Theorem ${ }^{61}$. Equation (4.2) shows this formulation where $\rho$ is the density of the fluid, $v$ is the velocity, $\mathrm{V}$ is volume, $\mathrm{M}$ is the momentum, $\mathrm{n}$ is a unit vector, and $\mathrm{S}$ is the control surface.

$$
\frac{d M}{d t}=\frac{d}{d t} \iiint_{V} \rho v d V+\iint_{S} \rho v(\bar{v} \cdot \bar{n}) d S
$$

This expression is simplified by eliminating the triple integral because of steady flow. The $(\mathrm{v} \cdot \mathrm{n}) \mathrm{dS}$ term can be rewritten as the product of the velocity and the change in the area. This expression now becomes Newton's second law.

$$
F=\frac{d M}{d t}=\iint_{S} \rho v(v d A)
$$




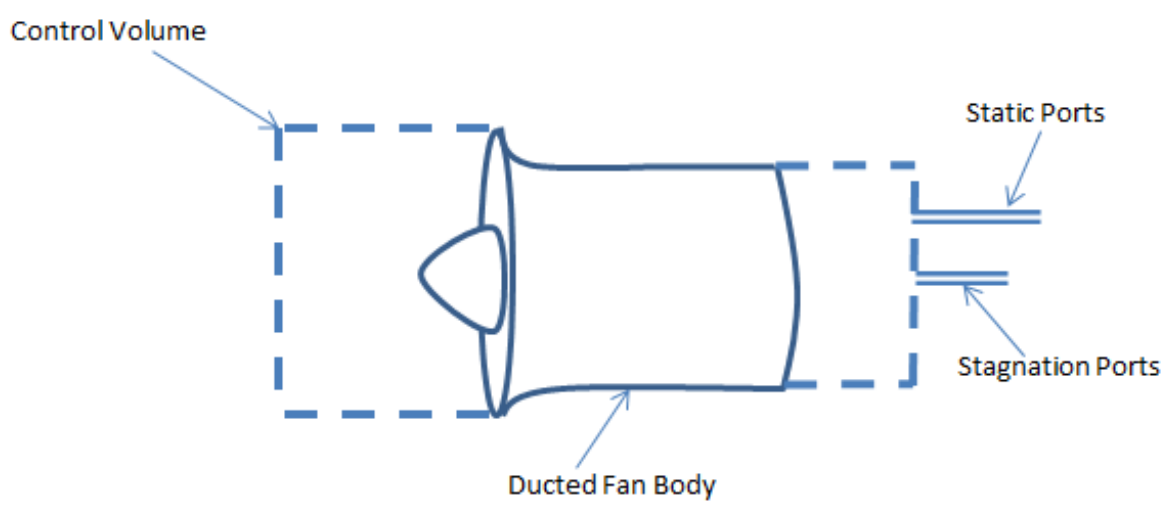

Figure 16: Control Volume Defined for Reynolds Transport Theorem

The integral is evaluated at the inlet and exit of the control volume shown in Figure 16, ignoring the static pressure difference, so that the expression becomes:

$$
T=\left(\rho v_{\text {out }} A_{\text {out }}\right) * v_{\text {out }}-\left(\rho v_{\text {in }} A_{\text {in }}\right) * v_{\text {in }}
$$

This value for dynamic thrust was used in the force and moment equations as part of the nominal and differential thrust modeling processes. A full momentum exchange is assumed to establish a relationship between the inlet and exit. With respect to the ducted fans, the air that enters the front of the duct must also exit the duct. A simple expression can be derived for this relationship using the volumetric flow rate ${ }^{62}$.

$$
\dot{Q}_{i}=\dot{Q}_{e}
$$

The volumetric flow rate $\dot{Q}$ was found using Eq. (4.6) where $A$ represents the area of the inlet or exit of the control volume, and $v$ represents the average velocity of the flow, assuming no losses in the system.

$$
\dot{Q}=A v
$$

The area of the duct was found using the expression for the area of a circle. Combining Eq. (4.5) and Eq.(4.6), and including the expression for the respective areas of the inlet and exit, Eq. (4.7) 
may be defined as:

$$
\frac{\pi d_{i}^{2}}{4} v_{i}=\frac{\pi d_{e}^{2}}{4} v_{e}
$$

Equation (4.7) neglects the area of the hub with the assumption that the control volume exceeds the ducted fan beyond where the hub is present. The velocity at the exit of the duct was determined experimentally using wind tunnel experiments implementing a wake rake, while the velocity at the inlet was calculated using Eq. (4.7). The wake rake utilizes 5 static ports and forty stagnation ports, whose difference defines the dynamic pressure measurement. The velocities were derived from wind tunnel measurements as a function of a pressure differential recorded using manometers. The pressures measured by the wake rake were converted to a velocity using the expression shown in Eq. (4.8), where $\rho$ is the air density, and pe is the exit pressure defined as the difference between stagnation pressure and static pressure.

$$
V=\sqrt{\frac{2 p_{e}}{\rho}}
$$

The air density was found using Eq. (4.9) where $p_{\infty}$ is the pressure at infinity, $R$ is the universal gas constant, and $T_{\text {tunnel }}$ is the temperature inside the tunnel.

$$
\rho=\frac{p_{\infty}}{R_{\text {air }} T_{\text {tunnel }}}
$$

The wind tunnel experiments were used to identify how the dynamic thrust of the motor is affected by the throttle setting, wind speed, and angle of attack. A predefined angle of attack and wind speed were held constant while the throttle setting was cycled through six positions ranging from zero to half throttle. The wind speed was then set to a new, predefined value while the angle of attack was held constant. The throttle was again cycled through the same values. This process was repeated until the eleven desired air speeds ranging from $0 \mathrm{~m} / \mathrm{s}$ to approximately 30 $\mathrm{m} / \mathrm{s}$ were evaluated. Once all of the air speed and throttle setting combinations were tested, the angle of attack of the motor was changed to the next specified value. Figure 17 shows the ducted fan mounted in the wind tunnel with the wake rake positioned at the duct exit. 


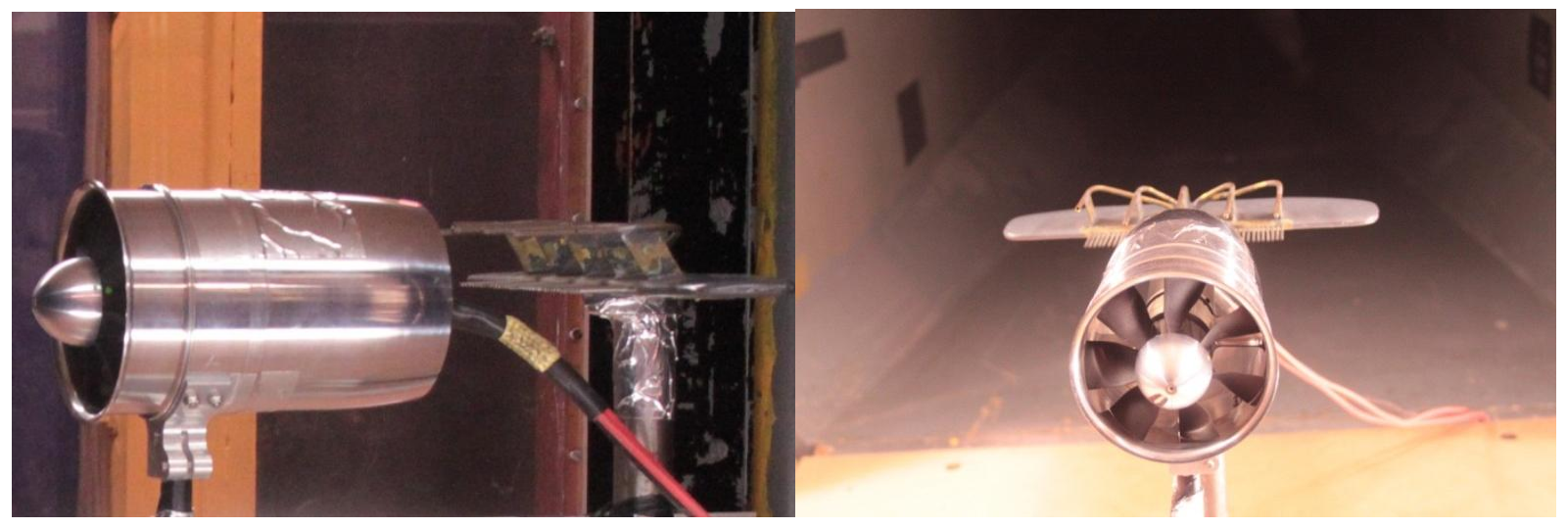

Figure 17: Ducted Fan and Wake Rake in Wind Tunnel

This testing scheme allowed for the evaluation of the dynamic thrust at constant throttle settings with varying wind speeds and angle of attack. Table 5 shows the testing matrix used to identify the dynamic thrust.

Table 5: Wind Tunnel Testing Scheme with Recorded Motor RPM Values

\begin{tabular}{|c|c|c|c|c|c|c|c|c|c|c|c|}
\hline & \multicolumn{10}{|c|}{ Air Speed (m/s) } \\
\hline Throttle Setting & 0 & 9.222 & 13.042 & 15.974 & 18.445 & 20.622 & 22.59 & 24.4 & 26.085 & 27.667 & 29.164 \\
\hline 0 Clicks (trim) & 0 & 0 & 0 & 0 & 0 & 0 & 0 & 0 & 0 & 0 & 0 \\
\hline 10 Clicks (trim) & 5385.2 & 5806.75 & 5793.7 & 6024.4 & 6112.75 & 6348.5 & 6833 & 6867.25 & 7016.35 & 7307.25 & 7490.45 \\
\hline 20 Clicks (trim) & 10700.2 & 10991.05 & 10802.5 & 10785.3 & 10705.05 & 10772.85 & 11418.5 & 11317.5 & 11235.95 & 11317.5 & 11317.5 \\
\hline 30 Clicks (trim) & 14198 & 14439 & 14184.4 & 14069.7 & 13908 & 13832.5 & 14604 & 14439 & 14266.2 & 14227.15 & 14217.5 \\
\hline 3/8 Throttle & 17748.5 & 18221.8 & 18004 & 17570.5 & 17480 & 17502.15 & 18393.5 & 18022.3 & 17996.7 & 17714.2 & 17640.45 \\
\hline $1 / 2$ Throttle & 23051.75 & 23000 & 22689.8 & 22535 & 22289 & 22144 & 23043.5 & 22718.8 & 22535 & 22436 & 22281.15 \\
\hline
\end{tabular}

An accurate way to interpret the pressure measurments obtained using the wake rake, would be to multiply the derived velocity of a single stagnation port by the incremental area associated with that port location. This would be repeated for each stagnation port in the slip stream and these products would then be added together to obtain the average exit velocity. Figure 18 shows an example of the segmentation of the exit area, corresponding to the stagnation ports on the wake rake.

$$
V_{a v g}=\sum \frac{V_{i} A_{i}}{A_{\text {Total }}}
$$




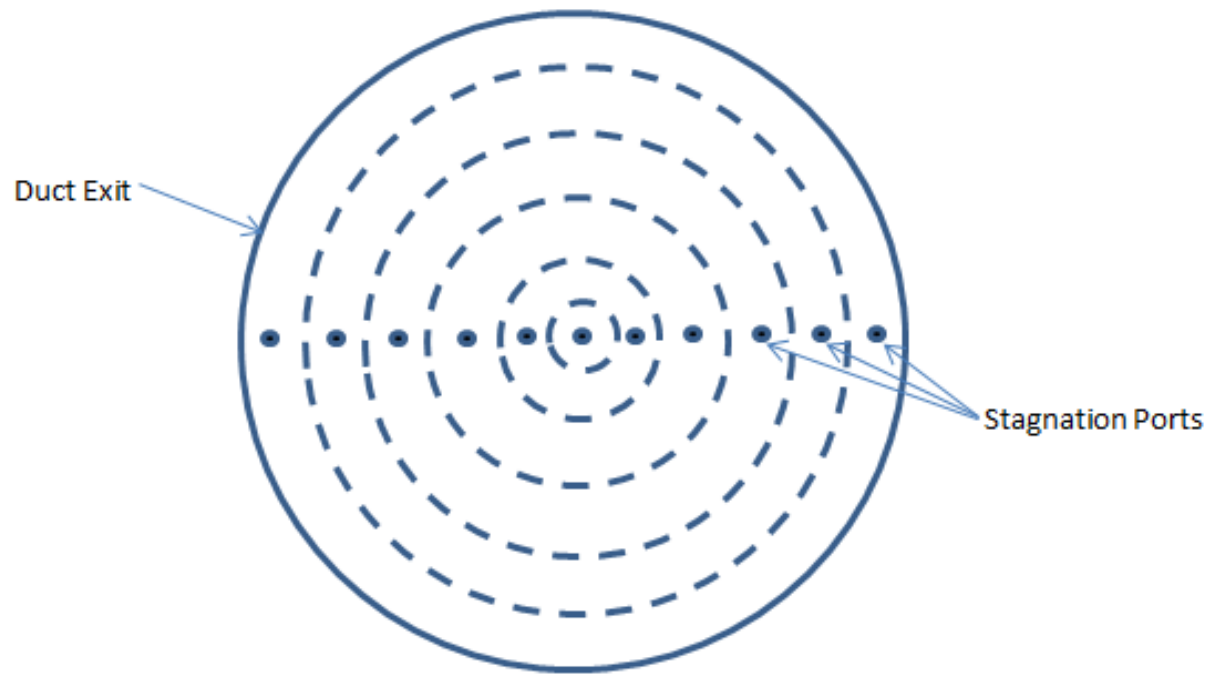

Figure 18: Incremental Areas Corresponding to Respective Stagnation Ports

This method was not used due to limitations in the test setup. The manometer bank used to read the wake rake pressures contained leaks and therefore rendered this incremental method unusable. Alternatively, several accurate ports were selected along the exit profile and their average was assumed to be the total exit pressure and average exit velocity. Some error could be associated with this assumption. A comparison of the wind tunnel tests and static thrust was performed by looking at the error between the dynamic thrust measurement at zero wind speed and the static thrust mapping. Table 6 shows the thrust values for a given RPM found through wind tunnel tests at zero wind speed and the static thrust mapping.

Table 6: Wind Tunnel Thrust Measurements and Static Thrust Comparison

\begin{tabular}{|c|c|c|c|}
\hline RPM & $\begin{array}{c}\text { Thrust Measured with } \\
\text { Wind Tunnel (N) }\end{array}$ & $\begin{array}{c}\text { Thrust Calculated with Static } \\
\text { Thrust Mapping (N) }\end{array}$ & \% Error \\
\hline 0 & 0 & 0 & 0 \\
\hline 5300 & 0.48 & 0.56 & 14.29 \\
\hline 11000 & 3.19 & 3.07 & 3.91 \\
\hline 14200 & 5.43 & 5.33 & 1.88 \\
\hline 18100 & 9.1 & 8.91 & 2.13 \\
\hline 23000 & 14.86 & 14.7 & 1.09 \\
\hline
\end{tabular}


Figure 19 shows how the thrust changes at constant RPM values with an increasing wind speed. This change in thrust signifies how much the thrust is affected by wind speed at the given RPM values.
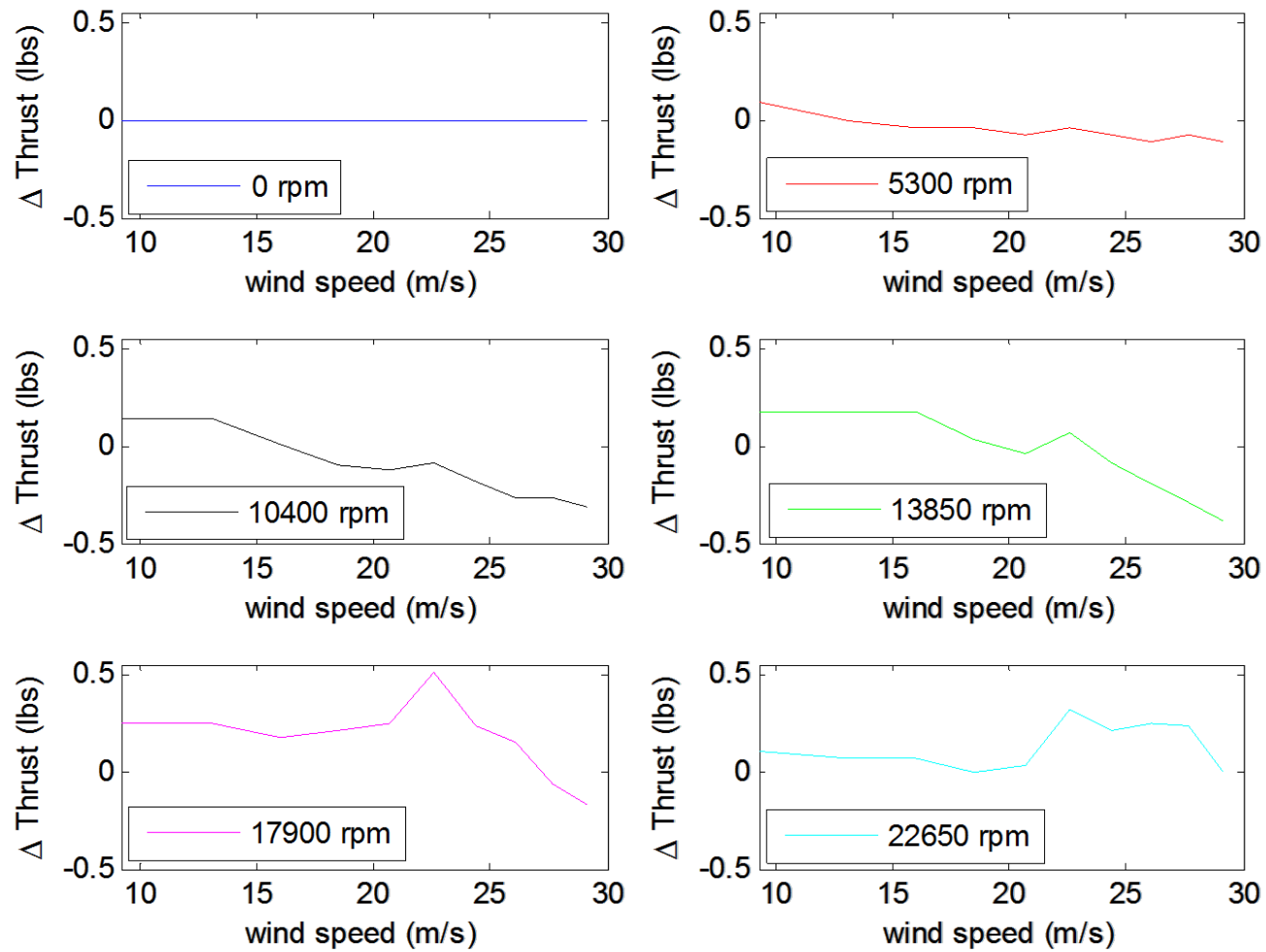

Figure 19: Change in Thrust for Constant RPM and Varying Wind Speed

It is shown in the plots that at lower RPM values the thrust begins to drop off with an increase in air speed, while at higher RPM values the thrust first increases before decreasing. The sharp increase in thrust occurring around $22 \mathrm{~m} / \mathrm{s}$ is due to a higher voltage on the battery. The test was performed with one battery for the first half of the data points, and then a second fresh battery was used for the second half of the data points. A constant power supply was considered but due to the high current draw of the motor (50 amps), the battery was a better option. The trend matches the theory that an increase in air speed decreases the velocity differential from the inlet of the duct to the exit of the duct. A decrease in the velocity differential means a decrease in thrust according to the conservation of mass. An increased air speed also assists in forcing more 
air into the duct and therefore produces a slight increase in thrust. However, this slight thrust increase does not offset the loss of thrust from the reduction in velocity differential from the inlet to the outlet of the duct. Drag was not measured in this experiment and therefore must be subtracted out, along with the overall drag of the aircraft, during the aircraft modeling process.

Data was also collected at various angles of attack ranging from zero up to 30 degrees to test stall on the propeller. The wake rake was still positions directly behind the duct to measure the flow being forced straight out the duct exit. Once again drag was not measured during these experiments. At the various angles of attack, the difference in thrust was again measured using the procedure described above to assure that during the tested range, there is no stall on the propeller.

At the testing conditions, minimal changes were observed for a difference in thrust. The forward thrust becomes a function of the angle of attack but this was modeled outside of this experiment. The results of this test showed that the motor performance was not affected by angles of attack less than 30 degrees, with respect to propeller stall. 


\section{Simulator}

\subsection{Overview of the Simulator}

The WVU PAC simulator is based in the Flight Dynamics and Control (FDC) toolbox ${ }^{63}$. FDC is a graphical tool used to design, develop, and analyze flight dynamics and control systems in a MATLAB and Simulink environment. It was originally developed to aid in the design of an auto-pilot for the Beaver aircraft but now has evolved into an advanced "proof of concept" package, which can be easily modified to model different aircraft, and analyze their flight characteristics $^{63}$. The WVU FCSL has developed a model of the PAC testbed which was inserted into FDC to design and test various control laws and flight configurations. Figure 20 shows the FDC graphical tool used at WVU.

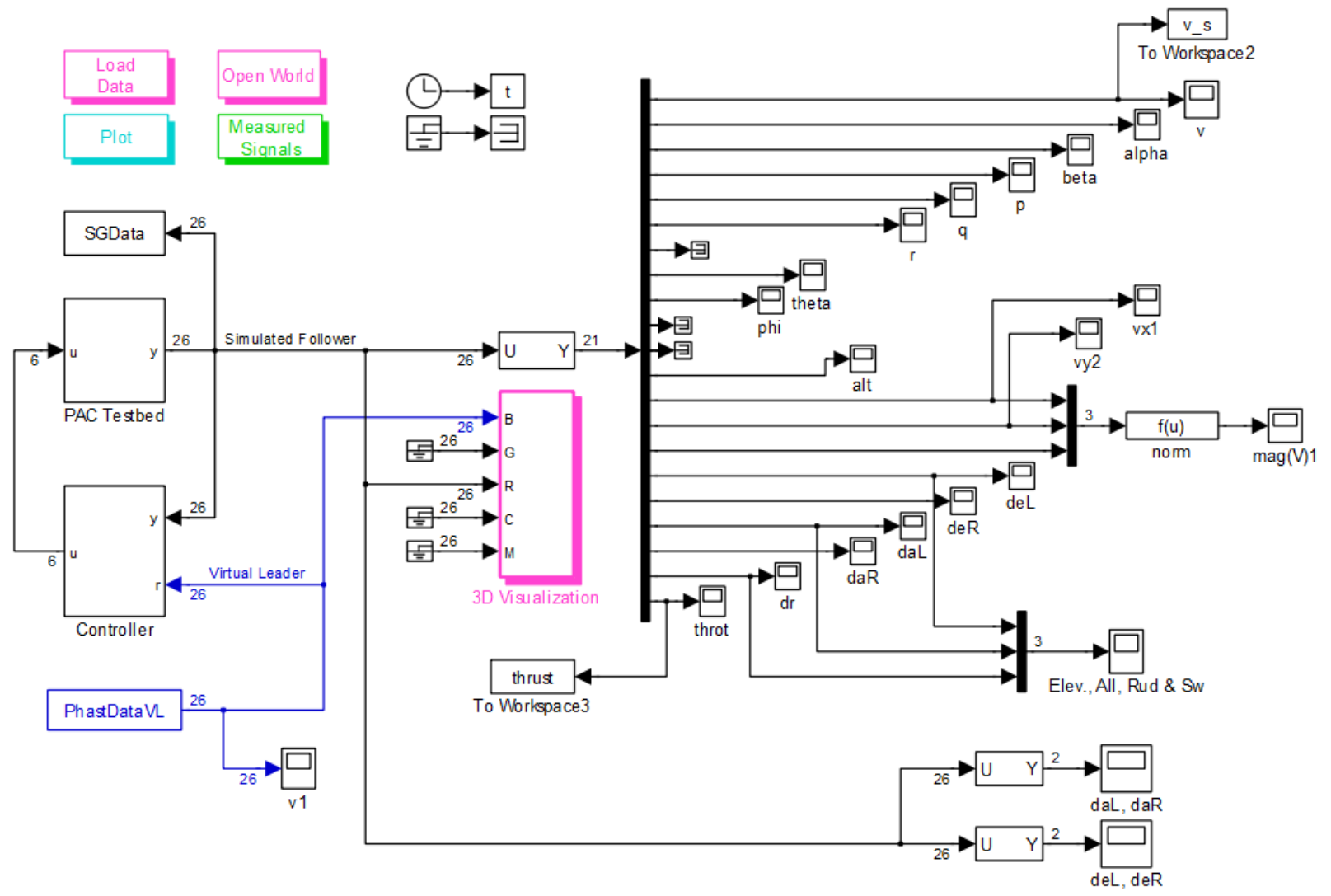

Figure 20: FDC Block Diagram 
The PAC Testbed block models the aircraft using the stability and control derivatives, as well as models the control surface deflections and the propulsive forces. Figure 21 shows inside the PAC Testbed block, where changes to the aircraft model were implemented.

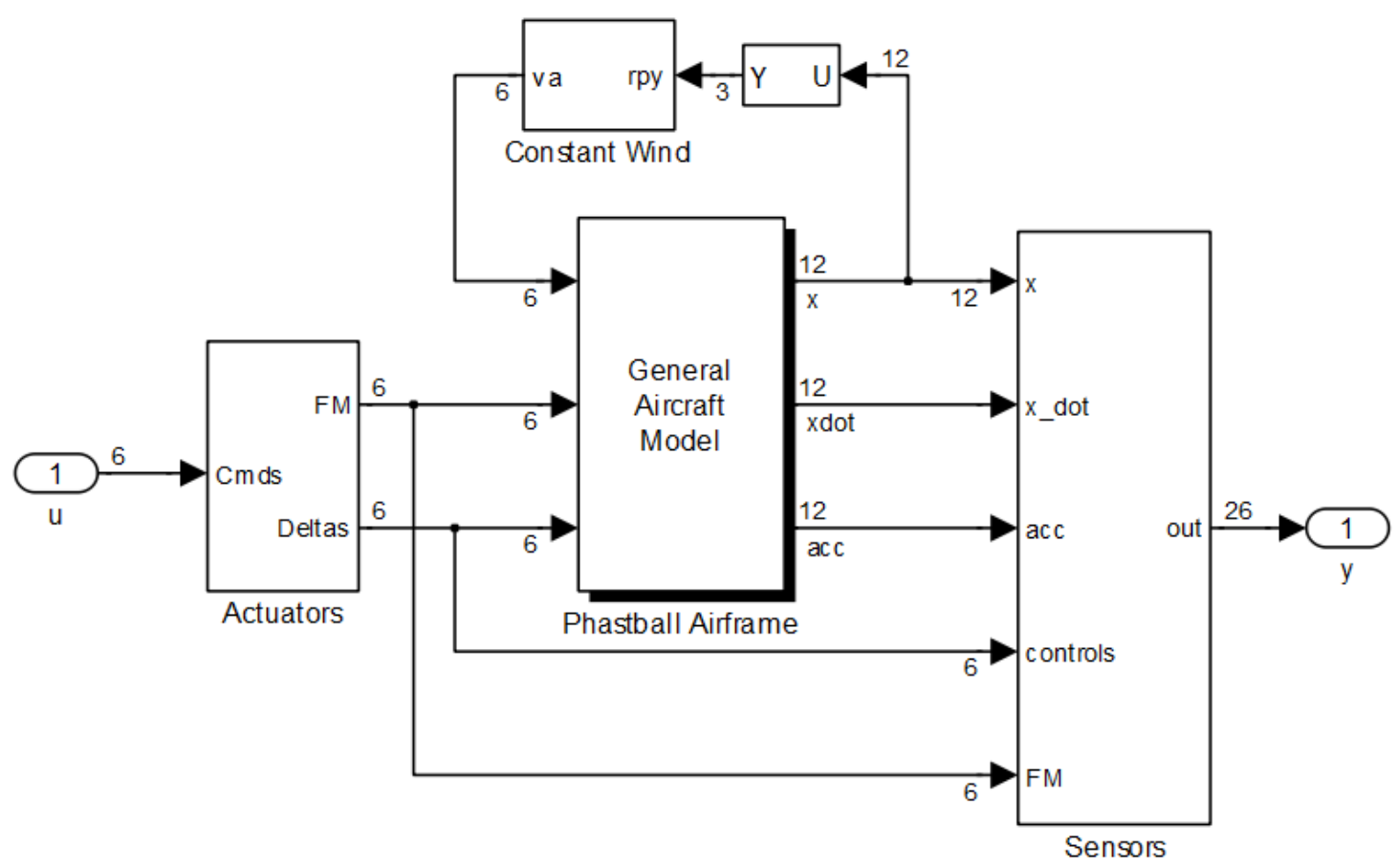

Figure 21: Aircraft Modeling Block

The forces and moments caused by the propulsion system are critical to the design of differential thrust and thrust vectoring. These forces and moments were modeled inside the actuators block, along with the control surface deflections. Figure 22 shows the control surface deflections driven by the commands from the controller output. 


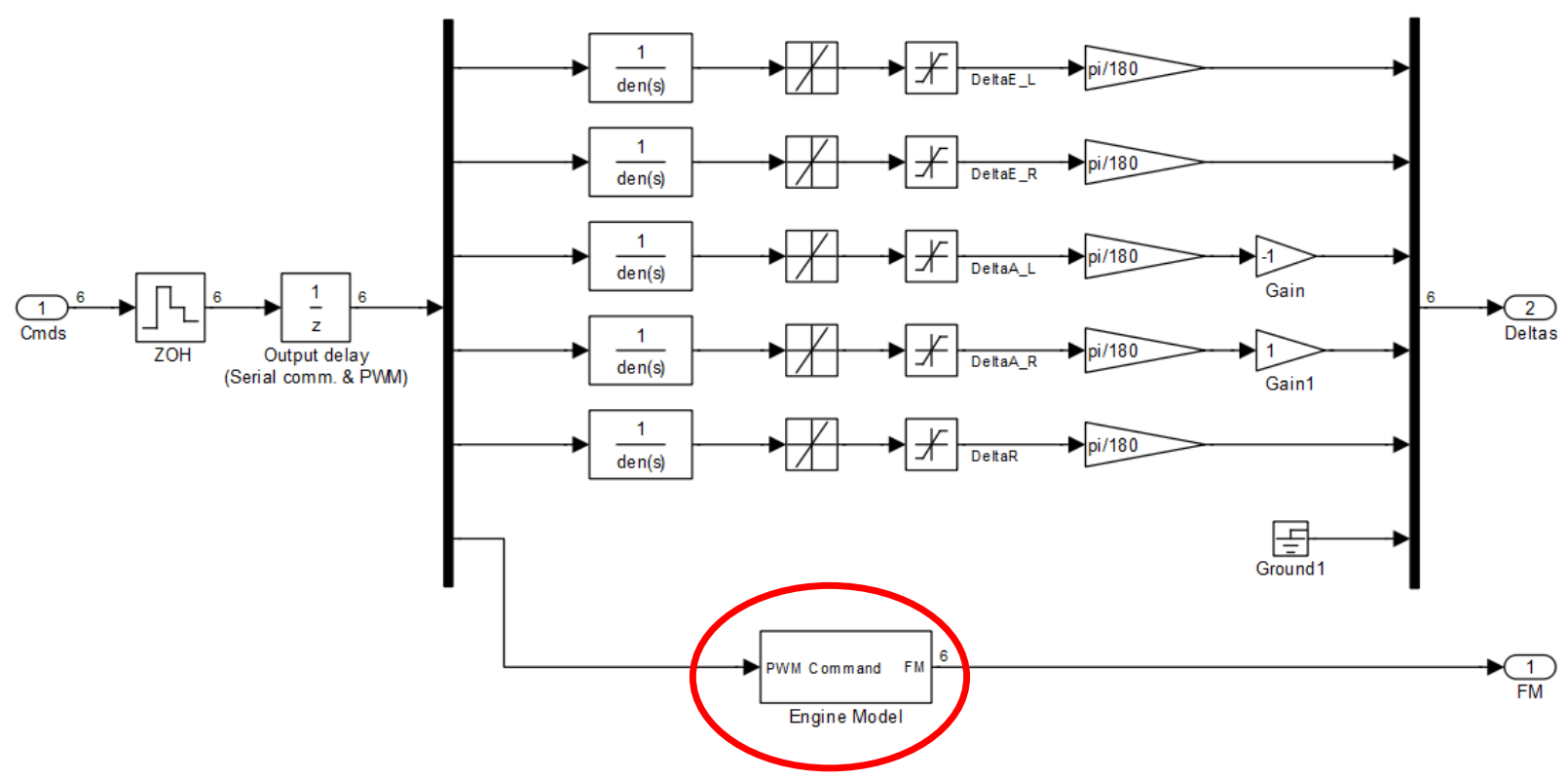

Figure 22: Actuators Block

\subsection{Differential Thrust and Thrust Vectoring Simulator}

The engine model block was developed to determine the propulsion forces and moments. Figure 23 shows the structure of the engine model, with propulsion assisted control capability.

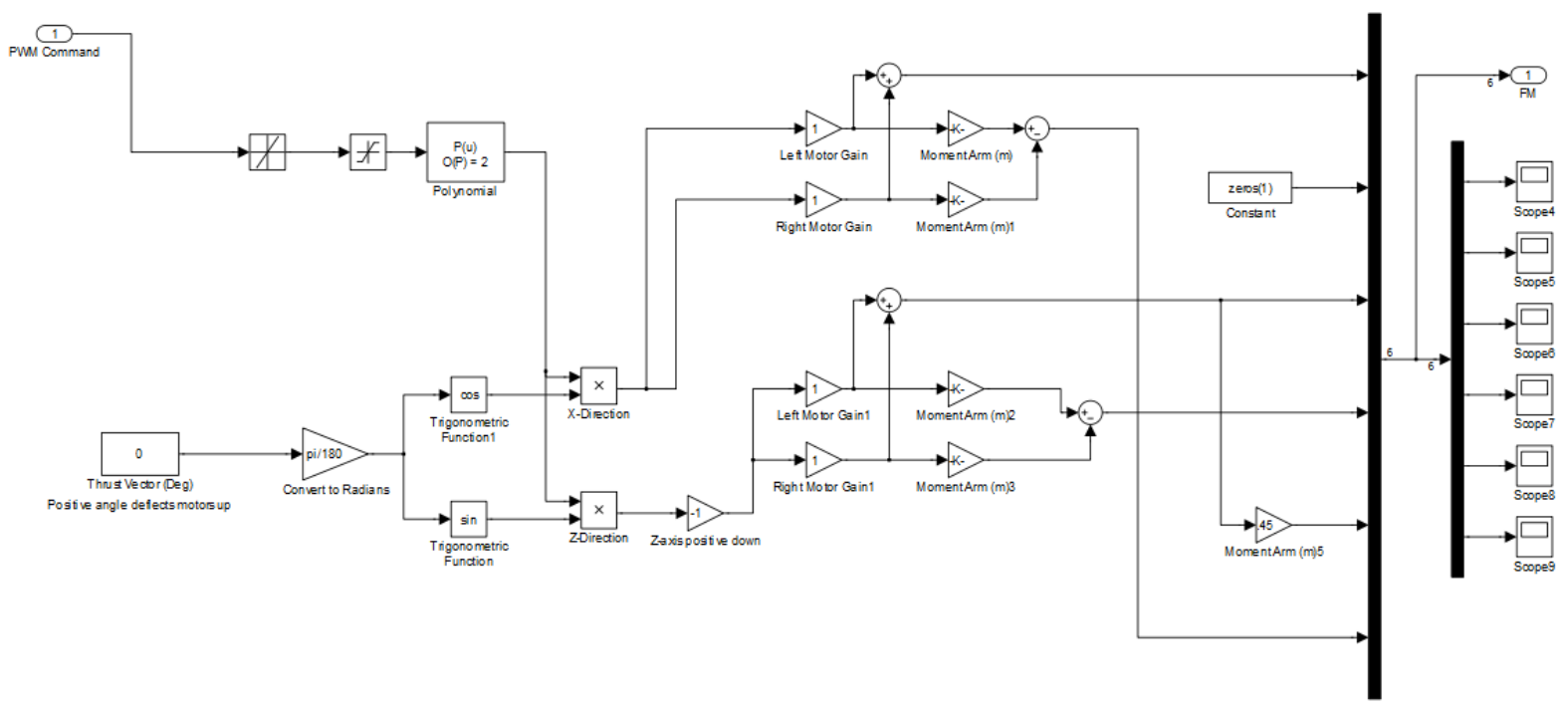

Figure 23: Engine Model for Differential Thrust and Thrust Vectoring 
The modeling of the engine occurred in several steps. First, the relationship gained from the static thrust testing, which converts a PWM signal to a thrust value, was implemented using a polynomial block. The PWM command was generated by the controller using the inverse relationship, based on the required level of thrust. If no thrust vectoring or differential thrust was necessary, this polynomial relationship is sufficient to model the propulsive forces. The net force produced from the engine thrust would be acting along the $\mathrm{x}$-axis of the aircraft and the other forces and moments would be equal to zero under nominal conditions. The introduction of differential thrust and thrust vectoring causes these other parameters to be non-zero. The mathematical modeling of these non-zero forces and moments are described in detail in the following sections of this paper.

The differential thrust forces were introduced using the known geometry of the aircraft and the forces produced by the motors. They were modeled as a moment balance between the counteracting moments produced by each motor mounted off of the x-axis of the aircraft. When the thrust forces produced from each engine are equivalent, the total z-moment is zero; however, when the forces are not equal, a non-zero z-moment is introduced. A gain on each motor is used to model the level of thrust produced, with a value of 1.0 signifying the actual commanded PWM. A number less than 1.0 would decrease the thrust to a value less than the commanded PWM, while a number greater than 1.0 would increase the thrust to a value greater than the commanded PWM. This allowed for the independent control of thrust produced by each motor. The total force along the $\mathrm{x}$-axis is equal to the sum of these two values. After setting the thrust value on each motor, the force is multiplied by the moment arm as determined from the aircraft geometry. These two moments are added, leading to the resultant z-moment. A thrust differential implemented for the configuration of the WVU PAC testbed only adds a moment about the aircraft body z-axis, assuming the thrust line runs perfectly through the CG.

The implementation of thrust vectoring into the simulator required additional changes. It was designed to work in conjunction with the differential thrust model implementation as to accommodate for future research applications where the two methods could be used simultaneously. The addition of thrust vectoring introduces a force component along the z-axis 
of the aircraft. This additional force also produces a pitching moment about the $y$-axis of the aircraft. The additional force component along the z-axis was modeled by multiplying the thrust force by the sine of the thrust vector angle. Additionally, the force along the x-axis could no longer be considered as the total combined force from the two engines. Instead, it was modeled as the cosine of the thrust vector angle multiplied by the force. Once the force along the $\mathrm{z}$-axis is determined, it is inverted to follow the z-body-axis positive down convention. The force from each engine along the z-axis is then multiplied by the moment arm determined by the geometry of the aircraft. This yields the magnitude of the pitching moment about the y-axis. A combination of differential thrust and thrust vectoring was modeled by comparing the counteracting moments produced by the forces along the z-axis, multiplied by the moment arm from the engines to the body $\mathrm{x}$-axis. 


\section{Differential Thrust}

\subsection{Differential Trust Modeling}

A thrust differential creates additional forces and moments that require modeling for estimating the stability and control derivatives ${ }^{64-66,67}$.

The differential thrust may be defined based on the aircraft geometry and the asymmetric thrust between the two motors. The motors are mounted off of the x-axis of the aircraft behind the center of gravity (CG) and produce counteracting moments around the CG. The motor producing the greater thrust force will create a larger moment causing yawing motion about the aircraft z-axis. Eq. (6.1) shows the parameters that affect the moment caused by differential thrust.

$$
\text { Moment }=f\left(R P M_{\text {Left }}, R P M_{\text {Right }}, \lambda, \beta, \text { airspeed }\right)
$$

In equation (6.1), $R P M_{\text {Left }}$ and $R P M_{\text {Right }}$ are the revolutions per minute for the left and right motor respectively, $\lambda$ is the angle of the motors with respect to the aircraft body $x$-axis, $B$ is the sideslip angle, and airspeed is the flight speed of the aircraft. The resulting total moment applied to the aircraft is the difference between the moments produced by each motor. Figure 24 shows a conceptual sketch of the thrust differential and the resulting moment applied to the aircraft.

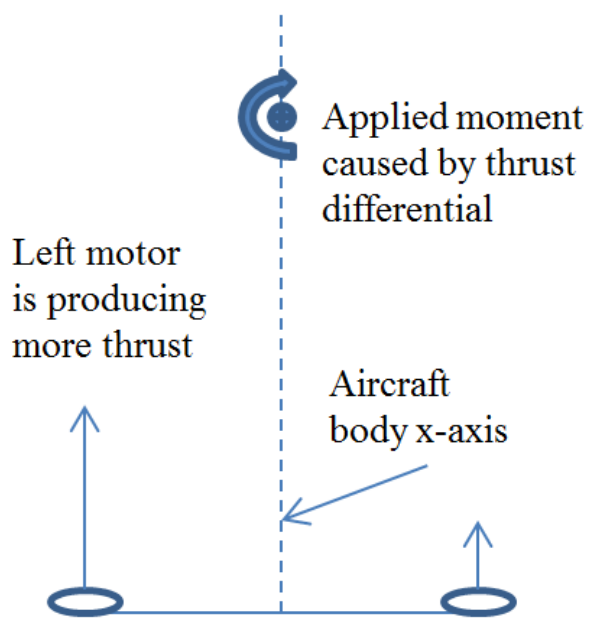

Figure 24: Differential Thrust Definition 
The previously defined moment equations have additional terms corresponding to the yawing moment caused by the thrust differential that require modeling. Based on the aircraft geometry, differential thrust also results in an asymmetric pressure distribution on the vertical tail and generates a side force as well as additional yawing and rolling moments, but these effects are expected to be minimal ${ }^{64-66}$. Eq. (6.2) represents the moment equations in matrix form with the additional terms due to the incorporation of differential thrust. The terms $T_{\text {Left }}$ and $T_{\text {Right }}$ correspond to the thrust produced by the left and right motors respectively, while $l_{T}$ is the moment arm between the thrust line of the motor and the $\mathrm{x}$-axis of the aircraft.

$$
\left[\begin{array}{c}
\dot{p} \\
\dot{q} \\
\dot{r}
\end{array}\right]=M_{1}\left[\begin{array}{l}
p^{2} \\
q^{2} \\
r^{2}
\end{array}\right]+M_{2}\left[\begin{array}{l}
q r \\
p r \\
p q
\end{array}\right]+\bar{q} S M_{0}\left[\begin{array}{l}
b C_{l} \\
\bar{c} C_{m} \\
b C_{n}
\end{array}\right]+\left[\begin{array}{c}
0 \\
0 \\
T_{L e f t} l_{T}+T_{\text {Right }} l_{T}
\end{array}\right]+\left[\begin{array}{l}
\varepsilon \\
0 \\
\varepsilon
\end{array}\right]
$$

In Eq. (6.2), the matrices $M_{0}, M_{1}$, and $M_{2}$ are defined as follows:

$$
\begin{aligned}
& M_{0}=\frac{1}{\operatorname{det}(I)}\left[\begin{array}{lll}
I_{y y} I_{z z}-J_{y z} J_{y z} & J_{x y} I_{z z}+J_{y z} J_{x z} & J_{x y} J_{y z}+I_{y y} J_{x z} \\
J_{x y} I_{z z}+J_{y z} J_{x z} & I_{x x} I_{z z}-J_{x z} J_{x z} & J_{y z} I_{x x}+J_{x y} J_{x z} \\
J_{x y} J_{y z}+I_{y y} J_{x z} & J_{y z} I_{x x}+J_{x y} J_{x z} & I_{x x} I_{y y}-J_{x y} J_{x y}
\end{array}\right] \\
& M_{1}=M_{0}\left[\begin{array}{ccc}
0 & J_{y z} & -J_{y z} \\
-J_{x z} & 0 & J_{x z} \\
J_{x y} & -J_{x y} & 0
\end{array}\right] \\
& M_{2}=M_{0}\left[\begin{array}{ccc}
I_{y y}-I_{z z} & -J_{x y} & J_{x z} \\
J_{x y} & I_{z z}-I_{x x} & -J_{y z} \\
-J_{x z} & J_{y z} & I_{x x}-I_{y y}
\end{array}\right]
\end{aligned}
$$

with $I$ being the inertia matrix of the aircraft, defined as: 


$$
I=\left[\begin{array}{ccc}
I_{x} & -J_{x y} & -J_{x z} \\
-J_{x y} & I_{y} & -J_{y z} \\
-J_{x z} & -J_{y z} & I_{z}
\end{array}\right]
$$

The body-axis velocity equations are differentiated to give expressions for $\dot{V}, \dot{\alpha}$ and $\dot{\beta}$, and are represented by Eqs. (6.7)-(6.9) ${ }^{64-66}$.

$$
\begin{gathered}
\dot{V}=\frac{1}{V}(u \dot{u}+v \dot{v}+w \dot{w}) \\
\dot{\alpha}=\left(\frac{u \dot{w}-w \dot{u}}{u^{2}+w^{2}}\right) \\
\dot{\beta}=\frac{\left(u^{2}+w^{2}\right) \dot{v}-v(u \dot{u}+w \dot{w})}{V^{2} \sqrt{u^{2}+w^{2}}}
\end{gathered}
$$

Substituting the body-axis velocities and the updated force equations, the differential equations incorporating the differential thrust effects become:

$$
\begin{aligned}
& \dot{V}=-\frac{\bar{q} S}{m}\left(C_{D} \cos \beta-C_{Y} \sin \beta\right)+\left(\frac{T_{\text {Left }}+T_{\text {Right }}}{m}\right) \cos (\alpha+\lambda) \cos \beta \\
&+g(\cos \phi \cos \theta \sin (\alpha+\lambda) \cos \beta+\sin \phi \cos \theta \sin \beta-\sin \theta \cos (\alpha+\lambda) \cos \beta) \\
& \dot{\alpha}=- \frac{\bar{q} S}{m V \cos \beta} C_{L}+q-\tan \beta(p \cos (\alpha+\lambda)+r \sin (\alpha+\lambda))-\frac{\left(T_{\text {Left }}+T_{\text {Right }}\right) \sin (\alpha+\lambda)}{m V \cos \beta} \\
&+\frac{g}{V \cos \beta}(\cos \phi \cos \theta \cos (\alpha+\lambda)+\sin \theta \sin (\alpha+\lambda)) \\
& \dot{\beta}=\frac{\bar{q} S}{m V}\left(C_{Y} \cos \beta+C_{D} \sin \beta\right)+p \sin \alpha-r \cos \alpha+\frac{g}{V} \cos \beta \sin \phi \cos \theta \\
&+\frac{\sin \beta}{V}\left(g \cos (\alpha+\lambda) \sin \theta-g \sin (\alpha+\lambda) \cos \phi \cos \theta-\frac{\left(T_{\text {Left }}+T_{\text {Right }}\right) \cos (\alpha+\lambda)}{m}\right)
\end{aligned}
$$

\subsection{Simulator Results for Differential Thrust}

The differential thrust simulations were performed to analyze the response of the aircraft to a thrust differential. Using the simulator described in Chapter 5 and utilizing the adapted engine 
model, tests were run for various amounts of thrust differential while the roll angle was recorded. To exaggerate the effects of the differential thrust, larger differentials were tested including one motor producing zero thrust while the other produced a cruising thrust of $12 \mathrm{~N}$. This test configuration simulated a motor failure during the cruise phase of flight. The roll angle was used to evaluate the effects of the thrust differential while the rudder and ailerons were set to zero deflection. As mentioned earlier in this paper, a differential thrust generates sideslip which, through the dihedral effect, causes a rolling moment in the aircraft. Figure 25 shows the roll angle for a differential thrust of $12 \mathrm{~N}$ with zero deflection on the lateral-directional control surfaces. This appears to be a significant effect with the roll angle reaching approximately $-25^{\circ}$. It should also be noted that there was no controller applied to this simulation to compensate for the differential thrust.
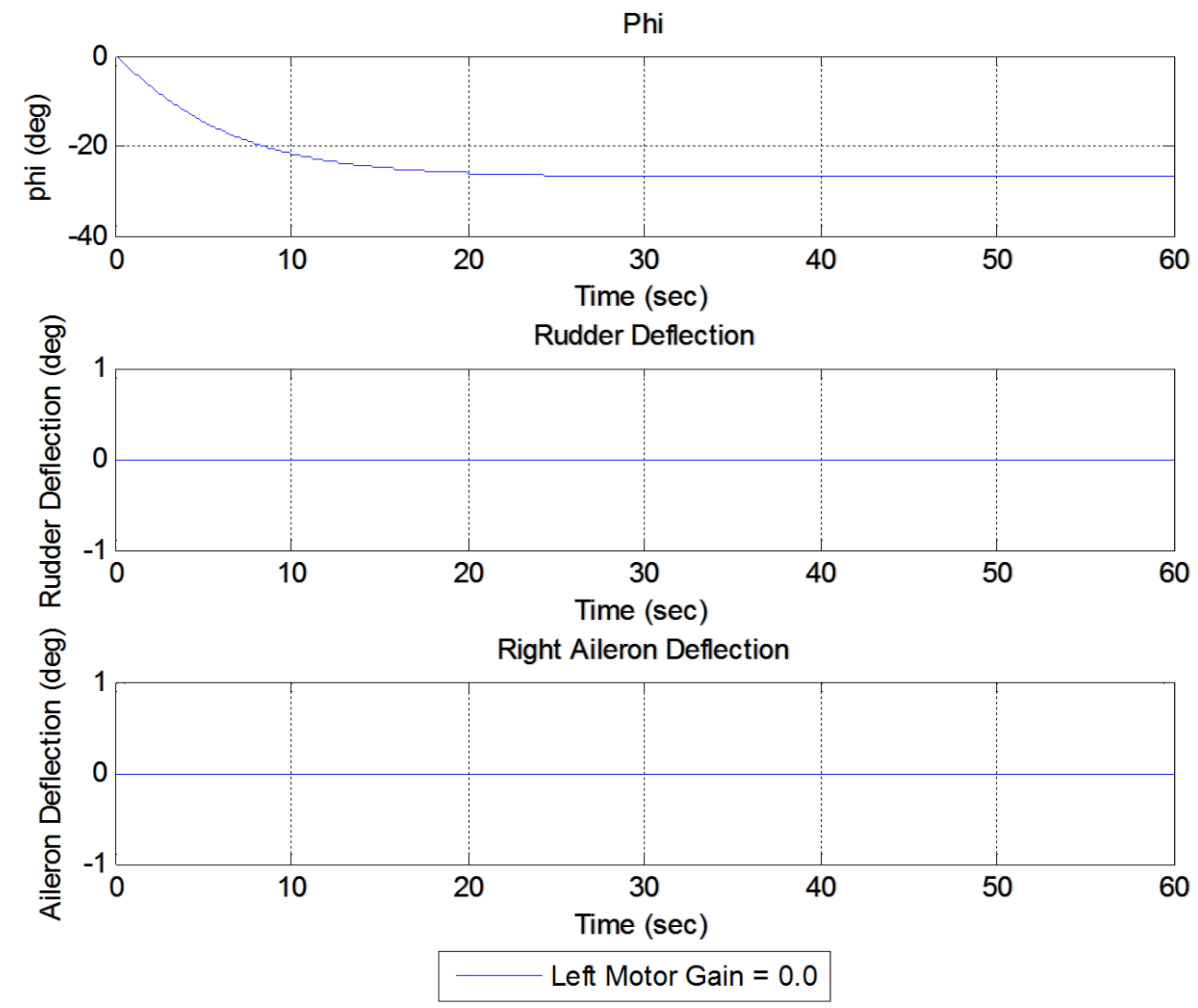

Figure 25: Simulated Aircraft Roll Response to a Thrust Differential 
In order to better quantify these effects, another simulation was run for the same thrust differential, but an aileron deflection was added to counteract the rolling moment. Various aileron deflections were tested until a value was reached which would maintain a roll angle of approximately zero degrees. This value was found to be $0.578^{\circ}$ deflection on the ailerons. The rudder was still set at $0^{\circ}$ and once again no controller aided in the compensation. The aileron deflection was held constant for the duration of the test, as was the level of differential thrust. Figure 26 shows the roll angle as well as the rudder deflection and the aileron deflection. The roll angle drifts slightly from zero degrees but is kept within a small magnitude. The implementation of a feedback controller could regulate the aileron deflection to maintain a zero rolling angle.
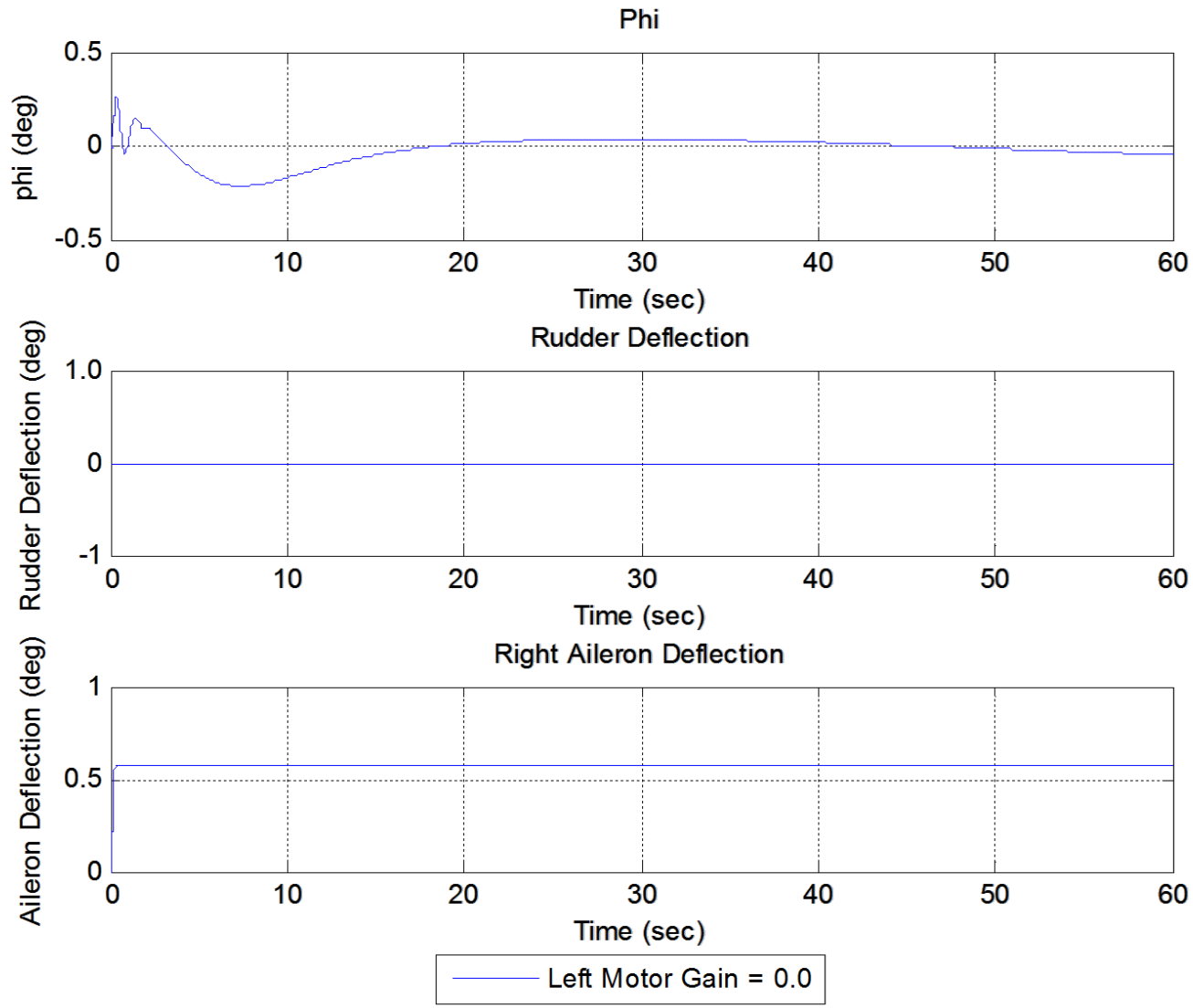

Figure 26: Simulated Aircraft Roll Response to a Thrust Differential with Aileron Compensation 
To understand the relationshiop between the differential thrust and rudder defletion, a linear quadradic regulator controller on the rudder channel was utilized to compensate for a differential thrust injected after 30 seconds of simulation, while the aileron deflection was set to zero. Figure 27 shows the rudder deflection as driven by the feedback controller reaching a value of approximately -5 degrees.
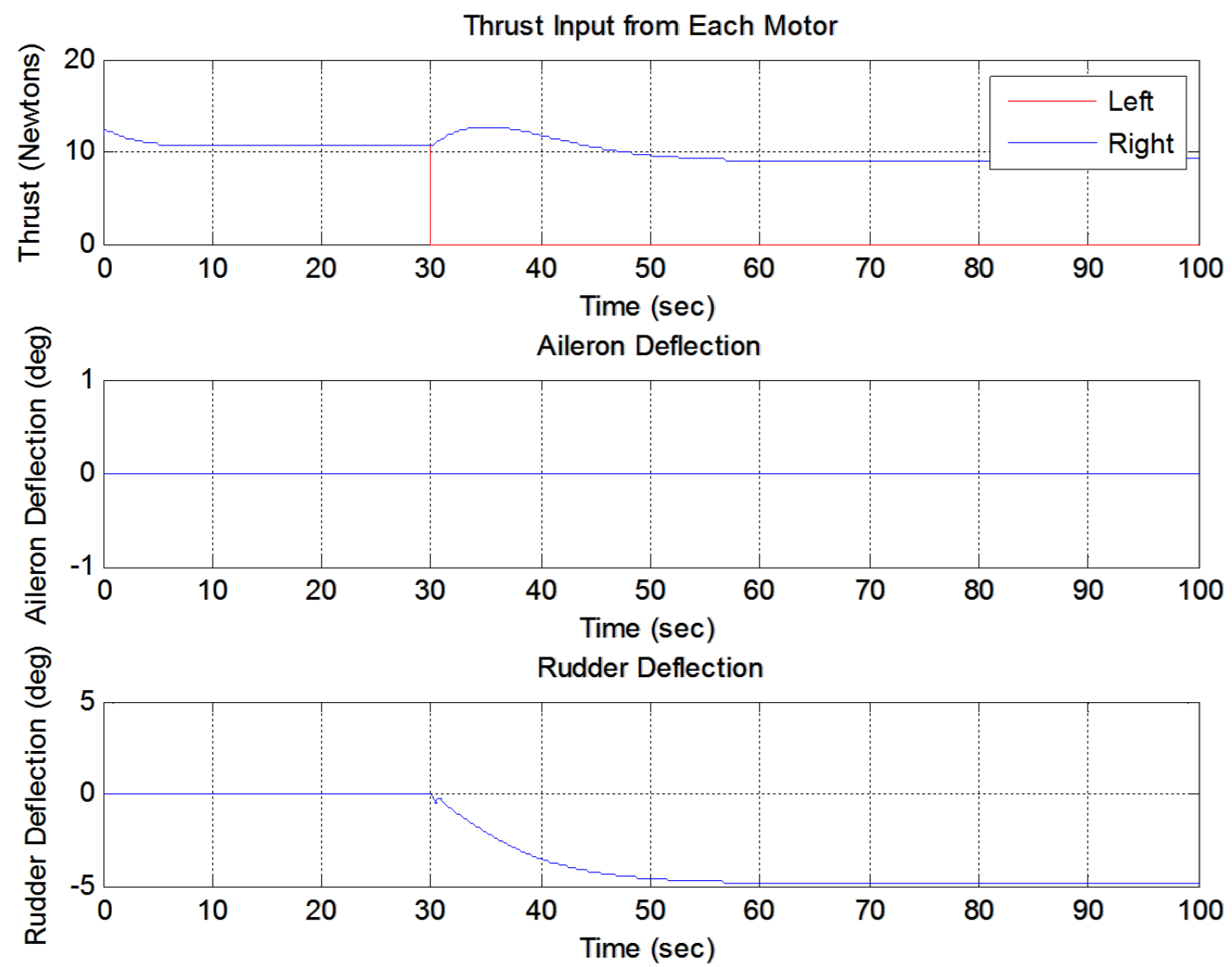

Figure 27: Rudder Compensation for a Differential Thrust of $12 \mathrm{~N}$

Finally, the simulations were run with the linear quadratic controller actively tracking a pitch and roll angle of $2^{\circ}$ and $0^{\circ}$ respectively. As the differential thrust was increased, the compensation from the ailerons and rudder increased. Figure 28 shows the roll angle, aileron deflection, and rudder deflection for thrust differentials of $0 \mathrm{~N}, 6 \mathrm{~N}$, and $12 \mathrm{~N}$. 

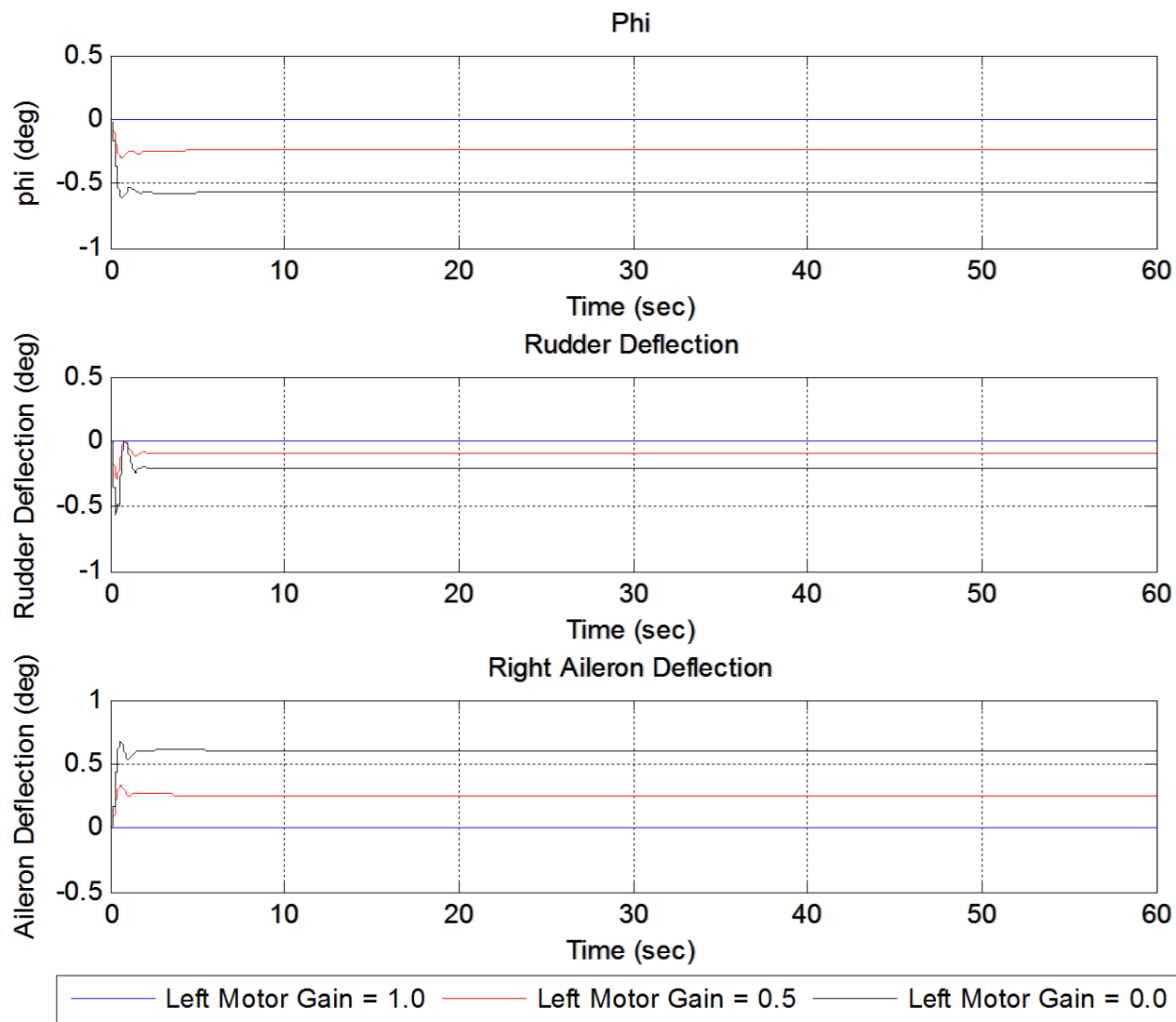

Figure 28: Simulated Aircraft Response to a Thrust Differential

The ailerons have a greater control authority when compensating for the cross coupled effects of roll and yaw produced by the differential thrust.

\subsection{Flight Test Results for Differential Thrust}

Flight tests were conducted with the WVU propulsion assisted control test bed implementing differential thrust. The differential thrust was controlled by the on board avionics that commands the PWM signal to the electronic speed controllers. The on-board computer was controlled by a switch on the transmitter, which gave timing authority of the differential thrust to the pilot. The tests were set up to mimic an engine failure implying that the commanded PWM to one of the speed controllers was such that the thrust produced was equal to zero. This experimental setup was selected to produce a large thrust differential in order to accentuate its effects on the aircraft for modeling purposes. 
Three types of maneuvers were performed to evaluate the effectiveness of the differential thrust. The first maneuver incorporated a simulated failed motor by setting the thrust to zero, followed by a quick recovery back to cruising thrust. This test was selected because of its similarity to a control surface doublet. This was repeated five times while the angular displacements, angular rates, and GPS coordinates of the aircraft were recorded. The second type of maneuver was designed to simulate a longer engine failure for which the computer set one motor to zero thrust and the aircraft was flown "hands-off" so the natural dynamics of the aircraft driven by this failure could be observed. This maneuver was carried out for approximately 4.5 seconds while the angular displacements and rates were recorded. The third type of maneuver consisted of an engine failure with a duration of 13 seconds, in which one of the motors was set to deliver zero thrust. For this maneuver, however, the pilot attempted to maintain steady, level flight by incorporating a rudder deflection. This maneuver proved to be the most conclusive test of the three, providing quantitative results.

Figure 29 shows the recorded control switch for the 13-second maneuver described above, where a value of zero constitutes the switch in the "off" position while a value of one constitutes the switch in the "on" position. The rudder deflection during the simulated engine failure is also shown in Figure 21, which shows a slight delay between the control switch and the rudder deflection while the pilot compensated using ailerons. However a clear relationship between the rudder deflection and differential thrust exists, providing evidence to support this concept. The rudder deflection required to compensate for the differential thrust was approximately 6 degrees, supporting the concept that differential thrust has the necessary authority to trim an aircraft; a potential application to replace or aid the rudder deflection, which can significantly increase drag or lead to the saturation of the control surface deflection. 


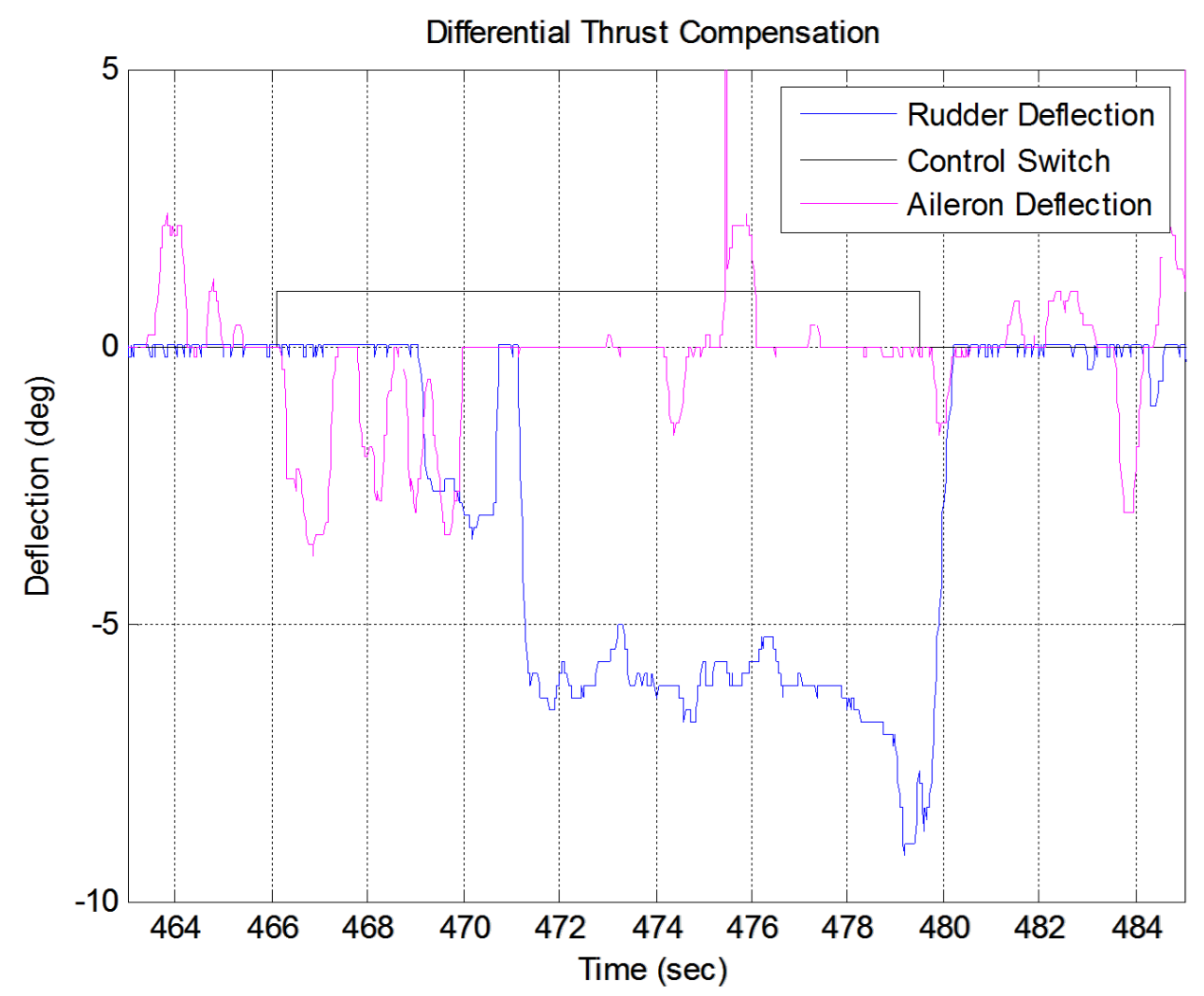

Figure 29: Rudder Deflection Required to Compensate for Engine Failure

This result is the only available data point at this time and therefore cannot be considered conclusive evidence. The differential thrust test parameters were maximized with one motor producing zero thrust while the other produced a cruising thrust of approximately $12 \mathrm{~N}$. This result is similar to simulation tests but future tests need to be conducted to verify this result. 


\section{Thrust Vectoring}

\subsection{Thrust Vector Modeling}

For thrust vector modeling, the angle $\lambda$ is defined as the difference between the motor deflection and the trim position, with a positive angle corresponding to an upward deflection. This configuration implies that the propulsive forces are no longer only acting along the $\mathrm{x}$-axis of the aircraft. When the motors are vectored the force along the $\mathrm{x}$-axis corresponding to the aircraft velocity is reduced to the cosine of the deflection angle. There is an additional force along the $\mathrm{z}-$ axis of the aircraft, corresponding to the pitching moment that is driven by the sine of the deflection angle. A combination of the differential thrust and thrust vectoring capabilities leads to the ability to roll the aircraft using only propulsive forces. Eq. (7.1) represents the moment equations with the additional terms produced from both differential thrust and thrust vectoring.

$$
\left[\begin{array}{c}
\dot{p} \\
\dot{q} \\
\dot{r}
\end{array}\right]=M_{1}\left[\begin{array}{l}
p^{2} \\
q^{2} \\
r^{2}
\end{array}\right]+M_{2}\left[\begin{array}{l}
q r \\
p r \\
p q
\end{array}\right]+\bar{q} S M_{0}\left[\begin{array}{l}
b C_{l} \\
\bar{c} C_{m} \\
b C_{n}
\end{array}\right]+\left[\begin{array}{c}
T_{\text {Left }} \sin \lambda\left(l_{T-x}\right)+T_{R i g h t} \sin \lambda\left(l_{T-x}\right) \\
T_{\text {Left }} \sin \lambda\left(l_{T-C G}\right)+T_{R i g h t} \sin \lambda\left(l_{T-C G}\right) \\
T_{\text {Left }} \cos \lambda\left(l_{T-x}\right)+T_{R i g h t} \cos \lambda\left(l_{T-x}\right)
\end{array}\right]+\left[\begin{array}{c}
\varepsilon \\
0 \\
\varepsilon
\end{array}\right]
$$

In Eq. (7.1), $T_{\text {Left }}$ and $T_{\text {Right }}$ represent the thrust forces being produced by the respective motors, $\lambda$ is the deflection angle of the motors, $l_{T-x}$ is the moment arm from the thrust line to the aircraft Xaxis, and $l_{T-C G}$ is the moment arm from the motor to the center of gravity. The small additional terms produced from varying flow on either side of the vertical tail are represented by $\varepsilon$. Following the same procedure as was described in Section 6.1 and adding the additional terms produced by thrust vectoring, the force equations become:

$$
\begin{aligned}
\dot{V}= & -\frac{\bar{q} S}{m}\left(C_{D} \cos \beta-C_{Y} \sin \beta\right)+\left[\left(\frac{T_{\text {Left }}+T_{\text {Right }}}{m}\right) \cos \lambda \cos \alpha+\left(\frac{T_{\text {Left }}+T_{\text {Right }}}{m}\right) \sin \lambda \sin \alpha\right] \cos \beta \\
& +g(\cos \phi \cos \theta \sin (\alpha+\lambda) \cos \beta+\sin \phi \cos \theta \sin \beta-\sin \theta \cos (\alpha+\lambda) \cos \beta)
\end{aligned}
$$




$$
\begin{gathered}
\dot{\alpha}=-\frac{\bar{q} S}{m V \cos \beta} C_{L}+q-\tan \beta(p \cos (\alpha+\lambda)+r \sin (\alpha+\lambda)) \\
+\frac{g}{V \cos \beta}(\cos \phi \cos \theta \cos (\alpha+\lambda)+\sin \theta \sin (\alpha+\lambda)) \\
+\left[\frac{\left(T_{\text {Left }}+T_{\text {Right }}\right) \sin \lambda \cos \alpha-\left(T_{\text {Left }}+T_{\text {Right }}\right) \cos \lambda \sin \alpha}{m V \cos \beta}\right] \\
\dot{\beta}=\frac{\bar{q} S}{m V}\left(C_{Y} \cos \beta+C_{D} \sin \beta\right)+p \sin \alpha-r \cos \alpha+\frac{g}{V} \cos \beta \sin \phi \cos \theta \\
+\frac{\sin \beta}{V}(g \cos (\alpha+\lambda) \sin \theta-g \sin (\alpha+\lambda) \cos \phi \cos \theta) \\
-\frac{\sin \beta}{V}\left(\left[\frac{\left(T_{\text {Left }}+T_{\text {Right }}\right) \sin \lambda \sin \alpha+\left(T_{\text {Left }}+T_{\text {Right }}\right) \cos \lambda \cos \alpha}{m}\right]\right)
\end{gathered}
$$

\subsection{Simulator Results for Thrust Vectoring}

Thrust vectoring was tested in the simulator by imposing several types of maneuvers on the motors, and observing the aircraft response. Thrust vectoring produces vertical forces that apply a pitching moment to the aircraft. For each of the thrust vectoring maneuvers imposed on the aircraft in the simulator, the change in the aircraft pitch and angle of attack is observed. The first type of maneuver was a doublet of the motors in which they were first angled to a desired deflection in the positive direction, followed by the same deflection in the negative direction. Figure 30 shows an example of a doublet on the motors with a deflection of 15 degrees. 


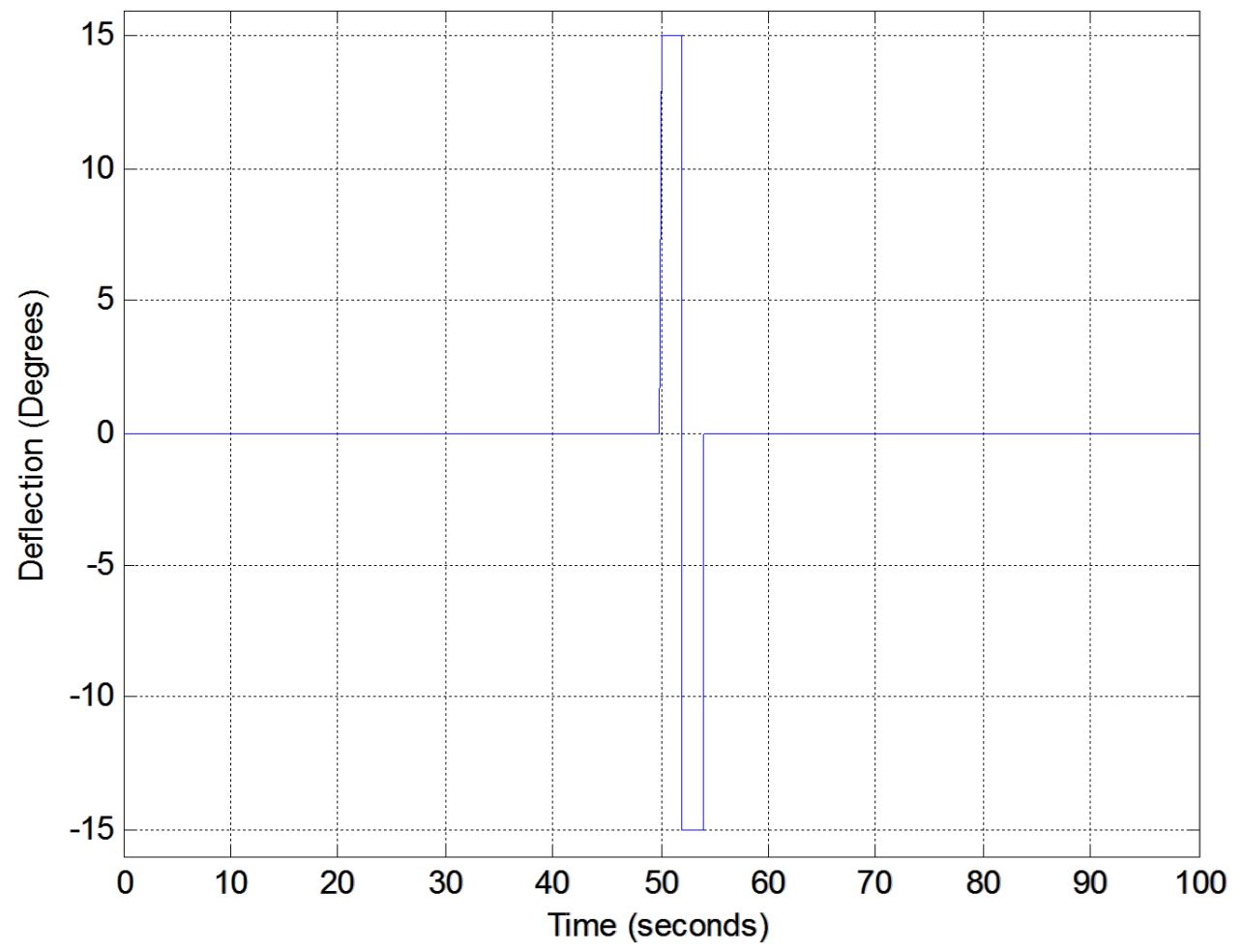

Figure 30: Thrust Vectoring Doublet Maneuver Performed on the Motors

The maneuvers were injected 50 seconds into the simulation, with all the control surfaces set to trim values. The aircraft was flying a straight trajectory at the simulated cruising velocity of $30 \mathrm{~m} / \mathrm{s}$. Figure 31 shows the pitch angle and the angle of attack of the aircraft, following a motor doublet of 5 degrees. 

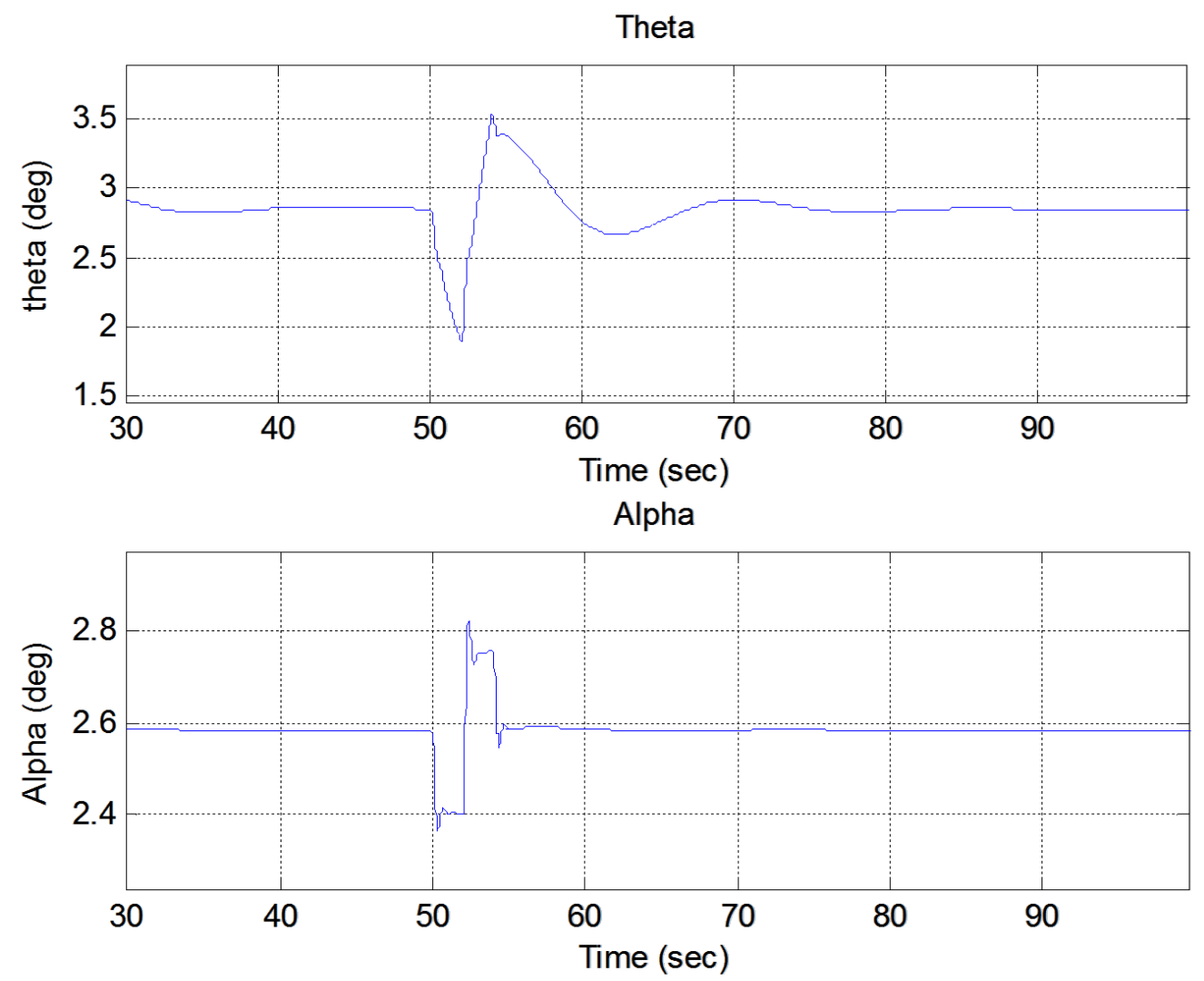

Figure 31: Aircraft Response to a 5 Degree Thrust Vector Doublet

The response was very insignificant with the angle of attack only changing 0.2 degrees in both the positive and negative directions. For direct comparison purposes the same maneuver was simulated with a higher deflection angle of 10 degrees, in an attempt to increase the effects on the aircraft response. Figure 32 shows the changes in aircraft pitch and angle of attack after the imposed 10 degree motor doublet. Throughout the maneuver the surfaces remained at trim, isolating the effects of the motor doublet. 
Theta

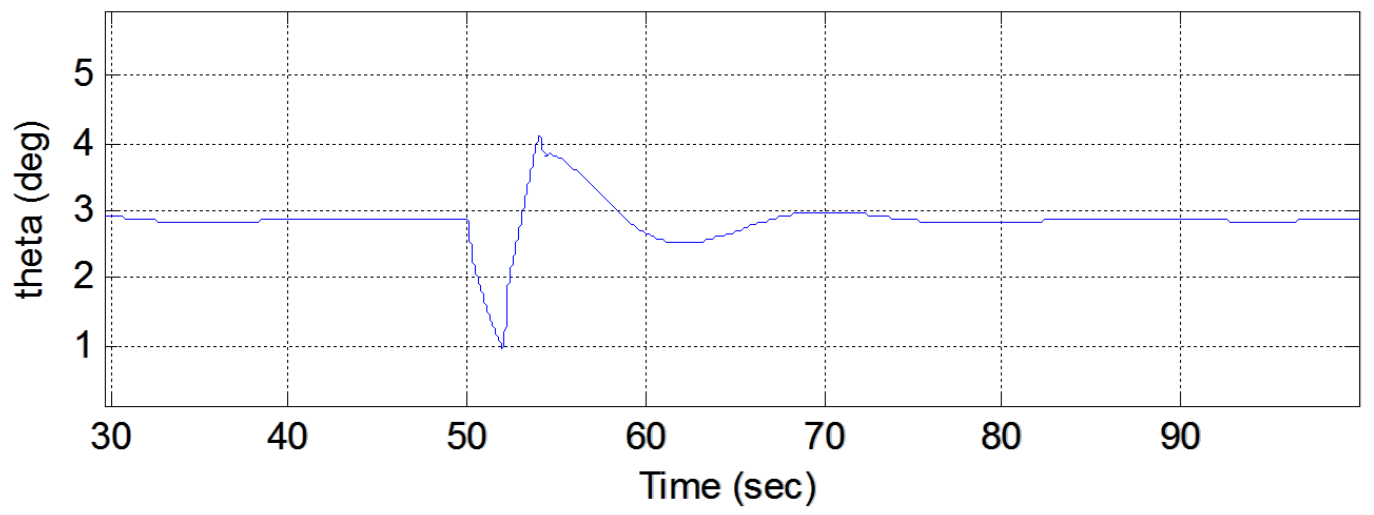

Alpha

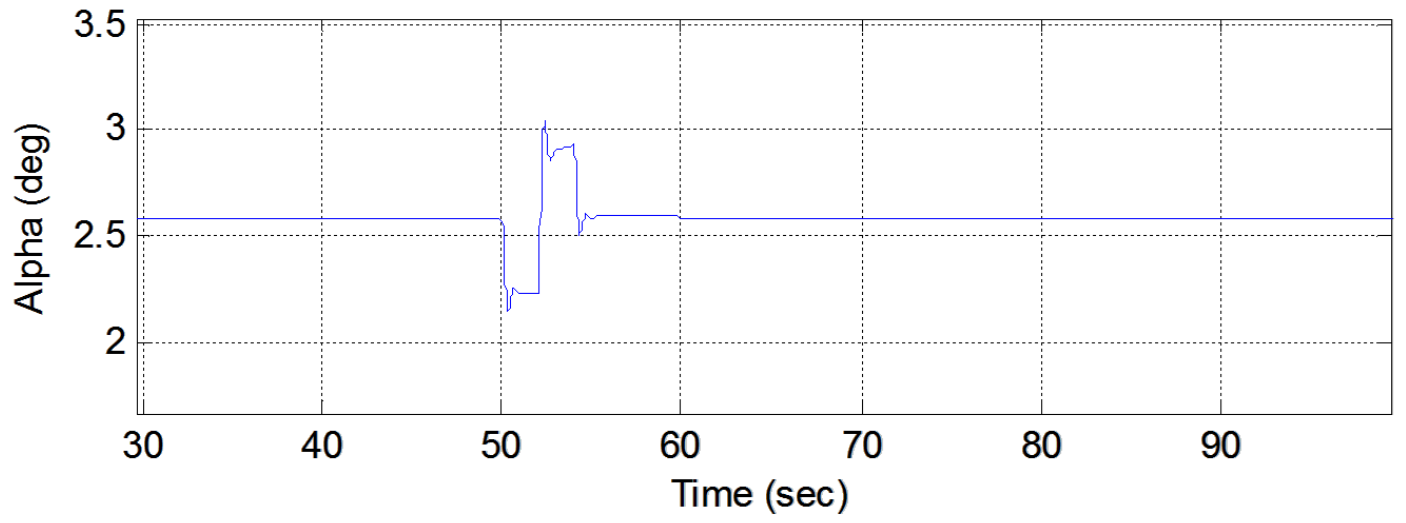

Figure 32: Aircraft Response to a 10 Degree Thrust Vector Doublet

The aircraft response was increased with respect to the 5 degree doublet, but remained small with approximately a 0.4 degree positive and negative change of angle of attack. It is unlikely this response would cause noticeable effects in flight. A greater response could be achieved by either increasing the magnitude of the maneuver of increasing the duration of the maneuver

A change of the angle of attack by 0.4 degrees is well within the regularly observed magnitudes of this parameter. A very accurate sensor would be needed to measure changes of this magnitude, along with near perfect flight conditions. Any amount of wind gusting could cause a similar aircraft reaction. These results are very inconclusive and do not prove to accurately quantify the effect of thrust vectoring on the aircraft. 
A different approach was explored in which a controller attempted to maintain a desired pitch and roll angle while the thrust vectoring maneuvers were performed. The desired outcome of this procedure was a relationship between the elevator deflection and the thrust vectoring. The three maneuvers were repeated, with the controller active, as the elevator deflection was observed. Figure 33 shows the aircraft response to these maneuvers, as well as the elevator deflection needed to compensate for the additional pitching moment.
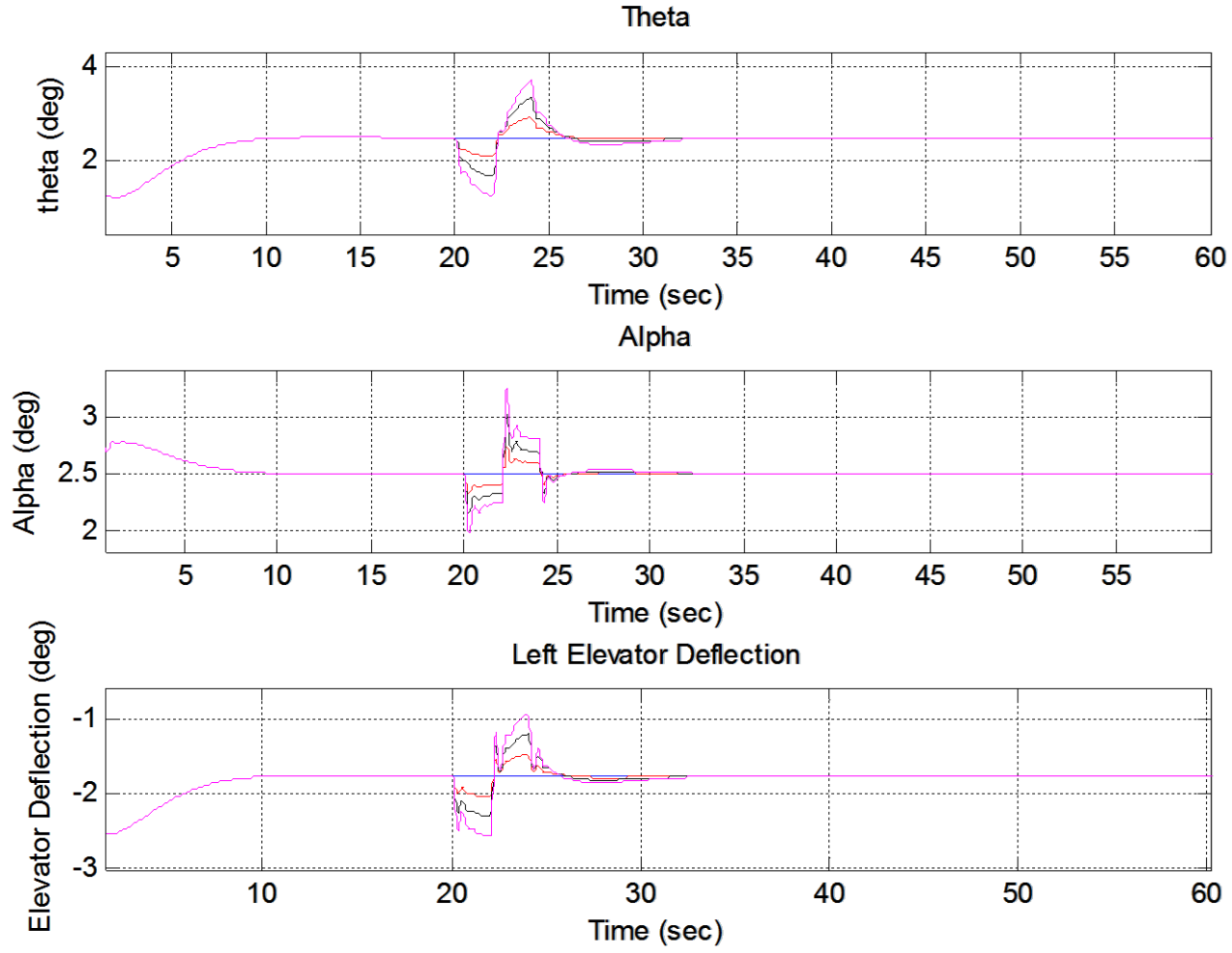

Doublet Magnitude $=0 \longrightarrow$ Doublet Magnitude $=5-$ Doublet Magnit ude $=10$

Doublet Magnitude $=15$

\section{Figure 33: Simulated Aircraft Response to a Compensated Thrust Vector Doublet}

The maximum elevator deflection observed was approximately 0.8 degrees from the trim value corresponding to the 15 degree motor doublet. For the simulated flight conditions, the elevator was found to have approximately 19 times the effectiveness in pitching the aircraft as the thrust vectoring. 
Keeping the test conditions constant at a velocity of $30 \mathrm{~m} / \mathrm{s}$, surfaces at trim, steady level flight, and injecting a maneuver after 50 seconds of simulation, a step on the thrust vector channel of 15 degrees was imposed on the aircraft. Figure 34 shows the step maneuver performed on the motors after 50 seconds of simulation.

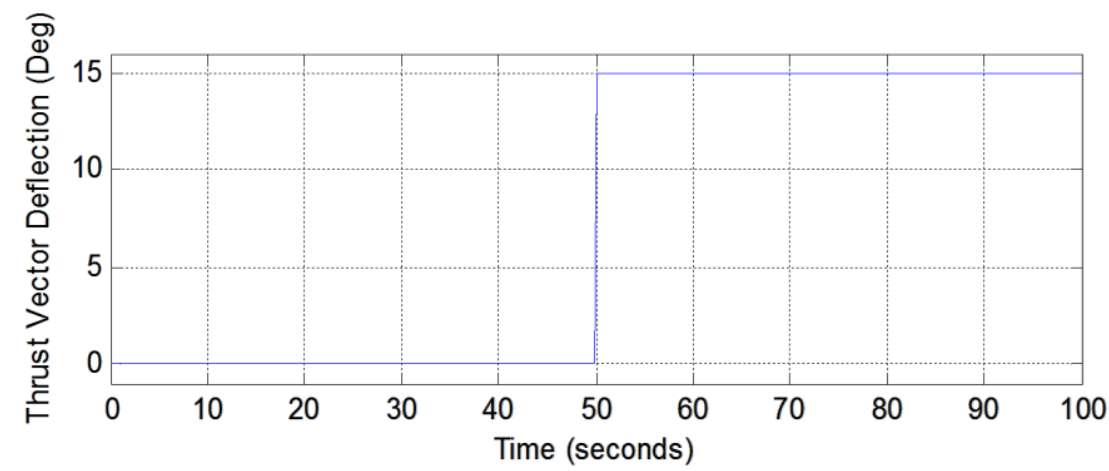

\section{Figure 34: Thrust Vector Step Maneuver Performed on the Motors}

The response of the aircraft to the step maneuver was observed in the pitch and angle of attack. Figure 35 shows the response with the angle of attack changing approximately 0.6 degrees before leveling off 0.5 degrees from the initial value.
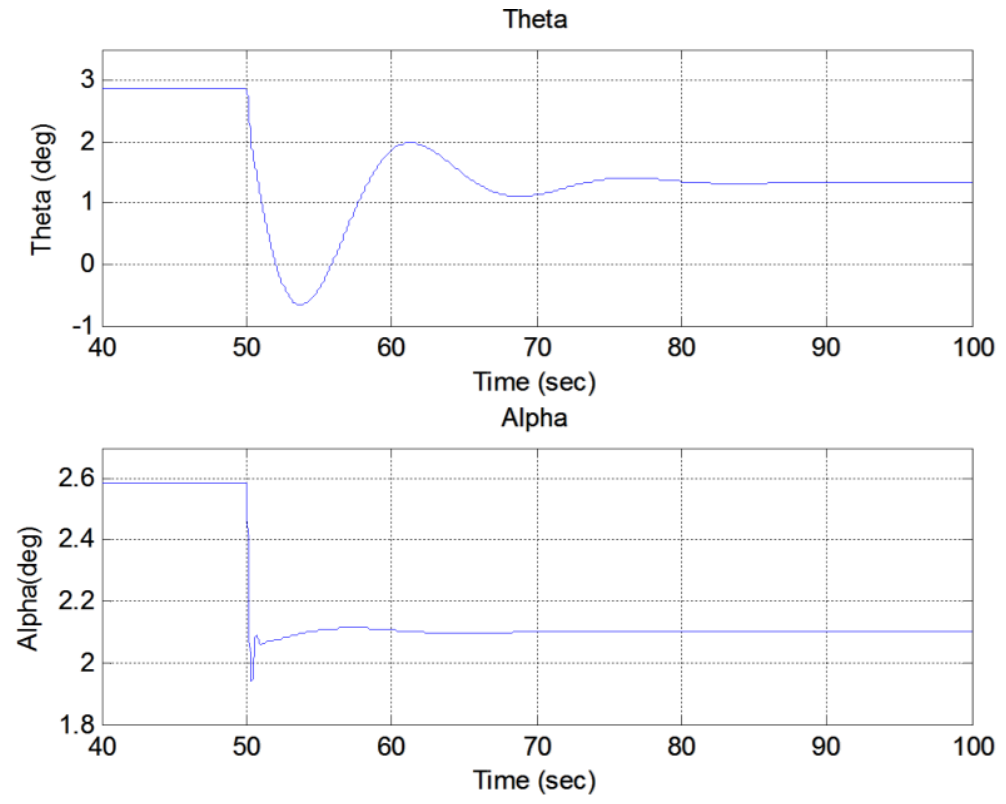

Figure 35: Aircraft Response to a Thrust Vector Step of 15 Degrees 
Similarly to the doublet maneuvers, a linear quadratic regulator controller was implemented to maintain a desired pitch and roll angle while the step maneuver was imposed on the system. Figure 36 shows the response of the aircraft with the pitch angle damping out more quickly than without the controller.
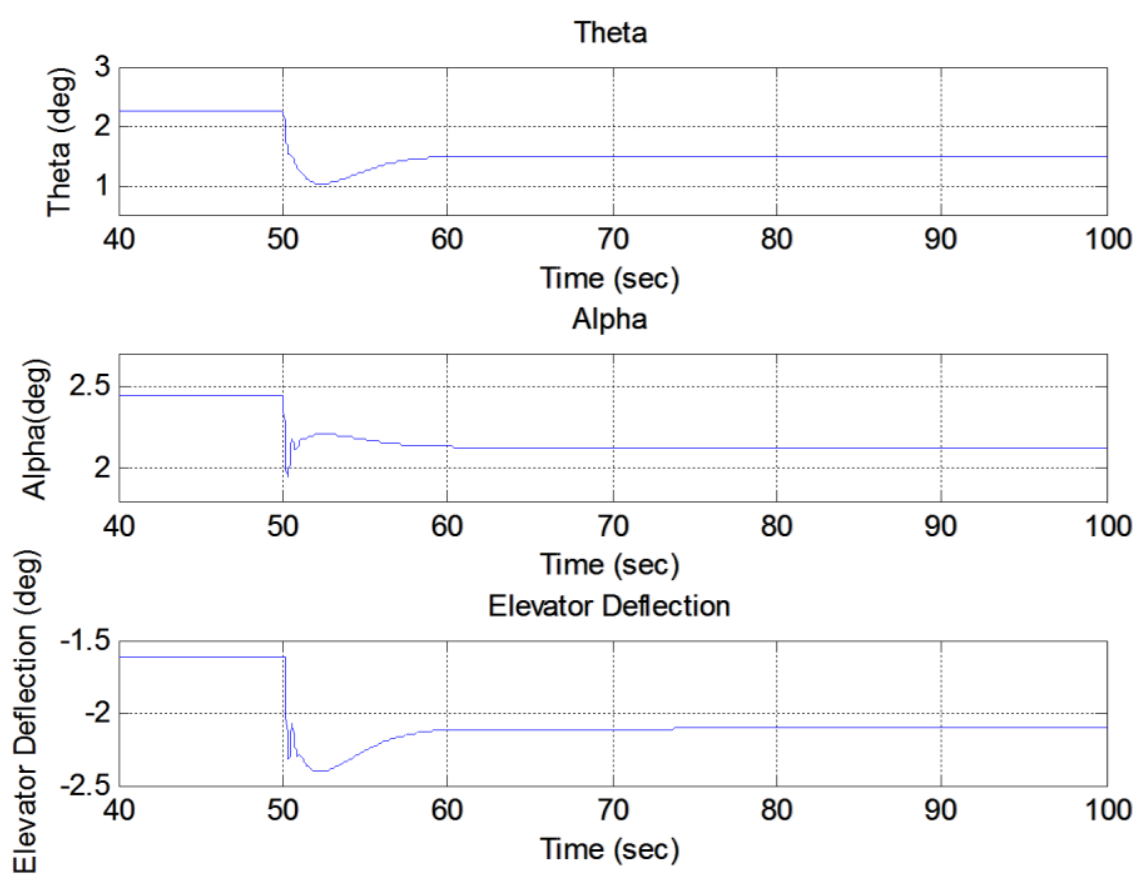

\section{Figure 36: Simulated Aircraft Response to a Compensated Thrust Vector 15 degree Step}

The initial changes in the aircraft pitch and angle of attack are lower, but a steady value is eventually reached and maintained, off of the initial trim value. The elevator deflection remains less than one degree as it did during the doublet maneuvers. To produce a stronger response, the test conditions would need to be altered, and the magnitude of the maneuver would need to be increased.

\subsection{Thrust Vectoring Test Stand}

Prior to implementing thrust vectoring on the aircraft, a test stand was designed and constructed to determine the design feasibility. The design process originated through the use of 
computer aided design (CAD) software with which a model was developed to visualize component interaction. The test stand was designed to mimic the setup on the aircraft, including an aluminum support rod for the motors rotating in a carbon rod. Aluminum adapters were designed in-house to rigidly attach the motors to the aluminum rod via a duct. In the test stand, the aluminum rod is able to rotate inside of the carbon rod, causing the two motors to pivot around their connection point. A driving rod was attached to center of the aluminum rod to yield rotational control of the aluminum rod. The driving rod is linked to a high torque servo that was controlled through a transmitter by the experimenter. Figure 37 shows the CAD model of the thrust vectoring test stand with the two $90 \mathrm{~mm}$ ducted fans mounted on the aluminum rod.

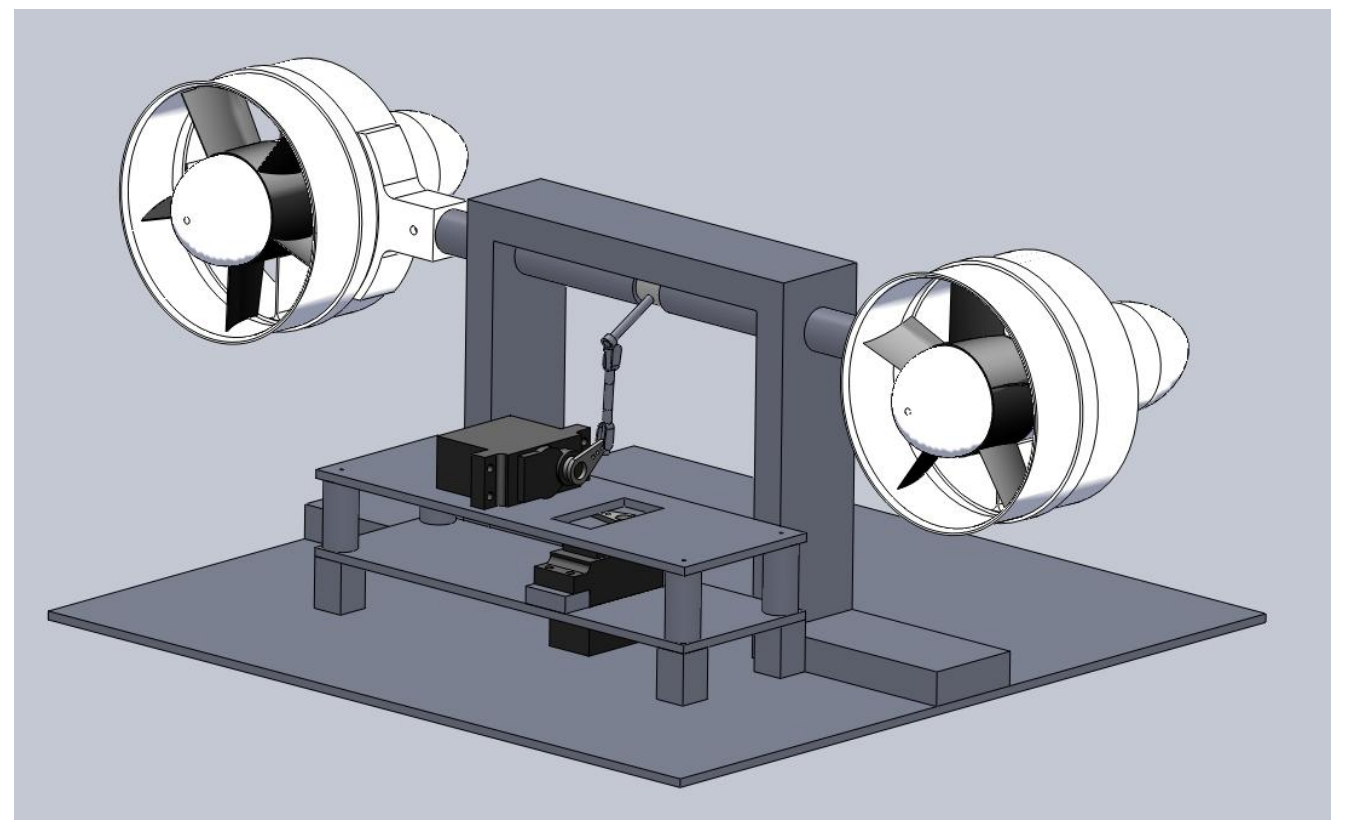

Figure 37: CAD Model of the Thrust Vectoring Test Stand

The horizontally mounted servo (top board) pushes or pulls the driving rod, which then turns the aluminum rod and tilts the motors up or down. The degree to which the motors tilt is a function of the length of the servo arm, length of the driving rod, and the throw on the servo. Since small deflections are desired, a short servo arm was used and the throw on the servo was decreased using the transmitter settings. 
One of the major considerations when this thrust vectoring technique was being developed was the ability of the servo to both produce enough force to move the motors and maintain a desired deflection while minimizing vibrations. Several tests were run to ensure that the servo could handle the loads and achieve the desired deflection angles. First, the test stand was equipped with a single motor while the deflection was measured and assigned to a desired value. The servo was initially connected to a flap channel on the receiver in order to command a predefined thrust vector angle. The servo was centered so that a half flap deflection corresponded to a zero deflection angle. This allowed the motors to be moved both up and down for transmitter commands of zero flap and full flap, respectively. The angle of deflection was set using the "travel adjust" control inside the transmitter.

The first test performed was at a low RPM value and a low deflection angle to ensure everything was functioning properly. The motor was powered on and set to a low throttle setting while the deflection angle of the motors was set at zero. Once the motor was running the flap switch was moved to the full flap position, angling the motor to approximately five degrees in the positive (up) direction. The flap switch was then moved back to the half flap position before moving it to the zero flap position to test the negative deflection performance. There were no observable vibrations or undesired oscillations in the system so the throttle setting was increased to half throttle. The same procedure was repeated where the motor was first throttled up to half throttle, the flap switch was moved and the motor responded with an approximate five degree deflection angle.

Next, the angle of deflection was increased to approximately ten degrees positive and negative deflection by changing the travel of the servo in the transmitter. The same tests were performed with a low throttle setting followed by tests at half throttle paired with the ten degree deflection angle. Finally, the servo was plugged into the elevator channel on the receiver to move the motor continuously instead of having a preset location. The motor was run at half throttle while the deflection was continuously changed through the entire range of 10 degrees each direction. These tests showed that the high torque servo was capable of handling the loads 
applied by a single motor and could provide smooth thrust vectoring for deflection angles up to ten degrees.

With the success of the single motor tests, a second motor was mounted to the thrust vectoring test stand. The servo was connected to the elevator channel to once again allow the motors to be vectored continuously through the entire range of the servo. The deflection range was set to the full range of the servo which equated to about fifteen degrees of movement in either direction. The motors were run at a low RPM and the servo was driven to its full deflection up and down; the motors moved smoothly and the system did not show any immediate signs of significant vibrations. The RPM was increased to approximately half throttle (the cruising RPM), and the servo was again moved through its entire range. At specific deflections, the servo was held constant to examine the ability of the servo to hold the motors at a given deflection for a length of time. These tests were also successful in showing that there were no significant vibrations or other adverse effects.

\subsection{Implementation of Thrust Vectoring on the Aircraft}

After the successful tests with the thrust vectoring stand, the design was integrated into the WVU PAC aircraft. The same "driver arm" was driven by a servo, which rotated the motors up or down. The initial design featured a second tier above the rudder servo plate, on which the vectoring servo was to be mounted. When this design was integrated into the aircraft, it was

found that the vertical distance between the plate and the driver arm was too short. To compensate, the vectoring servo was moved to the bottom plate, switching positions with one of the speed controllers on the aircraft. This lengthened the linkage and provided sufficient travel to vector the motors through the desired range. Figure 38 shows a CAD model of the design at both a zero deflection and a positive (up) deflection. 


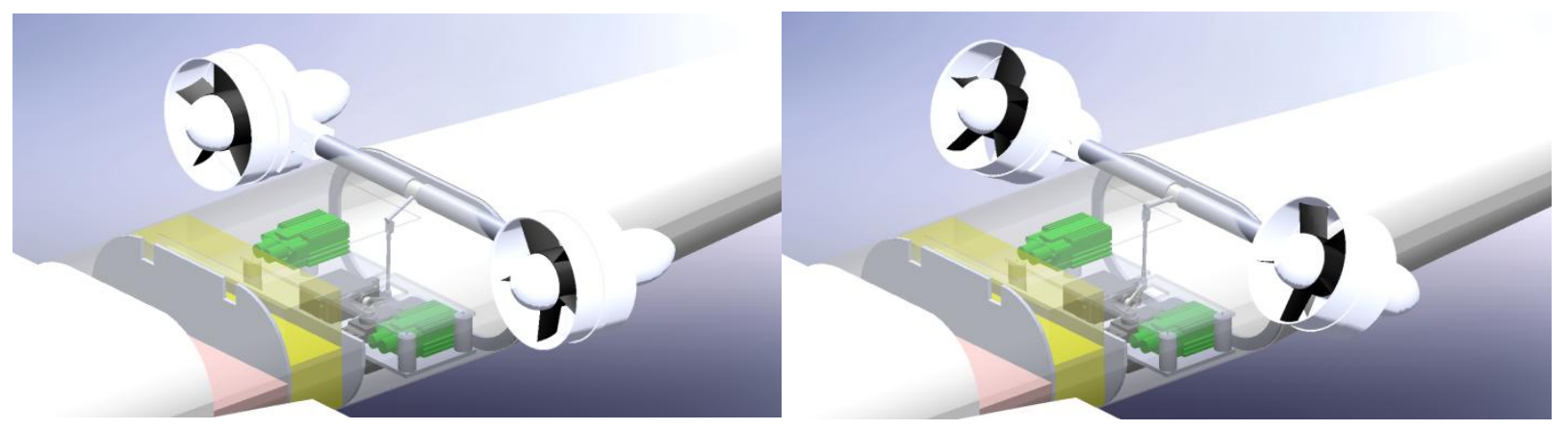

Figure 38: Thrust Vectoring on the WVU PAC Aircraft

This configuration allows for a maximum of fifteen degrees positive and negative deflection. Additionally, limits were placed on the rotation of the motor mount to assure that, in the occurrence of a servo failure, the motors would remain within this deflection range.

\subsection{Flight Test Results for Thrust Vectoring}

The thrust vectoring was flight tested to validate the results gained from the simulations. The aircraft was flown in a track configuration with two straight sections parallel to the runway and two semi circles connecting the straight sections. The length of the track was about 400m while the width of the track was $200 \mathrm{~m}$. A scheme was developed to drive the thrust vectoring using a control switch on the transmitter. The scheme injected a single doublet of approximately 8 degrees on the thrust vectoring channel for each activation of the control switch. The maneuver was implemented during the straight leg sections of the flight path followed by a "hands-off" period when the pilot refrained from deflecting the control surfaces to observe the natural response of the aircraft.

A second scheme was also developed that incorporated the controller used to track a given pitch and roll angle. Upon activation of the switch, a step on the motors was injected while the controller used the elevator to compensate for the produced pitching moment. The size of the step would increase by two degrees, starting at 5 and finishing at 13 degrees. This would allow more data points to be collected during a single flight.

The thrust vectoring was also enabled on the flap switch where the pilot could manually deflect the motors from the trim condition to positive 15 degrees. This simulates a step input on 
the system, similar to what was performed during simulation. The pilot was asked to compensate for any noticeable effects to keep the aircraft flying straight and level. In this way the elevator deflection required to counteract the pitching moment caused by the thrust vectoring could be quantified.

The first tested scenario was the 8 degree doublet scheme, injected on the straight legs with "hands-off” flight. Figure 39 shows the doublet performed by the motors.

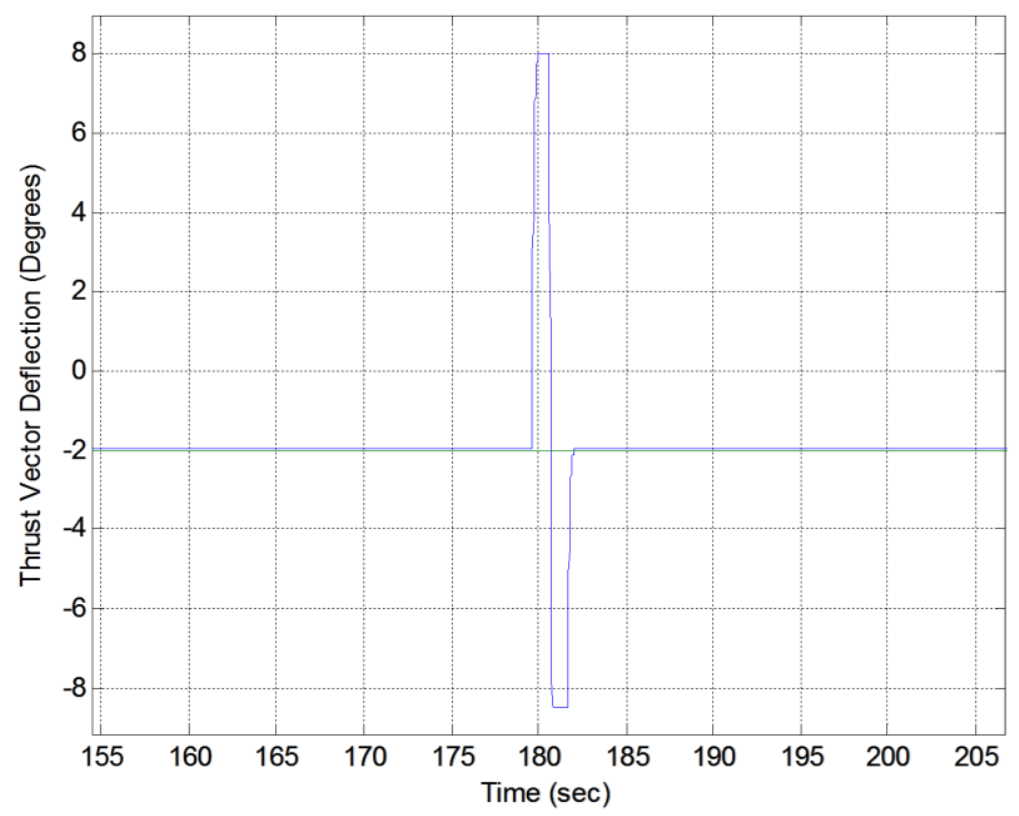

Figure 39: Thrust Vector Doublet Maneuver Performed In-Flight

Recalling from simulation, this maneuver produced a change of 0.4 degrees in the angle of attack. In flight the signal to noise ratio was too low to observe changes of this magnitude.

Figure 40 shows the angle of attack recorded during the 8 degree doublet maneuver as measured using directional vanes. 


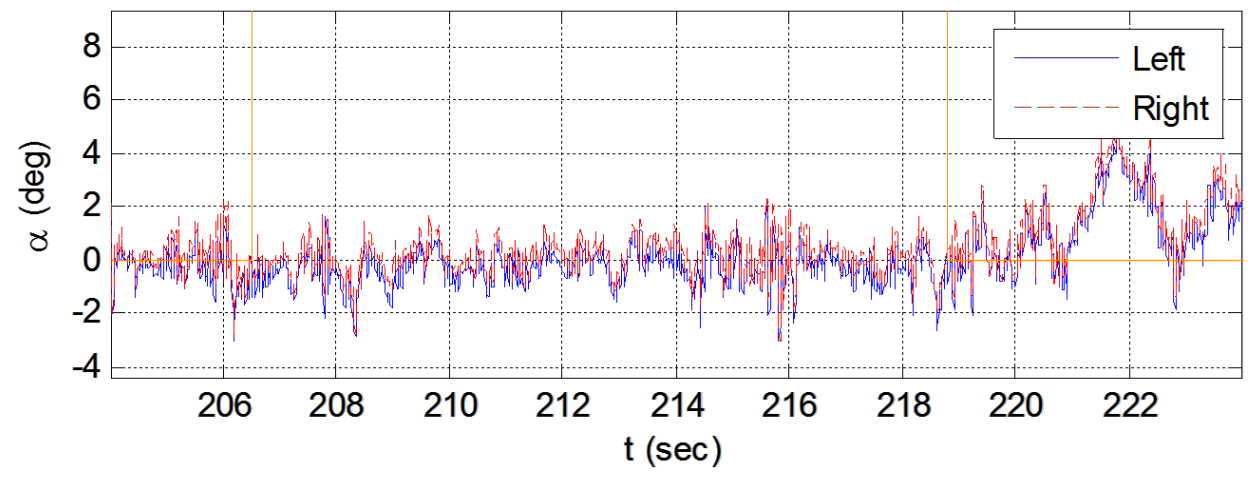

Figure 40: Angle of Attack during a Doublet Maneuver on the Motors

This data is inconclusive as the noise is too high to show small changes in the parameter. There does not appear to be a trend present from which conclusions can be drawn. The pitch angle showed a similar result with too low a signal to noise ratio to provide quantitative results. Figure 41 shows the pitch angle with no clear trends corresponding to the control switch activations.

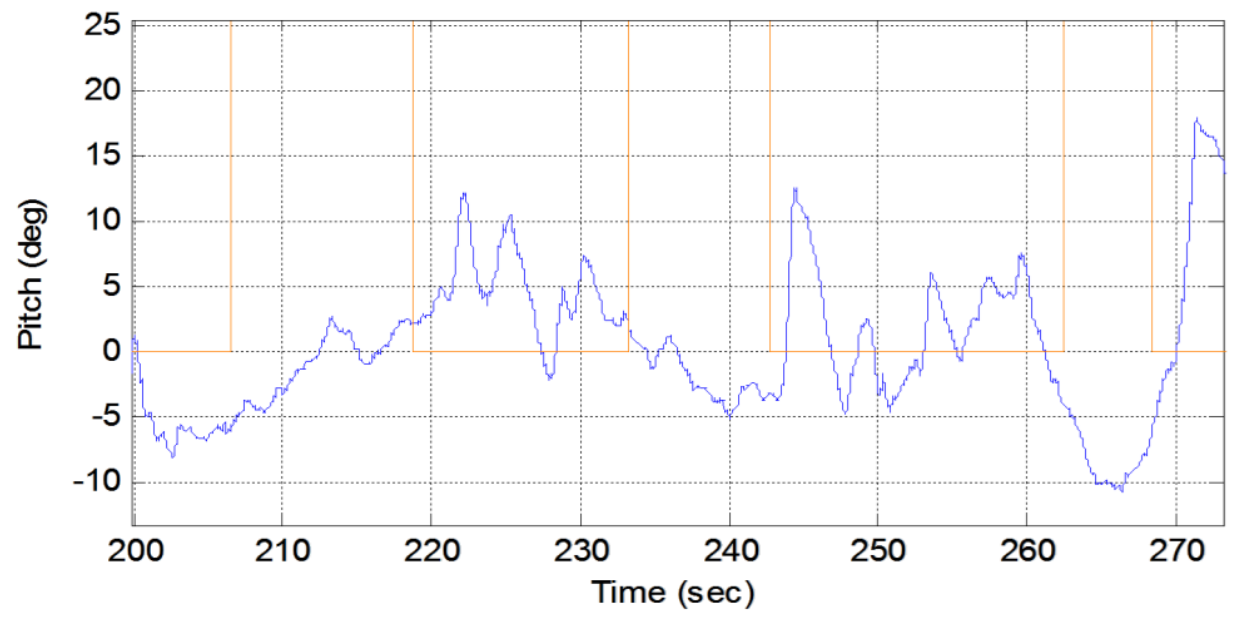

Figure 41: Pitch Angle during the Doublet Maneuver

The next tested scenario consisted of a step input on the thrust vectoring, manually injected by the pilot. During this maneuver the pilot used the elevator to compensate for the pitching moment created by the motors. Simulations proved that the pitching moment created by the 
motors could be compensated by an elevator deflection of less than 1 degree. This test was performed to determine if this is an accurate relationship between the thrust vectoring and the elevators. Figure 42 shows the step maneuvers injected on the thrust vector through the flap channel.

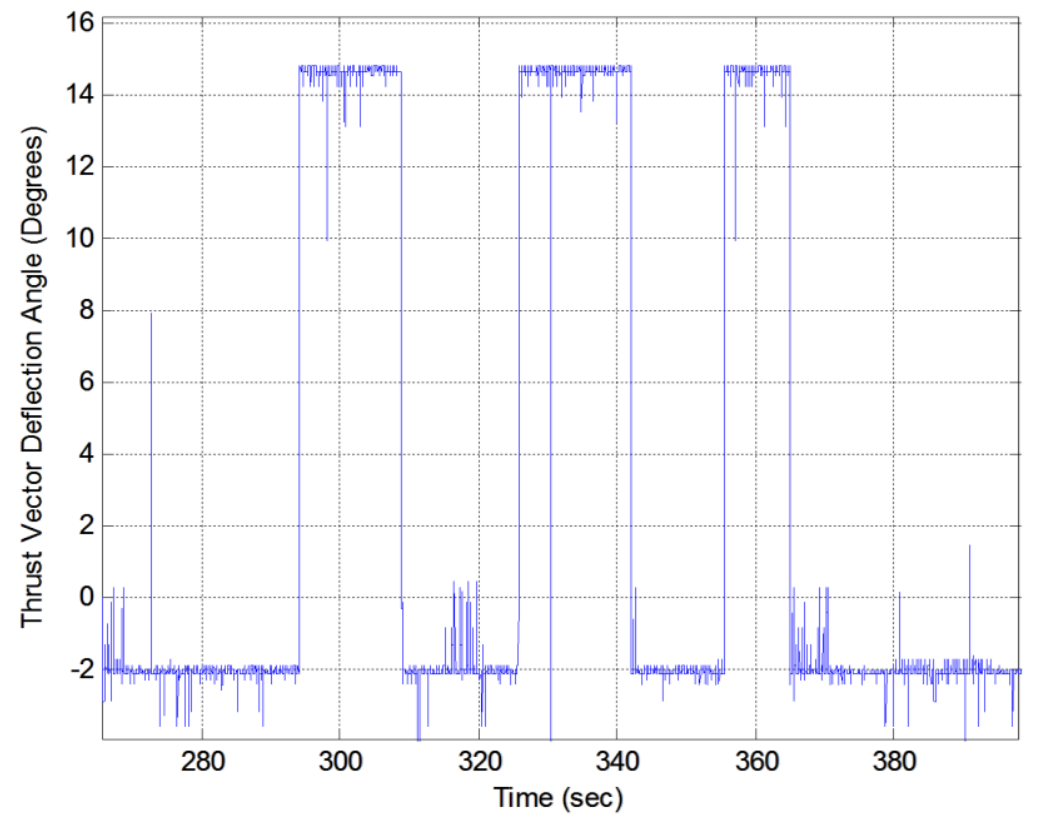

Figure 42: Thrust Vector Step Maneuvers

Figure 43 shows the elevator deflection before, during, and after the thrust vector step maneuver. The blue and red lines signify the left and right control surfaces respectively and are offset because of the trim on these surfaces. 

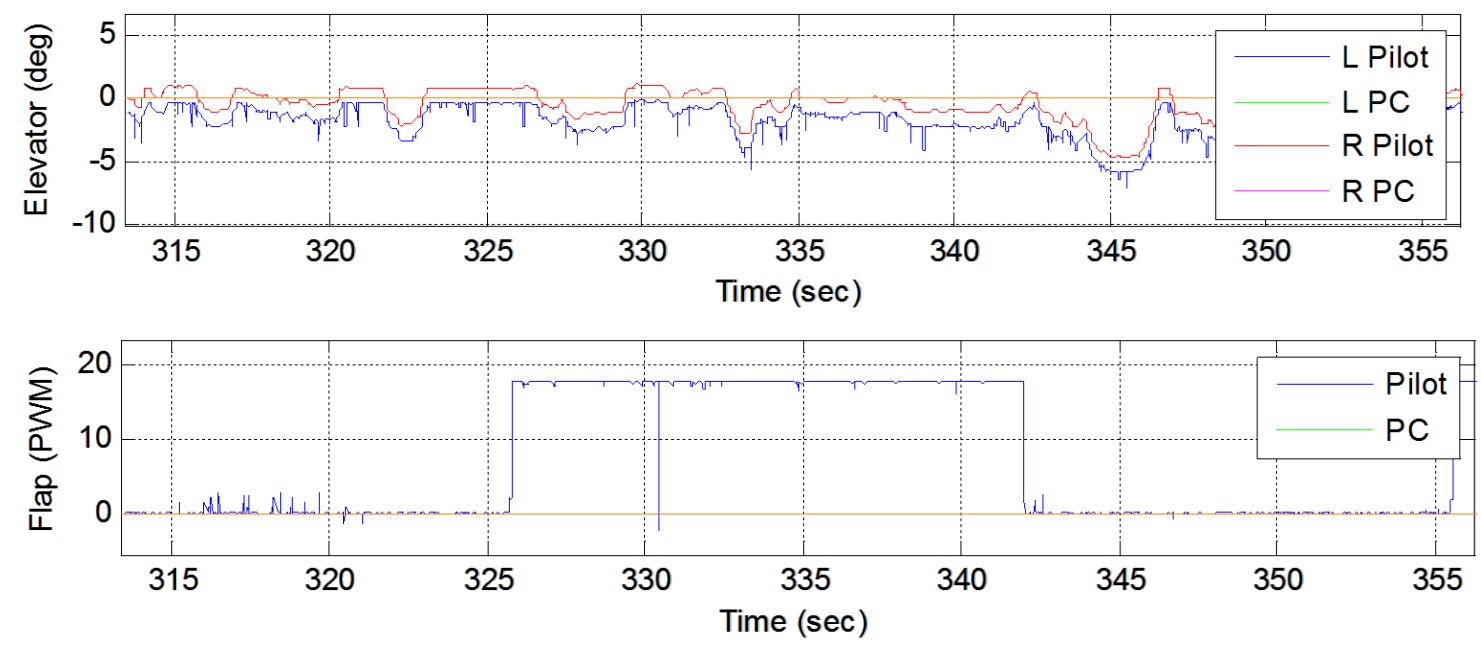

Figure 43: Elevator Deflection during Thrust Vector Step Manuever

There does not seem to be a clear change in the elevator deflection during the maneuver. This serves to support the simulation data, where a small change in the elevator deflection can compensate for the moment produced by the thrust vectoring. With the pilot compensating for any pitch changes, there are no changes in angle of attack directly related to this step input.

Additional flight tests were performed in which the motors were deflected negative $20^{\circ}$ and negative $30^{\circ}$. This was done in an attempt to produce a larger vertical force and cause a greater pitching moment on the aircraft. For both the $20^{\circ}$ and $30^{\circ}$ deflections, the aircraft pitch response was once again masked by the measurement noise. The small moment arm associated with this aircraft configuration prevents the thrust vectoring from having significant pitch control authority. 


\section{Conclusions}

A ducted fan propulsion assisted control system was successfully designed, modeled, and implemented on the research aircraft. The propulsive forces were modeled and incorporated into a simulator that was adapted to facilitate differential thrust and thrust vectoring. Simulations were then performed to quantify the effectiveness of propulsion assisted control on this research aircraft. The simulation studies yielded a small effect on the aircraft dynamics from both differential thrust and thrust vectoring. For a differential thrust of 12 Newtons (only one motor running), control surface compensation was small with the rudder deflecting 0.25 degrees and the ailerons deflecting 0.6 degrees to maintain steady level flight. For a thrust vector angle of positive 15 degrees, the elevator compensation was only 0.8 degrees, making the elevator approximately 19 times more effective at pitch control than the vectored motors at the tested flight condition.

Flight testing of differential thrust yielded similar results when compared to the simulations. The aircraft was easily controlled using a small aileron deflection or a slightly higher magnitude rudder deflection. One experiment yielded promising results with a rudder deflection corresponding to the thrust differential, but this result needs to be verified through future testing. The in-flight testing of the thrust vectoring showed minimal effects on the aircraft during the maneuvers. The on-board sensors recorded too much noise to be able to identify small changes in the parameters. For example, the angle of attack was expected to change approximately 0.5 degrees to the injected maneuver but the noise on this channel was averaging two or three

degrees. The flight results for thrust vectoring proved to be inconclusive, but did not disprove the simulation data.

The modeling process outline in this paper proved to accurately predict the magnitude of the aircraft response to injected maneuvers of differential thrust and thrust vectoring. The exact response could not be verified due to the small responses expected in flight. The signal to noise ratio was too low to accurately measure changes in the parameters most affected by the propulsion assisted control system. A more accurate validation of the simulation results could be 
achieved by changing the flight conditions such as velocity of the aircraft, angle of attack, thrust, and magnitude of the maneuvers. 


\section{Future Work}

The implementation of thrust vectoring on the WVU research aircraft opens up several new research opportunities. One area that often coincides with thrust vectoring research is high angle of attack flights. Aircraft with this capability can extend the fight envelope and increase maneuverability. The future direction of this research will be to increase the available thrust vector deflection from 15 degrees to 30 degrees (limited to only one direction) and attempt to put the aircraft into a controlled high angle of attack flight condition. In high angle of attack flights, the forward speed of the aircraft will decrease, causing the elevators to have less effect at a given deflection. The thrust from the motors can be increased to produce a stronger moment, increasing the effectiveness that the thrust vectoring will have on the pitch of the aircraft. Additional research objectives could include short takeoff and landing, stall recovery, and pitch control for fault tolerant flight control laws.

\section{Bibliography}

1. National Transportation and Safety Board, "Aircraft Accident Report: United Airlines Flight 232," NTSB/AAR-90/06. US Government Printing Office, Washington, D.C. 20594. 1990.

2. Davis, C.R. -Major General, USAF, "F-35 Program Overview," Program Executive Officer brief to Aviation Week, February 13, 2008.

3. Kebabjian, R. Statistics. Plane Crash Info Online. Accessed January 6, 2010. http://www.planecrashinfo.com/cause.htm.

4. Guttman, Robert. "Caproni Flying Barrel: Luigi Stipa Claimed His 'Intubed Propeller' Was the Ancestor of the Jet Engine." Aviation History. March 2010. ISSN 10768858.

5. "Caproni-Stipa - Research Aircraft." All the World's Helicopters and Rotorcraft - the Most Complete Helicopter Collection in the World. Helicopters, Autogyros, Tiltrotors, Tilt-wings Etc. Web. 30 Oct. 2011.

6. Longbottom, Jon. "Investigation into the Reduction of the Drag Area of a Paramotor," University College, University of New South Wales, School of Aerospace Civil and Mechanical Engineering, Thesis. October 7, 2006.

7. Ohanian III, Osgar J. Ducted Fan Aerodynamics and Modeling, with Applications of Steady and Synthetic Jet Flow Control. Diss. Virginia Polytechnic Institute and State University, 2011. Print.

8. Milam, M., Murray, R.M., "A Testbed for nonlinear Flight Control Techniques: The Caltech Ducted Fan," 1999 Conference on Control Applications, August 22-27, 1999. 
9. Choi, H.; Sturdza, P.; Murray, R.M.; , "Design and construction of a small ducted fan engine for nonlinear control experiments," American Control Conference, 1994 , vol.3, no., pp. 2618- 2622 vol.3, 29 June-1 July 1994

10. Abrego, Anita I., and Robert W. Bulaga. Performance Study of a Ducted Fan. Tech. San Fransisco: American Helicopter Society International, 2002.

11. Martin, Preston., Tung, Chee., "Performance and Flowfield Measurements on a 10inch Ducted Rotor VTOL UAV," Army/NASA Rotorcraft Division Aeroflightdynamics Directorate, AMRDEC., June 2004.

12. "Aircraft Accident Investigation Report Japan Air Lines Co., Ltd. Boeing 747 SR100, JA8119 Gunma Prefecture, Japan August 12, 1985." 8 (19/332). Retrieved on August 18, 2010.

13. B. Gal-Or, "A New Era in Flight Control, Civilizing Military Thrust Vectoring Flight Control to Maximize Flight Safety and Agility", Vector Turbo Power B.V \& the Gas Turbine Consortium, 128 Teslastraat, 1098, Amsterdam, Holland, 2000.

14. A.J. Steer, "Integrated Control of a Second Generation Supersonic Commercial Transport Aircraft Using Thrust Vectoring”, AIAA-2000-4109, 2000.

15. Gal-Or, Vectored Propulsion, Supermaneuverability and Robot Aircraft, Springer Verlag, ISBN 3-540-97161-0, 2000.Härefors, M. and Bates, D.G., "Integrated Propulsion-Based Flight Control System Design for a Civil Transport Aircraft", Control and Instrumentation Research Group, Department of Engineering, University of Leicester, University Road, Leicester LE1 7RH, U.K.

16. Harefors, M. \& Bates, D.G., "Integrated Propulsion-Based Flight Control System Design for a Civil Transport Aircraft," IEEE International Conference on Control Applications, September 2002. Glasgow, Scotland. IEEE 0-7803-7386.

17. Burcham, Frank W., Trindel A. Maine, John J. Burken, and Drew Pappas. "Development and Flight Test of an Augmented Thrust-Only Flight Control System on an MD-11 Transport Airplane." AIAA Guidance Navigation and Control Conference: July 29-31, 1996/San Diego, CA. 1996. Print.

18. Burcham, F.W., Burken, J.J., Maine, T.A., Fullerton, C.G., "Development and Flight Test of an Emergency Flight Control System Using Only Engine Thrust on an MD-11 Transport Airplane," NASA Publication, NASA/TP-97-206217. October 1997.

19. J.J. Burken, F.W. Burcham et al, "Flight Test of a Propulsion-Based Emergency Control System on the MD-11 Airplane with Emphasis on the Lateral Axis", AIAA96-3919, 1996.

20. J. Kaneshieg, J. Bull, E. Kudzia, F. W. Burcham, "Propulsion Control With Flight Director Guidance as an Emergency Flight Control System", AIAA-99-3962, 1999.

21. F. W. Burcham, T. A. Maine, and J. J. Burken. Using Engine Thrust for Emergency Flight Control: MD-11 and B-747 Results. NASA/TM-1998-206552, May 1998.

22. Burken, J.J., Maine, T.A., Burcham, F.W., Kahler, J.A., "Longitudinal Emergency Control System Using Thrust Modulation Demonstrated on an MD-11 Airplane," $32^{\text {nd }}$ AIAA/ASME/SAE/ASEE Joint Propulsion Conference, Lake Buena Vista, Florida. July 1-3, 1996. AIAA 96-3062. 
23. Burcham, F.W., Maine, T.A., Wolfe, T., "Flight Testing and Simulation of an F-15 Airplane Using Throttles for Flight Control,” NASA TM-104255, 1992.

24. Stepanyan, V., Krishnakumar, K., Nguyen, N., "Adaptive Control of a Transport Aircraft Using Differential Thrust," NASA Ames Research Center, Moffett Field, CA. NASA Publication.

25. Burcham, Frank W., and C. Gordon Fullerton. "Controlling Crippled Aircraft-With Throttles." NASA Dryden Flight Research Facility. September 1991.

26. Ochi, Yoshimasa, and Kimio Kanai. "Automatic Approach and Landing for Propulsion Controlled Aircraft by $\mathrm{H}_{\infty}$ Control." Proceedings of the 1999 IEEE International Conference on Control Applications Held Together with IEEE International Symposium on Computer Aided Control System Design: August 22-27, 1999, Hapuna Beach Prince Hotel, Kohala Coast-Island of Hawai'i, Hawai'i, USA. Piscataway, NJ: IEEE, 1999. 997-1002. Print.

27. Liu, Y., Tang, X., Gang, T., Joshi, S.M., “Adaptive Failure Compensation for Aircraft Tracking Control Using Engine Differential Based Model," Proceedings of the 2006 American Control Conference, Minneapolis, Minnesota, June 14-16, 2006.

28. Nguyen, N., Krishnakumar, K., Kaneshige, J, Nespeca, P., "Dynamics and Adaptive Control for Stability Recovery of Damaged Asymmetric Aircraft," Proceedings of AIAA Guidance, Navigation, and Control Conference, AIAA-2006-6049, 2006.

29. Kaneshige, J., Grundy-Burlet, K., "Integrated Neural Flight and Propulsion Control System," Proceedings of AIAA Guidance, Navigation, and Control Conference, AIAA-2001-4386.

30. Jonckheere, E.A., Gwo-Ruey, Y., "Propulsion Control of a Crippled Aircraft by $\mathrm{H}_{\infty}$ Model Matching," IEEE Transaction on Control Systems Technology, Vol. 7, No. 2, March 1999.

31. Smolka, James W., Walker, Laurence A., F-15 ACTIVE Flight Research Program. NASA Dryden Flight Research Center.

32. Linch, Edward H. "Dream Machine - Thrust Vectoring in the F-16." Editorial. Aces Aero. Aces Aero, 1999. Web. Sept. 2011.

33. Reigelsperger, W.C., Banda, S.S., "Nonlinear Simulation of a Modified F-16 with Full-Envelope Control Laws," Control Engineering Practice 6 (1998) pgs. 309-320.

34. Mason, S., Stalls, Spins, and Safety, McGraw-Hill, New York 1982.

35. Raghavendra, Pk, N. Ananthkrishnan, Manan Chauhan, P. Ashwani Kumar, and Tuhin Sahai. "Aircraft Spin Recovery, with and without Thrust Vectoring, Using Nonlinear Dynamic Inversion." Journal of Aircraft 42.6 (2005): 1492-503. Print.

36. Frederick, J.L., Davidson, J.B., Murphy, P.C., "A Method for Integrating ThrustVectoring and Actuated Forebody Strakes With Conventional Aerodyanmic Controls on a High Performance Fighter Airplane," NASA Technical Paper, September, 1998, NASA/TP-1998-208464.

37. Iliff, K.W., Wang, K.C., "Flight-Determined Subsonic Longitudinal Stability and Control Derivatives of the F-18 High Angle of Attack Research Vehicle (HARV) 
with Thrust Vectoring," NASA Technical Paper, December 1997, NASA/TP-97206539.

38. Mason, Mark S., and William J. Crowther. "Fluidic Thrust Vectoring of Low Observable Aircraft." Proc. of CEAS Aerospace Aerodynamics Research Conference, UK, Cambridge. 2002. Print

39. Gridley, M. C., and Walker, S. H., 1996, "Inlet and Nozzle Tech. for $21^{\text {st }}$ Century Aircraft," ASME 96-GT-244.

40. Panitz, T. Flow attachment to solid surfaces: The Coanda effect. AIChE journal 18.1 Jan 1972: 51-57. American Institute of Chemical Engineers. 06 Oct 2011.

41. Yagle, P. J., D. N. Miller, K. B. Ginn, and J. W. Hamstra. "Demonstration of Fluidic Throat Skewing for Thrust Vectoring in Structurally Fixed Nozzles." Journal of Engineering for Gas Turbines and Power 123.3 (2001): 502. Print.

42. Deere, K.A., "Computational Investigation of the Aerodynamic Effects on Fluidic Thrust Vectoring," Proceedings from the $36^{\text {th }}$ AIAA/ASME/SAE/ASEE Joint Propulsion Conference and Exhibit. July 17-19, 2000. AIAA-2000-3598.

43. Jadbabaie, A. Hauser, J., "Control of the Caltech Ducted Fan in Forward Flight: A Receding Horizon-LPV Approach," Proceedings of the American Control Conference, Arlington, VA. June 25-27, 2001. 0-7803-6495-3.

44. Hauser, J., Jadbabaie, A., "Aggressive Maneuvering of a Thrust Vectored Flying Wing: A Receding Horizon Approach," Proceedings of the $39^{\text {th }}$ IEEE Conference on Decision and Control, Vol. 4, pgs. 3582-3587. Sydney, Australia, December 2000. 07803-6638-7

45. The Boeing Company, SolarEagle (Vulture II), Boeing Defense, Space and Security. September 2010. St. Louis, MO.

46. Pinder, S., "Control Strategy for a Four-Rotor VTOL UAV," Proceedings of $46^{\text {th }}$ Aerospace Sciences Meeting and Exhibit, Reno, Nevada, January 7-10, 2008, AIAA 2008-210.

47. Cowling, I.D., Yakimenko, O.A., Whidborne, J.F., Cooke, A.K., "A Prototype of an Autonomous Controller for a Quadrotor UAV," ECC 2007, Kos, Greece, July 2-5, 2007.

48. Bryant, Ashley, "VTOL Flying Wings," VTOL Technologies Ltd., Reading, UK,

49. Bryant, Ashley, "Unmanned Flying Wings Come of Age: the Next Generation of Vertical Take-Off and Landing UAV," VTOL Technologies Ltd., Reading, UK, April 2009, VTOL-PR-1305/2009.

50. "Centre for Defence Enterprise Celebrates Rapid Contract Success," Codex News, Issue 2, Autumn 2008, Accessed October 6, 2011.

51. Deere, K.A., "PAB Simulations of a Nozzle with Fluidic Injection for Yaw Thrust Vector Control." July 1998, AIAA 98-3254.

52. Flamm, J.D., "Experimental Study of a Nozzle Using Fluidic Conterflow for Thrust Vectoring," July 1998, AIAA 98-3255.

53. Giuliano, V.J., Flugstad, T.H., Semmes, R., Wing, D.J., "Static Investigation and Computational Fluid Dynamics (CFD) Analysis of Flowpath Cross-Section and 
Trailing-Edge Shape Variations in Two Multiaxis Thrust Vectoring Nozzle Concepts," June 1994, AIAA 94-3367.

54. Johnson, Eric, N., Turbe, Michael, A., "Modeling, Control, and Flight Testing of a Small Ducted Fan Aircraft," Georgia Institute of Technology, AIAA Guidance, Navigation, and Control Conference and Exhibit., August 2005.

55. McGirk, J., "SELEX S\&AS Launches Unique Mini Unmanned Aerial Vehicle (UAV) - Damselfly at ParcAberporth 2007," SELEX Press Release, July 10, 2007.

56. Buonanno, A., Drikakis, D., Papachristou, C., Savvaris, A., Vamvakoulas, C., Warsop, C., "Computational Investigation of the DEMON Unmanned Air Vehicle Thrust Vectoring System," Proceedings of the Institution of Mechanical Engineers, Part G: Journal of Aerospace Engineering, April 1, 2010, 2010 224: 387.

57. Merceruio, Zachary., Phillips, Kerri., "Aerodynamic and Thrust Force Modeling for a Propulsion Assisted Control Aircraft Test Bed", AIAA Guidance, Navigation, and Control Conference 2011. Portland, OR. August, 2011.

58. Gross, J., Gu, Y., Seanor, B., Gururajan, S., Napolitano, M.R. Advanced Research Integrated Avionic (ARIA) System for Fault-Tolerant Flight Research, AIAA Guidance, Navigation, and Control Conference 2009. Chicago, IL. August 10-13, 2009.

59. Gross, J., "Sensor Fusion Based Fault-Tolerant Attitude Estimation Solutions for Small Unmanned Aerial Vehicles," Ph.D. Dissertation, Mechanical and Aerospace Engineering Dept., West Virginia University, Morgantown, WV, 2011

60. Phillips, K., "Aircraft Parameter Identification for Application Within a FaultTolerant Flight Control System," Ph.D. Dissertation, Mechanical and Aerospace Engineering Dept., West Virginia University, Morgantown, WV, 2011.

61. Fay, James A. Introduction to Fluid Mechanics. Cambridge, MA: MIT, 1994. Print.

62. "The Calculation and Design of Ducted Fans," Accessed January 2011. www.wattflyer.com/forums/attachment.php? attachmentid $=47262 \& d=1195410990$ the calculation and design of ducted fans.

63. Rauw, Marc., "FDC 1.2 - A Simulink Toolbox for Flight Dynamics and Control Analysis," M.O. Rauw, 1994.

64. Roskam, J. Airplane Flight Dynamics and Automatic Flight Controls - Part I, Design, Analysis, and Research Corporation, Lawrence, KS. 2003.

65. Klein, V., and Morelli, E.A., Aircraft System Identification: Theory and Practice, AIAA Education Series. American Institute of Aeronautics and Astronautics, Inc. Reston, VA., 2006.

66. Stevens, B. and Lewis, F. Aircraft Control and Simulation. $2^{\text {nd }}$ Ed. John Wiley \& Sons, Inc. Hoboken, NJ. 2003.

67. Lu, B., Wu, F., "Switching-Based Fault-Tolerant Control for an F-16 Aircraft with Thrust Vectoring," decision and Control, 2009 held jointly with $200928^{\text {th }}$ Chinese Control Conference. CDC/CCC 2009. Proceedings of the $48^{\text {th }}$ IEEE Conference. December 2009. 10.1109/CDC.2009.5400385. 